Article

\title{
Dual P-Glycoprotein and CA XII Inhibitors: A New Strategy to Reverse the P-gp Mediated Multidrug Resistance (MDR) in Cancer Cells ${ }^{\dagger}$
}

\author{
Elisabetta Teodori ${ }^{1}\left(\right.$, Laura Braconi $^{1}{ }^{1}$, Silvia Bua ${ }^{1}$, Andrea Lapucci ${ }^{2}$, Gianluca Bartolucci ${ }^{1}{ }^{1}$, \\ Dina Manetti ${ }^{1}$, Maria Novella Romanelli ${ }^{1}$ (), Silvia Dei ${ }^{1, *}$ (i) , Claudiu T. Supuran ${ }^{1}$ (1) and \\ Marcella Coronnello ${ }^{2}$ \\ 1 Department of Neuroscience, Psychology, Drug Research and Child's Health-Section of Pharmaceutical and \\ Nutraceutical Sciences, University of Florence, via Ugo Schiff 6, 50019 Sesto Fiorentino (FI), Italy; \\ elisabetta.teodori@unifi.it (E.T.); laura.braconi@unifi.it (L.B.); silvia.bua@unifi.it (S.B.); \\ gianluca.bartolucci@unifi.it (G.B.); dina.manetti@unifi.it (D.M.); novella.romanelli@unifi.it (M.N.R.); \\ claudiu.supuran@unifi.it (C.T.S.) \\ 2 Department of Health Sciences-Section of Clinical Pharmacology and Oncology, University of Florence, \\ Viale Pieraccini 6, 50139 Firenze, Italy; andrea.lapucci@unifi.it (A.L.); marcella.coronnello@unifi.it (M.C.) \\ * Correspondence: silvia.dei@unifi.it \\ + Dedicated to the memory of Professor Fulvio Gualtieri, our great mentor who recently passed away.
}

Academic Editor: Maria José Umbelino Ferreira

Received: 15 March 2020; Accepted: 8 April 2020; Published: 10 April 2020

\begin{abstract}
A new series of $N, N$-bis(alkanol)amine aryl diesters was synthesized and studied as dual P-glycoprotein (P-gp) and carbonic anhydrase XII inhibitors (CA XII). These hybrids should be able to synergistically overcome P-gp mediated multidrug resistance (MDR) in cancer cells. It was reported that the efflux activity of P-gp could be modulated by CA XII, as the pH reduction caused by CA XII inhibition produces a significant decrease in P-gp ATPase activity. The new compounds reported here feature both P-gp and CA XII binding moieties. These hybrids contain a N,N-bis(alkanol)amine diester scaffold found in P-glycoprotein ligands and a coumarin or benzene sulfonamide moiety to target CA XII. Many compounds displayed a dual activity against P-gp and CA XII being active in the Rhd 123 uptake test on K562/DOX cells and in the hCA XII inhibition test. On LoVo/DOX cells, that overexpress both P-gp and CA XII, some coumarin derivatives showed a high MDR reversal effect in Rhd 123 uptake and doxorubicin cytotoxicity enhancement tests. In particular, compounds 7 and 8 showed higher activity than verapamil and were more potent on LoVo/DOX than on K562/DOX cells overexpressing only P-gp. They can be considered as valuable candidates for selective P-gp/CA XII inhibition in MDR cancer cells.
\end{abstract}

Keywords: MDR reversers; P-gp modulators; CA XII inhibitors; K562/DOX; LoVo/DOX; hybrid compounds; multitarget ligands; dual P-gp/CA XII inhibitory activity; selective chemosensitizers

\section{Introduction}

The resistance of many tumor cells to structurally and mechanistically unrelated antineoplastic drugs is the main failure reason of anticancer chemotherapy [1,2]. This phenomenon is called multidrug resistance (MDR) and generally consists of acquired resistance as a result of chemotherapeutic treatment. MDR is mainly due to overexpression of some energy dependent transmembrane proteins belonging to the ABC (ATP Binding Cassette) transporter family [3,4]. These proteins act as extrusion pumps and are responsible of an accelerated efflux of chemotherapeutic agents out of the cancer cells. As a consequence, their cellular concentration decreases and the drug efficacy is reduced. Among the ABC proteins, three transporters, P-glycoprotein (P-gp or ABCB1), the multidrug-resistance-associated protein-1 (MRP1 or 
$\mathrm{ABCC} 1$ ) and the breast cancer resistance protein (BCRP or ABCG2) are mainly associated with cancer MDR being overexpressed in many cell lines [5].

P-glycoprotein is the most studied and characterized $A B C$ transporter. It is overexpressed in many tumors and its elevated expression has been considered the cause of the reduced chemotherapeutic responses in various cancer types including both blood and solid cancers [6,7]. For this reason, P-gp has been considered a possible target to overcome cancer multidrug resistance [8] and, in the last years, many P-gp modulators have been designed and synthesized. These compounds can be coadministered with classical antitumor drugs that are substrates of P-gp, restoring their therapeutic efficacy in resistant tumors [9]. Many compounds have been identified for this purpose, nevertheless few of them have reached clinical trials [10]. The main obstacle is the widespread tissue distribution of P-gp and its physiological role in the regulation of permeability of biological membranes, in controlling the secretion of physiologically important lipophilic molecules and in the extrusion of xenobiotics that entered the organism [11,12]. Therefore, P-gp modulators could interfere with the pharmacokinetics of other substances, including coadministered chemotherapeutic agents [13]. For this reason, an ideal MDR reverser should be a P-gp modulator able to inhibit selectively the efflux of anticancer drugs in tumor cells without affecting the normal tissue membrane permeability.

Carbonic anhydrases (CAs, EC4.2.1.1) are metalloenzymes that catalyze the conversion of carbon dioxide to bicarbonate and a proton. They play a crucial role for the maintenance of $\mathrm{pH}$ homeostasis in the body and also have a metabolic function in several biosynthetic processes $[14,15]$. Therefore, CAs are involved in a multitude of physiological and pathological processes. Human CAs (hCAs) comprise of 15 different $\alpha$-CA isoforms varying for their tissue distribution and cellular localization (membrane, cytosol and mitochondria) [14]. Among these isoforms, CA IX and XII are extracellular, membrane bound CAs associated with tumor progression and metastases formation [15].

The overexpression of these two isoenzymes is induced in most hypoxic solid tumors by the hypoxia inducible factor $1 \alpha$ (HIF-1 $\alpha$ ) [16-18]. The translocation of HIF-1 $\alpha$ from the cytosol to the nucleus leads to the formation of an active transcription factor, which induces the overexpression of proteins involved in the proliferation and invasion of hypoxic tumor [19-22]. The overexpression of these proteins shifts the metabolism of tumor cells toward an anaerobic fermentation with the prevalence of glycolysis with respect to oxidative phosphorylation. The glycolytic pathway leads to the production of organic acids, which are extruded from the cells leading to an extracellular acidification. This condition is also supported by the extrusion of protons, produced by carbon dioxide hydration catalyzed by the transmembrane CA isoenzymes IX and XII, and the intracellular retention of bicarbonate ions. Thus, in cancer cells CA IX and XII are responsible for maintaining an alkaline intracellular $\mathrm{pH}$ and an extracellular acidosis that is beneficial for the growth of tumor cells but impairs the growth of normal cells $[23,24]$. It has recently been shown [25] that even in normoxia the HIF-1 $\alpha$ factor accumulates in the cell cytoplasm and allows the transcription of some of its target genes including CA IX and CA XII, acting as a pH sensor.

Kopecka and colleagues reported in recent work that the activity of the efflux transmembrane transporter P-gp could be modulated by CA XII [26]. The P-gp efflux activity is known to be influenced by intracellular $\mathrm{pH}$, as the optimal $\mathrm{pH}$ at which $\mathrm{P}$-gp operates is slightly alkaline. This condition is maintained by the CA XII catalytic activity, which assures the suitable intra- and extracellular $\mathrm{pH}$ in tumor cells overexpressing it. CA XII is highly expressed in some chemoresistant P-gp positive cancer cells [26] and its activity is critical for the P-gp efflux function and contribution to MDR. In fact, there are recent evidences that the reduction of $\mathrm{pH}$, caused by the inhibition of CA XII, produces a significant decrease in P-gp ATPase activity [26,27].

Compounds endowed with dual P-gp/CA XII inhibitory activity could thus be useful as chemosensitizers able to overcome P-gp mediated MDR in cancer cells. This synergistic mechanism should allow such compounds to be selective P-gp inhibitors for resistant tumor cells. Notably, they may have low interference with the physiological activity of P-gp in the regulation of the membrane permeability of normal tissues. 
Acetazolamide and other classical CA inhibitors contain an aromatic sulfonamide moiety, which coordinates the zinc ion buried at the bottom of the conical CA active site [28]. The aromatic and heteroaromatic sulfonamides are non-selective inhibitors and, therefore, able to block both the transmembrane isoforms CA IX and CA XII, and the physiological relevant cytosolic isoenzymes CA I and CA II, thus leading to side effects [28]. Coumarin derivatives are a relatively new class of CA inhibitors [29-31] that show high selectivity for inhibiting the tumor associated CA IX and CA XII isoforms. This selectivity is explained by their particular binding mode; in fact, the hydrolyzed coumarin moiety is able to obstruct the active site cavity, binding at its entrance, which is the most variable part of the site among the various hCAs [32].

The aim of this study was to obtain compounds able to overcome the P-gp mediated MDR in cancer cells by a synergistic mechanism of interference with CA XII and P-gp activity. For this aim, we designed and synthesized a new series of hybrid inhibitors characterized by the presence of both P-gp and CA XII binding moieties in order to possess a dual P-gp/CA XII inhibitory effect. We incorporated coumarin or benzene sulfonamide moieties in a typical scaffold of P-glycoprotein ligands that were previously studied by some of us. For many years one of our research group has been involved in the study of P-gp ligands with the aim to discover potent MDR modulators [33-39]. For this purpose, we designed and synthesized several compounds carrying the structural elements considered important for P-gp interaction, such as high lipophilicity, the presence of hydrogen bond acceptor groups, aromatic moieties and one or more protonable nitrogen atoms [40]. The structure of these molecules is characterized by the presence of a basic nitrogen atom linked to aromatic ester residues by spacers of different flexibility and length [33-39]. Most of these compounds are N,N-bis(alkanol)amine aryl diesters that were potent and efficient $\mathrm{P}$-gp-dependent multidrug resistance reversers on the doxorubicin-resistant erythroleukemia K562 cell line (Structure A, Chart 1) [35-39].

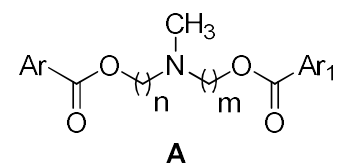

$\mathrm{Ar}, \mathrm{Ar}_{1}=$ aromatic or methoxy-substituted aromatic moieties

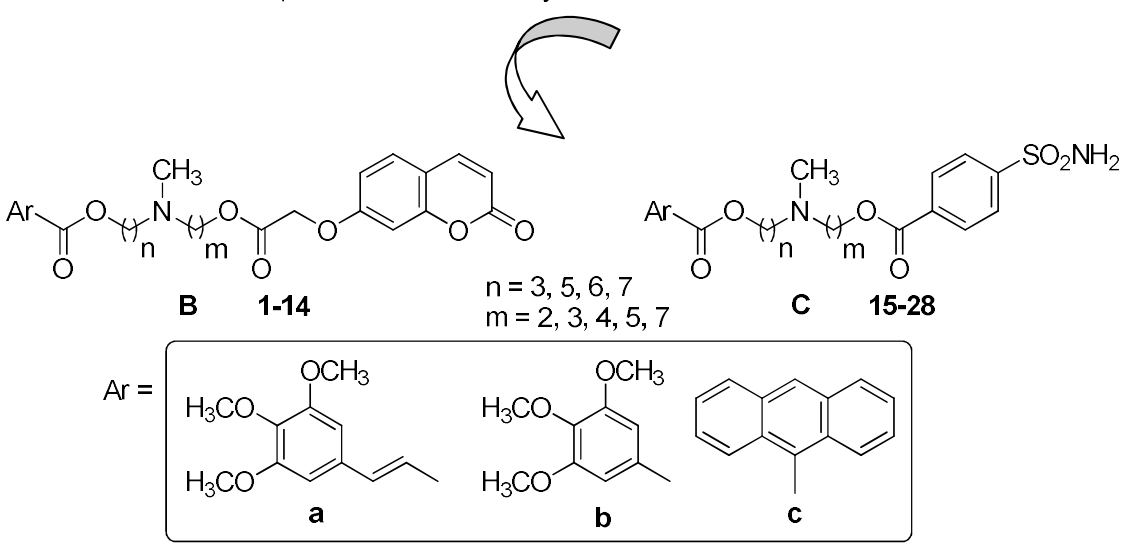

Chart 1. General structures of the leads and newly synthesized compounds.

In this study we report a new series of $N, N$-bis(alkanol)amine aryl diesters (1-28), incorporating two polymethylenic chains of variable length, carrying the (E)-3-(3,4,5-trimethoxyphenyl)vinyl, 3,4,5-trimethoxyphenyl or the anthracene residues $(\mathbf{a}, \mathbf{b}$ and $\mathbf{c})$, combined with coumarin or benzene sulfonamide moieties (Structures B and C, Chart 1).

The synthesized compounds were evaluated for their P-gp modulating activity by measuring the uptake increase of the specific P-gp substrate rhodamine-123 (Rhd 123) on doxorubicin-resistant erythroleukemia K562 cells (K562/DOX) that overexpress the membrane P-gp. The CA inhibition efficacy of compounds 1-28 was evaluated on the tumor associated hCA IX and hCA XII and on the physiological relevant cytosolic hCA I and II isoforms, to verify their CA isoforms selectivity profiles. 
The expression levels of the two transmembrane proteins, P-gp and CA XII, were evaluated by real time polymerase chain reaction (RT-PCR) analysis, on resistant K562/DOX and parental K562 cell lines. The results showed a substantial increase in the mRNA expression level for the MDR1 gene but only a low increase in the mRNA expression level for the CA XII gene on the resistant K562/DOX line. Therefore, to prove the synergistic effect on the MDR reversal activity due to dual P-gp/CA XII inhibition, the selected compounds were evaluated by the Rhd 123 uptake test, on human colorectal carcinoma LoVo/DOX cells, which overexpress both P-gp and CA XII, as confirmed by the RT-PCR analysis performed on both resistant and parental cell lines (LoVo/DOX, LoVo). The P-gp expression level in both resistant K562/DOX and LoVo/DOX cells was also investigated using flow cytometric analysis with a P-gp-specific antibody.

Finally, the selected compounds were evaluated by the doxorubicin cytotoxicity enhancement test on K562/DOX and LoVo/DOX cells. Moreover, the susceptibility of derivatives 1-28 to spontaneous hydrolysis was assessed in phosphate buffer solution.

\section{Results and Discussion}

\subsection{Chemistry}

Compounds 1-28 were prepared using a reaction pathway (Scheme 1) that has been previously applied to the synthesis of analogues with the general formula A (Chart 1) [35-38]. In this work, some new intermediates have been synthesized for preparing all the newly designed hybrids. Thus, chloroester $\mathbf{2 9}$ was obtained by esterification of 6-chlorohexan-1-ol with the commercially available 3,4,5-trimethoxybenzoic acid using EDC hydrochloride ( $N$-(3-dimethylaminopropyl)- $N^{\prime}$-ethylcarbodiimide hydrochloride) and DMAP (4-dimethylaminopyridine) in anhydrous $\mathrm{CH}_{2} \mathrm{Cl}_{2}$. The chloroalkyl ester was transformed in the corresponding iodo derivative $\mathbf{3 0}$ using $\mathrm{NaI}$ in acetone, in order to achieve higher yields in the following reactions. Treatment of $\mathbf{3 0}$ with 3-aminopropan-1-ol in acetonitrile gave the desired secondary amine 31. The same reaction performed on the already described 6-iodohexyl anthracene-9-carboxylate [38], gave 32. These compounds were alkylated by reductive methylation with $\mathrm{HCOOH} / \mathrm{HCHO}$ to give the corresponding tertiary amines 33 and 34. Final compounds 1-14 were obtained by esterification of 33, 34 and the previously reported analogues 35-46 [35-38] with 2-((2-oxo-2H-chromen-7-yl)oxy)acetic acid (48) (described in Scheme 2) using EDC hydrochloride and HOBt (1-hydroxybenzotriazole hydrate) in anhydrous $\mathrm{CH}_{3} \mathrm{CN}$. In turn, compounds 15-28 were prepared by esterification of 33-46 with 4-sulfamoylbenzoyl chloride obtained from 4-sulfamoylbenzoic acid by reaction with $\mathrm{SOCl}_{2}$.

2-((2-Oxo-2H-chromen-7-yl)oxy)acetic acid (48) was synthesized as reported in Scheme 2. Alkylation of commercially available 7-hydroxy-2H-chromen-2-one with ethyl bromoacetate gave ester 47, which was hydrolyzed under alkaline conditions to obtain 48. 


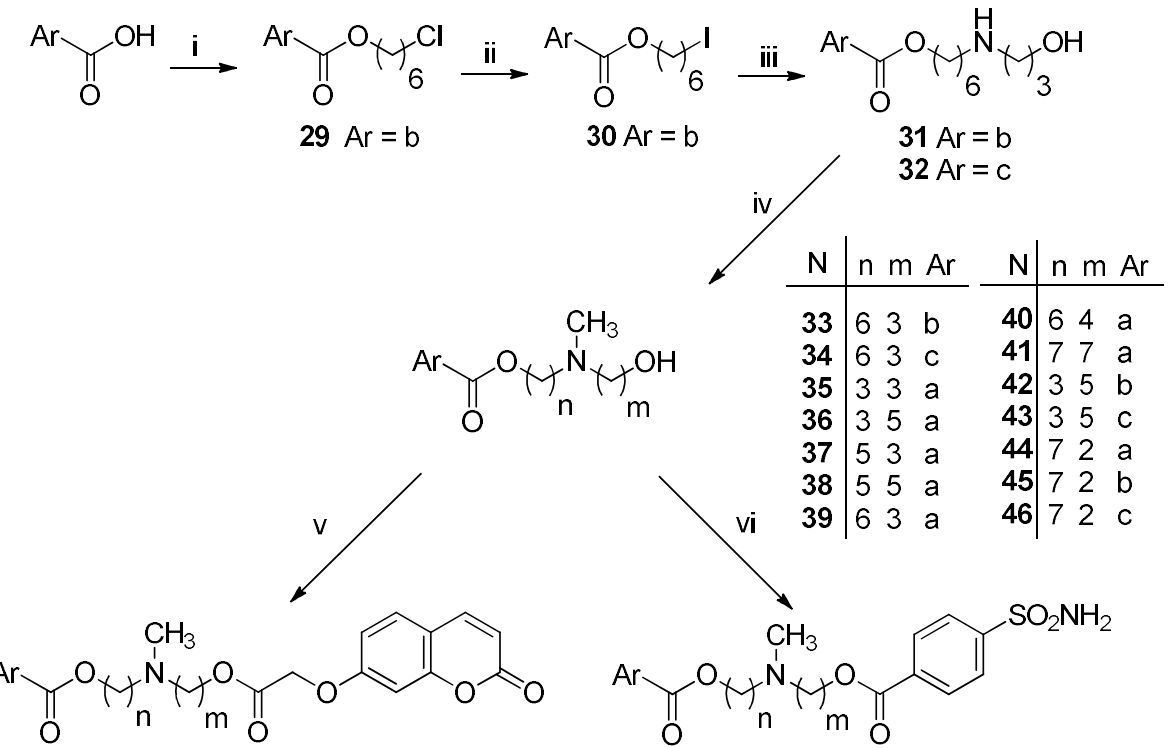

\begin{tabular}{|c|c|c|c|c|c|c|c|}
\hline $\mathrm{N}$ & $\mathrm{n} \mathrm{m} \mathrm{Ar}$ & $\mathrm{N}$ & $\mathrm{n} \mathrm{m} \mathrm{Ar}$ & $\mathrm{N}$ & $n \mathrm{~m} \mathrm{Ar}$ & $\mathrm{N}$ & $\mathrm{n} \mathrm{m} \mathrm{Ar}$ \\
\hline 1 & $33 a$ & 8 & 77 a & 15 & $33 a$ & 22 & $77 a$ \\
\hline 2 & $35 a$ & 9 & $35 \mathrm{~b}$ & 16 & $35 a$ & 23 & $35 \mathrm{~b}$ \\
\hline 3 & $53 a$ & 10 & $63 \mathrm{~b}$ & 17 & $53 a$ & 24 & $63 \mathrm{~b}$ \\
\hline 4 & 55 a & 11 & $72 \mathrm{~b}$ & 18 & $55 a$ & 25 & $72 b$ \\
\hline 5 & $63 a$ & 12 & $35 \mathrm{c}$ & 19 & $63 a$ & 26 & $35 \mathrm{c}$ \\
\hline 6 & 64 & 13 & $63 \mathrm{c}$ & 20 & $64 a$ & 27 & $63 \mathrm{c}$ \\
\hline 7 & $72 a$ & 14 & $72 \mathrm{c}$ & 21 & $72 a$ & 28 & $72 c$ \\
\hline
\end{tabular}

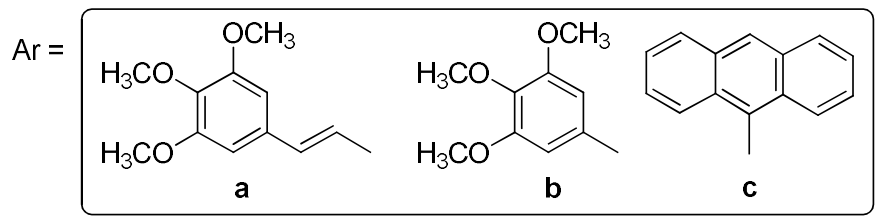

Scheme 1. Reagents and conditions: (i) 6-chlorohexan-1-ol, EDC hydrochloride, DMAP and $\mathrm{CH}_{2} \mathrm{Cl}_{2}$; (ii) NaI, acetone; (iii) $\mathrm{H}_{2} \mathrm{~N}\left(\mathrm{CH}_{2}\right)_{3} \mathrm{OH}$ and $\mathrm{CH}_{3} \mathrm{CN}$; (iv) $\mathrm{HCOOH} / \mathrm{HCHO}$, EtOH; (v) 2-((2-Oxo-2H-chromen-7-yl)oxy)acetic acid (48), EDC hydrochloride, $\mathrm{HOBt}$ and $\mathrm{CH}_{3} \mathrm{CN}$; (vi) 4-sulfamoylbenzoyl chloride, ethanol-free $\mathrm{CHCl}_{3}$.

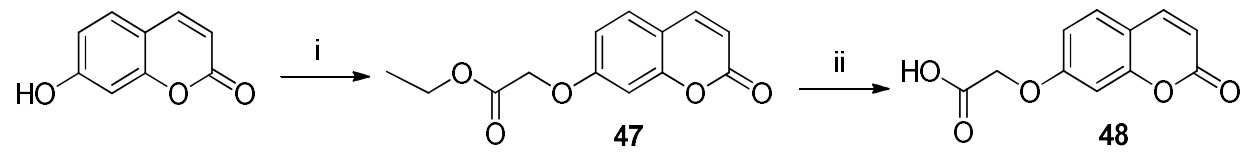

Scheme 2. Reagents and conditions: (i) $\mathrm{BrCH}_{2} \mathrm{COOC}_{2} \mathrm{H}_{5}, \mathrm{~K}_{2} \mathrm{CO}_{3}$, acetone and (ii) $\mathrm{NaOH} 10 \%$.

\subsection{Chemical Stability}

In order to evaluate the chemical stability of our compounds during biological tests, a study on the susceptibility to spontaneous hydrolysis of derivatives 1-28 was planned. For this purpose, a series of experiments were carried out adding a known amount of analyte in phosphate buffer solution (PBS). The samples were analyzed by LC-MS/MS method operating in the multiple reaction monitoring (MRM) mode [39]. The solution stability of each studied compound was verified by monitoring the variation of the analyte concentration at different incubation times. The processed raw data and the used LC-MS/MS methods are reported in the Supplementary Material.

The obtained results demonstrated that compounds 1-28 were stable in PBS showing a negligible decay rate ( $\mathrm{k}$ values close to 0 ). Therefore, extremely high half-life values can be calculated for these derivatives. Since $240 \mathrm{~min}$ is the maximum time of observation in our experimental protocol, it is possible to assume that the half-lives of these hybrids should be greater than $240 \mathrm{~min}$. 


\subsection{Rhodamine-123 Uptake Test on K562/DOX Cells}

The ability of compounds 1-28 to inhibit the P-gp transport activity was evaluated by measuring the uptake of the specific P-gp substrate rhodamine-123 (Rhd 123) in K562/DOX cells, as described in Material and Methods.

K562 is a highly undifferentiated erythroleukemia cell line originally derived from a patient with chronic myelogenous leukemia [41]. The doxorubicin resistant K562/DOX cell line overexpresses almost exclusively the transporter membrane protein P-gp [42].

The P-gp inhibitory activity of compounds 1-28, tested at 3 and $30 \mu \mathrm{M}$ concentrations, are reported in Table 1 together with those of verapamil, used as standard inhibitor.

Table 1. Rhd 123 uptake enhancement on K562/DOX cells and inhibitory activity on hCA I, II, IX and XII isoforms of compounds 1-28 and of the two reference compounds verapamil and acetazolamide (AAZ).<smiles>C/C=C/c1cc(OC)c(OC)c(OC)c1</smiles>

\begin{tabular}{|c|c|c|c|c|c|c|c|c|c|c|}
\hline \multicolumn{5}{|c|}{ Compounds } & \multicolumn{2}{|c|}{$F^{a}$} & \multicolumn{4}{|c|}{$\mathrm{K}_{\mathrm{I}}(\mathrm{nM})^{b}$} \\
\hline $\mathbf{N}$ & $\mathbf{n}$ & m & Ar & Structure & $3 \mu \mathrm{M}$ & $30 \mu \mathrm{M}$ & hCA I & hCA II & hCA IX & hCA XII \\
\hline 1 & 3 & 3 & $\mathrm{a}$ & B & 1.44 & 4.76 & $>10,000$ & $>10,000$ & 142.5 & 9.3 \\
\hline 2 & 3 & 5 & a & B & 1.57 & 5.81 & $>10,000$ & $>10,000$ & 47.4 & 8.9 \\
\hline 3 & 5 & 3 & a & B & 1.00 & 2.58 & $>10,000$ & $>10,000$ & 54.6 & 48.8 \\
\hline 4 & 5 & 5 & a & B & 1.99 & 5.45 & $>10,000$ & $>10,000$ & 26.6 & 18.9 \\
\hline 5 & 6 & 3 & a & B & 3.67 & 5.85 & $>10,000$ & $>10,000$ & 26.7 & 6.4 \\
\hline 6 & 6 & 4 & a & B & 1.39 & 1.98 & $>10,000$ & $>10,000$ & 40.2 & 36.4 \\
\hline 7 & 7 & 2 & $\mathrm{a}$ & B & 2.08 & 4.48 & $>10,000$ & $>10,000$ & 29.7 & 9.1 \\
\hline 8 & 7 & 7 & a & B & 2.33 & 4.15 & $>10,000$ & $>10,000$ & 24.2 & 7.1 \\
\hline 9 & 3 & 5 & $\mathrm{~b}$ & B & 1.00 & 3.95 & $>10,000$ & $>10,000$ & 133.3 & 9.2 \\
\hline 10 & 6 & 3 & $\mathrm{~b}$ & B & 1.16 & 2.18 & $>10,000$ & $>10,000$ & 103.1 & 8.9 \\
\hline 11 & 7 & 2 & $\mathrm{~b}$ & B & 1.11 & 1.58 & $>10,000$ & $>10,000$ & 97.1 & 8.3 \\
\hline 12 & 3 & 5 & c & B & 1.00 & 2.53 & $>10,000$ & $>10,000$ & 150.8 & 45.7 \\
\hline 13 & 6 & 3 & c & B & 1.43 & 2.45 & $>10,000$ & $>10,000$ & 82.7 & 9.1 \\
\hline 14 & 7 & 2 & c & B & 1.25 & 4.22 & $>10,000$ & $>10,000$ & 125.8 & 42.9 \\
\hline 15 & 3 & 3 & a & C & 1.00 & 2.30 & 55.1 & 151.7 & 178.4 & 91.0 \\
\hline 16 & 3 & 5 & a & C & 1.08 & 1.83 & 447.2 & 554.8 & 210.6 & 94.3 \\
\hline 17 & 5 & 3 & a & C & 1.13 & 3.90 & 56.6 & 203.7 & 215.3 & 33.1 \\
\hline 18 & 5 & 5 & a & C & 1.00 & 4.99 & 62.6 & 424.8 & 226.5 & 62.6 \\
\hline 19 & 6 & 3 & a & C & 1.06 & 3.23 & 509.6 & 8.4 & 39.7 & 58.6 \\
\hline 20 & 6 & 4 & $\mathrm{a}$ & C & 1.01 & 2.58 & 84.5 & 14.0 & 33.9 & 41.7 \\
\hline 21 & 7 & 2 & a & C & 1.30 & 3.70 & 533.2 & 48.9 & 68.4 & 35.2 \\
\hline 22 & 7 & 7 & $\mathrm{a}$ & C & 2.85 & 3.20 & 73.7 & 445.0 & 171.9 & 96.7 \\
\hline 23 & 3 & 5 & b & C & 1.00 & 1.66 & 284.4 & 127.5 & 26.6 & 63.7 \\
\hline 24 & 6 & 3 & $\mathrm{~b}$ & C & 1.42 & 2.88 & 83.5 & 8.9 & 25.3 & 57.6 \\
\hline 25 & 7 & 2 & $\mathrm{~b}$ & C & 1.44 & 3.50 & 42.7 & 90.2 & 117.0 & 8.0 \\
\hline 26 & 3 & 5 & c & C & 2.10 & 4.45 & 338.7 & 81.2 & 241.2 & 23.4 \\
\hline 27 & 6 & 3 & c & C & 1.08 & 2.03 & 616.7 & 422.4 & 28.2 & 31.3 \\
\hline 28 & 7 & 2 & c & C & 1.45 & 4.25 & 237.9 & 475.5 & 20.6 & 23.5 \\
\hline Ver & & & & & 3.30 & 4.71 & & & & \\
\hline AAZ & & & & & 1.00 & 1.00 & 250.0 & 12.0 & 25.0 & 5.7 \\
\hline
\end{tabular}

${ }^{a}$ Inhibition of the P-gp transport activity on K562/DOX cells expressed as FR that is the ratio between the average fluorescence intensity of rhodamine in the presence and in absence of modulators (FR $=$ Rhd uptake + modulator/Rhd uptake - modulator). ${ }^{b}$ Mean from 3 different assays, by a stopped flow technique (errors were in the range of $\pm 5-10 \%$ of the reported values). 
The new compounds were preliminary studied to evaluate their intrinsic cytotoxicity at 3 and $30 \mu \mathrm{M}$ concentrations by the MTT (3-(4,5-dimethylthiazolyl-2)-2,5-diphenyltetrazolium bromide) assay [43] on the K562/DOX cells line. At the concentrations tested, all compounds showed a negligible intrinsic toxicity (about $20 \%$, data not shown).

The results were expressed as the FR (fluorescence ratio), which is the ratio between the average fluorescence intensity of rhodamine in the presence and in the absence of modulators. Value 1 was attributed to the average fluorescence intensity of the samples exposed only to rhodamine.

The data reported in Table 1 indicate that at $3 \mu \mathrm{M}$ concentration most compounds were inactive in the inhibition of the P-gp transport activity (FR values equal to or close to the unity), but 4, 7, 8, 22 and 26 were able to increase the intracellular rhodamine uptake by at least twice o even more $(\mathrm{FR}=1.99,2.08,2.33,2.85$ and 2.10 , respectively), and compound 5 was active as verapamil $(\mathrm{FR}=3.67$ and 3.30 , respectively).

At $30 \mu \mathrm{M}$ concentration a significant increase in the intracellular rhodamine fluorescence intensity was observed for all compounds and many of them showed FR values in the 4.15-5.85 range. Notably, compounds 2, 4, 5 and 18 showed FR values higher than that of verapamil, tested at the same concentration $(\mathrm{FR}=5.81,5.45,5.85$ and 4.99 , respectively, vs. $\mathrm{FR}=4.71$ of verapamil). On the contrary, the standard CA inhibitor acetazolamide did not show any effect on K562/DOX cells at both the concentrations used.

The results showed in Table 1 indicate that the introduction of a coumarin or a benzene sulfonamide group maintains effective P-glycoprotein inhibitory ability, even if the potency is lower compared to the previously synthesized analogues carrying on both sides the aromatic moieties a-c reported in Chart 1 (General structure A) [38].

Notably, compounds from the coumarin series (Structure B, Table 1) were in general more potent than those from the benzene sulfonamide series (Structure C, Table 1; compare 2 vs. 16, 4 vs. 18 and 5 vs. 19). On the other hand, considering the nature of the Ar group, compounds bearing a (E)-3-(3,4,5-trimethoxyphenyl)vinyl moiety were in general more active. Disappointingly, and differently from what found in previous series [38], a clear influence of the length of the linkers on the activity was not observed with the new derivatives reported here.

\subsection{CA Inhibitory Activity}

The CA inhibitory efficacy of compounds 1-28 was evaluated on four human CA isoforms, the two cytosolic hCA I and II and the transmembrane tumor-associate hCA IX and XII isoforms. The hCA inhibition data of the new compounds were determined by a Stopped-Flow $\mathrm{CO}_{2}$ hydrase assay [44] and are reported in Table 1 together with those of the sulfonamide acetazolamide (AAZ), used as a standard inhibitor.

Derivatives 1-14, characterized by the presence of a coumarin scaffold, inhibited both hCA IX and XII isoforms at nanomolar concentrations, while they were inactive against the off-target isoforms hCA I and II, in accord with the selectivity usually displayed by CA inhibitors decorated with this aromatic moiety. In addition, this series of compounds showed lower Ki values on hCA XII (Ki = 6.4-48.8 nM) than on hCA IX (Ki = 24.2-150.8 nM). Some compounds (1, 9, 10 and 11) displayed an interesting 12-15 fold preference for hCA XII with respect to hCA IX: compounds 9, 10 and $\mathbf{1 1}$ are 3,4,5-trimethoxyphenyl derivatives while 1 carries a (E)-3-(3,4,5-trimethoxyphenyl)vinyl moiety. The latter group can also confer high potency, since 5 (Ki $6.4 \mathrm{nM}$ ) was the most potent compound on hCA XII of this series. On the contrary, derivatives with an anthracene moiety were, in general, less potent and selective, with the exception of 13, which was nine times more active on hCA XII than on hCA IX. The linkers' length seemed not to be crucial for the interaction with hCA XII: for instance, compounds 1 having the shortest linkers $(n, m=3)$ were equipotent with 8 , which showed the longest linkers on both arms $(\mathrm{n}, \mathrm{m}=7)$. On hCA IX, if we take into account the compounds having the same Ar group $(\mathbf{1}-\mathbf{8}, \mathrm{Ar}=\mathbf{a})$ only the short $3+3$ linker seemed detrimental for activity, since compound 1 was 3-6 times less potent than 2-7. 
As expected, compounds 15-28, incorporating a benzene sulfonamide moiety, were able to inhibit all four isoforms, even if with different selectivity profiles, showing Ki values in the range of 20.6-241.2 $\mathrm{nM}$ and 8.0-96.7 $\mathrm{nM}$ ranges for hCA IX and XII isoforms, respectively. Almost all compounds were more effective CA XII than CA IX inhibitors, with the exception of $\mathbf{2 3}$ and $\mathbf{2 4}$ (twice more potent on hCA IX than on hCA XII), and of 20, 27 and 28, which showed similar $\mathrm{K}_{\mathrm{i}}$ values on both isoforms.

The selectivity profiles towards hCA XII with respect to the two hCA I and II isoforms were quite different. Compounds 16, 19, 21, 23, 26, 27 and 28 showed a preference for hCA XII vs. hCA I (4-20 times). In particular, compounds bearing an anthracene moiety (26, 27 and 28) were the most selective ones.

Compounds 19, 20 and 24 were the most potent on hCA II, with $\mathrm{Ki}=8.4,14.0$ and $8.9 \mathrm{nM}$, respectively with an hCA II vs. hCA XII preference of 7, 3 and 6.5 times, respectively. Conversely, some hCA XII vs. hCA II selectivity (2-20 times) was displayed by compounds 16, 17, 18, 22, 23, 25, 26, 27 and 28. Also in this case compounds bearing an anthracene moiety (26, 27 and 28) were all quite selective.

In conclusion, the data reported in Table 1 show that many compounds acted as effective CA inhibitors, although the Ar moiety (a-c) or the linkers' length did not clearly influence their activity on the four hCA isoforms. Notably, several coumarin derivatives $(\mathbf{1}, \mathbf{2}, \mathbf{5}, \mathbf{7 - 1 1}$ and 13) and one sulfonamide derivative (25) had Ki values on hCA XII in the low nanomolar range. On the contrary, sulfonamides 19, 20 and 24 displayed potent, although undesired, inhibitory activity on hCA II (Ki values between 8.4 and $14 \mathrm{nM}$ ).

\subsection{P-Glycoprotein and CA XII Expression in K562/DOX and LoVo/DOX Cells}

The gene expression levels of P-gp and CA XII were checked by real-time PCR analysis in K562 leukemic and LoVo colon carcinoma cells, both in sensitive and resistant lines. This test was based on the quantitative assessment of the presence of transcripts, i.e., messenger RNA molecules encoding the two proteins [45]. The real-time PCR analysis indicated a substantial increase in the mRNA expression level for the MDR1 gene on the resistant leukemic line, K562/DOX, with respect to the parental counterpart (about 173 times). On the contrary, a low increase in the mRNA expression level for the CA XII gene was observed on the resistant K562/DOX line compared with the parental one (about two times). The doxorubicin resistant colon carcinoma cell line $\mathrm{LoVo} / \mathrm{DOX}$, showed an increase in the mRNA expression level 53 times higher than the parental counterpart for the MDR1 gene. In this cell line an increase in the mRNA expression level for the CA XII gene of 11 times was also observed. Details are reported in Material and Methods and Supplementary Material.

The P-glycoprotein expression level in resistant K562/DOX and LoVo/DOX cells was also checked using flow cytometric analysis with the P-gp-specific monoclonal antibody Mab FITC conjugate CD243. The obtained results, reported as a fluorescence ratio between the resistant line and the parental counterpart, showed an increase in the protein expression of about 17.3 times in the K562/DOX line, and of about 8.6 times in the LoVo/DOX line. Details are reported in Material and Methods and Supplementary Material.

\subsection{Rhodamine-123 Uptake Test on LoVo/DOX Cells}

Based on the results on hCA inhibitory activity and on K562/DOX Rhd 123 uptake tests, compounds with the best profile in term of potency on P-gp and selectivity towards the hCA XII isoform were selected (coumarin 2, 5, 7 and 8, and benzene sulfonamide 21, 25 and 26 derivatives) for further evaluation on human colorectal carcinoma LoVo/DOX cells.

LoVo is a human colon adenocarcinoma cell line isolated from a metastatic nodule and its MDR variant, LoVo/DOX, was obtained from LoVo (parental line) by exposure to increasing concentrations of doxorubicin.

The selected compounds were preliminary studied at 3,10 and $30 \mu \mathrm{M}$ concentrations by the MTT (3-(4,5-dimethylthiazolyl-2)-2,5-diphenyltetrazolium bromide) assay [43] to evaluate their intrinsic 
cytotoxicity on LoVo/DOX cell line. The compounds displayed at 3 and $10 \mu \mathrm{M}$ concentrations a negligible intrinsic toxicity (about $20 \%$ ), that increased at the higher dose $(22 \%-42 \%)$. Therefore, the $30 \mu \mathrm{M}$ concentration was not used in the further studies and the rhodamine-123 uptake test on the colon carcinoma model (LoVo/DOX cells) was performed at 3 and $10 \mu \mathrm{M}$.

The results, expressed as FR values, were reported as the histograms shown in Figure 1. At $3 \mu \mathrm{M}$, the intracellular fluorescence intensity of rhodamine varied in the 1.32-6.70 range for compounds 2, 5, $\mathbf{7}$ and $\mathbf{8}$, but was negligible for $\mathbf{2 1}, \mathbf{2 5}$ and $\mathbf{2 6}$ (FR values equal to or close to the unity; Figure 1, panel A). At $10 \mu \mathrm{M}$, instead, all molecules showed a significant increase in the intracellular rhodamine uptake. Especially, compounds 2, 5, 7 and 8 showed FR values of 10.50, 6.30, 12.60 and 9.90, respectively, that resulted equal to or higher than that of verapamil (6.40) tested at the same concentration (Figure 1, panel B).
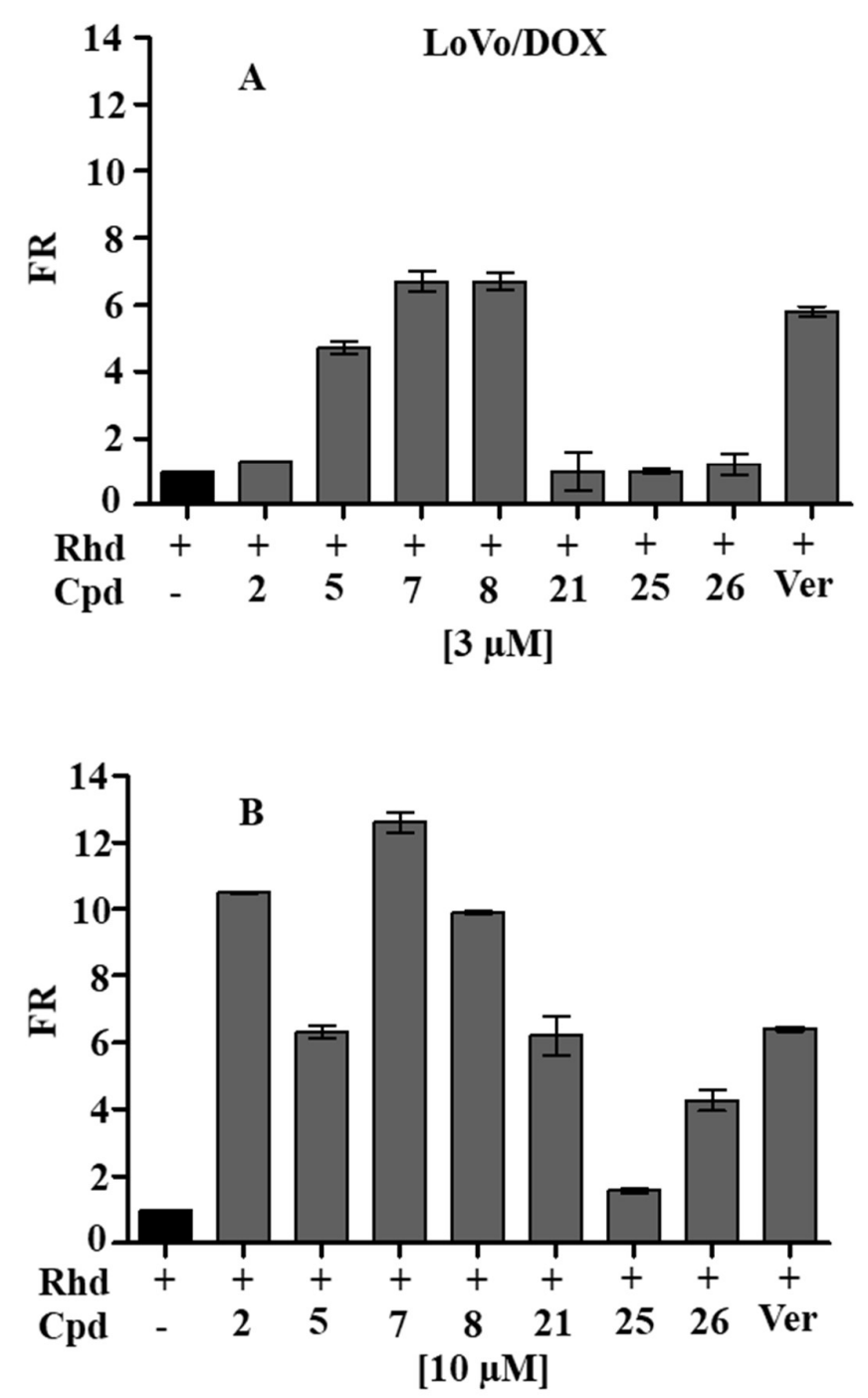

Figure 1. Fluorescence ratio (FR) values in LoVo/DOX cells incubated with rhodamine in the presence and in absence of modulators $2,5,7,8,21,25$ and 26 and verapamil at $3 \mu \mathrm{M}$ (panel A) and $10 \mu \mathrm{M}$ (panel B) concentrations. Value 1 was attributed to the average fluorescence intensity of the samples exposed only to rhodamine.

These results confirmed the already observed behavior on K562/DOX cell line; in fact, also on $\mathrm{LoVo} / \mathrm{DOX}$ cells, the coumarin derivatives were in general more potent in P-gp transport inhibition than compounds carrying the benzene sulfonamide moiety. 


\subsection{Enhancement of Doxorubicin Cytotoxicity}

Compounds 2, 5, 7, 8, 21, 25 and 26 were further evaluated, at 3 and $10 \mu \mathrm{M}$ concentrations, to assess their effects on the doxorubicin cytotoxicity enhancement on K562/DOX and LoVo/DOX cell lines.

Doxorubicin is a P-gp substrate and is usually inactive in tumors overexpressing the pump. The extent of resistance to doxorubicin of K562/DOX and LoVo/DOX cells was established and expressed by the resistance index, as reported in Material and Methods.

In this test, doxorubicin was used at the low toxic concentrations that caused a $20 \%$ cell growth inhibition $\left(\mathrm{IC}_{20}\right)$ on the two resistant lines $\left(\mathrm{IC}_{20}=0.5 \mu \mathrm{M}\right.$ for $\mathrm{K} 562 / \mathrm{DOX}$ cells and $0.3 \mu \mathrm{M}$ for LoVo/DOX cells).

On K562/DOX cells, all compounds at $3 \mu \mathrm{M}$ had low or no effect in the enhancement of doxorubicin $\mathrm{IC}_{20}$ cytotoxicity, except compound 5, which reduced the cell growth from $80 \%$ to $51.7 \%$. At $10 \mu \mathrm{M}$, all tested compounds increased doxorubicin cytotoxicity with different extent. Coumarin derivatives 5, 7 and 8 reduced the cell growth below 50\%, in particular compound 5 reduced it to 25.1\% (Table 2).

Table 2. Cells' growth experiments performed on K562/DOX and LoVo/DOX cells in the presence of $0.5 \mu \mathrm{M}(\mathrm{K} 562 / \mathrm{DOX})$ or $0.3 \mu \mathrm{M}$ (LoVo/DOX) concentrations of doxorubicin alone or in association with compounds $2,5,7,8,21,25$ and 26 at 3 and $10 \mu \mathrm{M}$ concentrations.

\begin{tabular}{lcc}
\hline & \multicolumn{2}{c}{ Cell Growth (\%) } \\
\hline \multicolumn{1}{c}{ Compounds } & K562/DOX cells & LoVo/DOX cells \\
\hline doxo & $80.0 \pm 3.6$ & $80.0 \pm 2.5$ \\
doxo $\left(\mathrm{IC}_{20}\right)+\mathbf{2}(3 \mu \mathrm{M})$ & $85.6 \pm 4.7$ & $82.7 \pm 10.2$ \\
doxo $\left(\mathrm{IC}_{20}\right)+\mathbf{2}(10 \mu \mathrm{M})$ & $65.0 \pm 5.2$ & $41.5 \pm 7.3$ \\
doxo $\left(\mathrm{IC}_{20}\right)+\mathbf{5}(3 \mu \mathrm{M})$ & $51.7 \pm 3.0$ & $58.0 \pm 2.4$ \\
doxo $\left(\mathrm{IC}_{20}\right)+\mathbf{5}(10 \mu \mathrm{M})$ & $25.1 \pm 12.0$ & $51.0 \pm 1.9$ \\
doxo $\left(\mathrm{IC}_{20}\right)+\mathbf{7}(3 \mu \mathrm{M})$ & $78.1 \pm 4.9$ & $61.0 \pm 3.3$ \\
doxo $\left(\mathrm{IC}_{20}\right)+\mathbf{7}(10 \mu \mathrm{M})$ & $48.0 \pm 5.0$ & $34.9 \pm 8.1$ \\
doxo $\left(\mathrm{IC}_{20}\right)+\mathbf{8}(3 \mu \mathrm{M})$ & $82.0 \pm 5.9$ & $68.0 \pm 2.9$ \\
doxo $\left(\mathrm{IC}_{20}\right)+\mathbf{8}(10 \mu \mathrm{M})$ & $49.0 \pm 2.3$ & $32.2 \pm 10.7$ \\
doxo $\left(\mathrm{IC}_{20}\right)+\mathbf{2 1}(3 \mu \mathrm{M})$ & $78.8 \pm 10.2$ & $82.0 \pm 2.7$ \\
doxo $\left(\mathrm{IC}_{20}\right)+\mathbf{2 1}(10 \mu \mathrm{M})$ & $68.7 \pm 3.6$ & $59.0 \pm 3.3$ \\
doxo $\left(\mathrm{IC}_{20}\right)+\mathbf{2 5}(3 \mu \mathrm{M})$ & $80.3 \pm 5.9$ & $73.7 \pm 0.015$ \\
doxo $\left(\mathrm{IC}_{20}\right)+\mathbf{2 5}(10 \mu \mathrm{M})$ & $76.0 \pm 3.7$ & $82.0 \pm 2.0$ \\
doxo $\left(\mathrm{IC}_{20}\right)+26(3 \mu \mathrm{M})$ & $77.9 \pm 6.1$ & $58.2 \pm 5.9$ \\
doxo $\left(\mathrm{IC}_{20}\right)+\mathbf{2 6}(10 \mu \mathrm{M})$ & $74.0 \pm 2.6$ & $51.0 \pm 0.06$ \\
doxo $\left(\mathrm{IC}_{20}\right)+$ Ver $(3 \mu \mathrm{M})$ & $69.0 \pm 0.03$ & $61.0 \pm 0.09$ \\
doxo $\left(\mathrm{IC}_{20}\right)+\operatorname{Ver}(10 \mu \mathrm{M})$ & $62.0 \pm 0.1$ & \\
\hline
\end{tabular}

${ }^{a}$ Data are the mean \pm SE of at least three determinations performed with quadruplicate cultures as described in Material and Methods.

On LoVo/DOX cells, compounds 5, 7 and 8 at $3 \mu \mathrm{M}$ reduced the cell growth to 58.0, 61.0 and 68.0\%, respectively, and the other derivatives had no effect.

At the higher concentration $(10 \mu \mathrm{M})$ almost all compounds were able to increase the doxorubicin cytotoxicity. Notably, compounds 2, 5, 7 and 8 caused a reduction of the cells' growth from $80 \%$ to $41.5 \%, 51.0 \%, 34.9 \%$ and $32.2 \%$, respectively. The date reported in Table 2 indicate that, in general, the ability of these compounds on the doxorubicin cytotoxicity enhancement was higher on LoVo/DOX cells than on K562/DOX cells.

\section{Material and Methods}

\subsection{Chemistry}

All melting points were taken on a Büchi apparatus and were uncorrected. NMR spectra were recorded on a Bruker Avance 400 spectrometer $\left(400 \mathrm{MHz}\right.$ for ${ }^{1} \mathrm{H}$ NMR, $100 \mathrm{MHz}$ for ${ }^{13} \mathrm{C}$ NMR) using residual solvent such as chloroform $(\delta=7.26)$ as the internal standard. ${ }^{1} \mathrm{H}$ and ${ }^{13} \mathrm{C}$ chemical shifts are 
expressed in ppm $(\delta)$ referring to TMS. Spectral data are reported using the following abbreviations: $\mathrm{s}=$ singlet, $\mathrm{bs}=$ broad singlet, $\mathrm{d}=$ doublet, $\mathrm{dd}=$ doublet of doublets, $\mathrm{t}=$ triplet and $\mathrm{m}=$ multiplet and coupling constants are reported in $\mathrm{Hz}$, followed by integration. Chromatographic separations were performed on a silica gel column by flash chromatography (Kieselgel 40, 0.040-0.063 mm; Merck). Yields were given after purification, unless otherwise stated.

The high-resolution mass spectrometry (HRMS) analysis was performed with a Thermo Finnigan LTQ Orbitrap mass spectrometer equipped with an electrospray ionization source (ESI). The accurate mass measure was carried out by introducing, via syringe pump at $10 \mu \mathrm{L} \mathrm{min}{ }^{-1}$, the sample solution $\left(1.0 \mu \mathrm{g} \mathrm{mL} \mathrm{m}^{-1}\right.$ in $\mathrm{mQ}$ water: acetonitrile 50:50), and the signal of the positive ions was acquired. The proposed experimental conditions allowed to monitoring the protonated molecules of studied compounds $\left([\mathrm{M}+\mathrm{H}]^{+}\right.$species $)$, that they were measured with a proper dwell time to achieve 60,000 units of resolution at full width at half maximum (FWHM). The elemental composition of compounds was calculated on the basis of their measured accurate masses, accepting only results with an attribution error less than 2.5 ppm and a not integer RDB (double bond/ring equivalents) value, in order to consider only the protonated species [46].

Compounds were named following IUPAC rules as applied by ChemBioDraw Ultra 14.0 software (Cambridgesoft, Perkin Elmer, Milan, Italy). When reactions were performed in anhydrous conditions, the mixtures were maintained under nitrogen. Free bases 15-28 were transformed into the hydrochloride by treatment with a solution of acetyl chloride (1.1 equivalents) in anhydrous $\mathrm{CH}_{3} \mathrm{OH}$. The salts were crystallized from abs. ethanol/petroleum ether.

6-Chlorohexyl 3,4,5-trimethoxybenzoate 29. A solution of $909 \mathrm{mg}$ (4.28 mmol) of 3,4,5-trimethoxybenzoic acid in $25 \mathrm{~mL}$ of anhydrous $\mathrm{CH}_{2} \mathrm{Cl}_{2}$ was cooled at $0{ }^{\circ} \mathrm{C}$ and $0.33 \mathrm{~mL}$ (2.86 mmol) of 6-chlorohexan-1-ol, $0.28 \mathrm{~g}$ (2.28 mmol) of DMAP and $0.98 \mathrm{~g}(5.14 \mathrm{mmol})$ of EDC hydrochloride were added in this order. The reaction mixture was stirred at $0{ }^{\circ} \mathrm{C}$ for $1 \mathrm{~h}$ and at room temperature for $48 \mathrm{~h}$, then treated with $\mathrm{CH}_{2} \mathrm{Cl}_{2}$. The organic layer was washed three times with water and twice with a saturated solution of $\mathrm{NaHCO}_{3}$. After drying with $\mathrm{Na}_{2} \mathrm{SO}_{4}$, the solvent was removed under reduced pressure. The crude product was then purified by flash chromatography using $\mathrm{CH}_{2} \mathrm{Cl}_{2} / \mathrm{CH}_{3} \mathrm{OH} 98: 2$ as eluent, yielding $943 \mathrm{mg}(100 \%)$ of the desired compound as an oil. ${ }^{1} \mathrm{H}-\mathrm{NMR}\left(400 \mathrm{MHz}, \mathrm{CDCl}_{3}\right) \delta: 7.22(\mathrm{~s}, 2 \mathrm{H}, \mathrm{CH})$; $4.24\left(\mathrm{t}, J=6.8 \mathrm{~Hz}, 2 \mathrm{H}, \mathrm{OCH}_{2}\right) ; 3.84\left(\mathrm{~s}, 6 \mathrm{H}, \mathrm{OCH}_{3}\right) ; 3.83\left(\mathrm{~s}, 3 \mathrm{H}, \mathrm{OCH}_{3}\right) ; 3.47\left(\mathrm{t}, J=6.4 \mathrm{~Hz}, 2 \mathrm{H}, \mathrm{CH}_{2} \mathrm{Cl}\right)$; 1.75-1.69 (m, 4H, $\left.\mathrm{CH}_{2}\right) ; 1.49-1.39\left(\mathrm{~m}, 4 \mathrm{H}, \mathrm{CH}_{2}\right) \mathrm{ppm}$.

6-Iodohexyl 3,4,5-trimethoxybenzoate 30. To a solution of $1.069 \mathrm{~g}$ (3.24 mmol) of compound $29 \mathrm{in} 15 \mathrm{~mL}$ of acetone, $\mathrm{NaI}(2.90 \mathrm{~g}, 19.4 \mathrm{mmol})$ was added, and the resulting mixture was maintained at reflux in the dark for $19 \mathrm{~h}$. The reaction mixture was cooled to room temperature, and the solvent was removed under reduced pressure; the residue was dissolved in $\mathrm{CH}_{2} \mathrm{Cl}_{2}$ and washed with water. The organic layer was dried with $\mathrm{Na}_{2} \mathrm{SO}_{4}$, and the solvent was removed under reduced pressure yielding $1.27 \mathrm{~g}$ (93\%) of the desired compound 30 as an oil, which was used as such for the next reaction. ${ }^{1} \mathrm{H}-\mathrm{NMR}$ $\left(400 \mathrm{MHz} \mathrm{CDCl}_{3}\right) \delta: 7.21(\mathrm{~s}, 2 \mathrm{H}, \mathrm{CH}) ; 4.24\left(\mathrm{t}, \mathrm{J}=6.4 \mathrm{~Hz}, 2 \mathrm{H}, \mathrm{OCH}_{2}\right) ; 3.83\left(\mathrm{~s}, 6 \mathrm{H}, \mathrm{OCH}_{3}\right) ; 3.82(\mathrm{~s}, 3 \mathrm{H}$, $\left.\mathrm{OCH}_{3}\right) ; 3.11\left(\mathrm{t}, \mathrm{J}=6.8 \mathrm{~Hz}, 2 \mathrm{H}, \mathrm{CH}_{2} \mathrm{I}\right) ; 1.77-1.69\left(\mathrm{~m}, 4 \mathrm{H}, \mathrm{CH}_{2}\right) ; 1.40-1.35\left(\mathrm{~m}, 4 \mathrm{H}, \mathrm{CH}_{2}\right)$ ppm.

6-((3-Hydroxypropyl)amino)hexyl 3,4,5-trimethoxybenzoate 31. To a solution of $1.27 \mathrm{~g}$ (3.00 mmol) of compound 30 in $20 \mathrm{~mL}$ of anhydrous $\mathrm{CH}_{3} \mathrm{CN}, 0.42 \mathrm{~g}$ ( $\left.3.00 \mathrm{mmol}\right)$ of $\mathrm{K}_{2} \mathrm{CO}_{3}$ and $0.70 \mathrm{~mL}(9.00 \mathrm{mmol})$ of 3-aminopropan-1-ol were added. The mixture was heated at $80{ }^{\circ} \mathrm{C}$ for $18 \mathrm{~h}$. Then the solvent was removed under reduced pressure; the residue was treated with $\mathrm{CH}_{2} \mathrm{Cl}_{2}$ and the organic layer was washed with $10 \% \mathrm{NaOH}$ solution. After drying with $\mathrm{Na}_{2} \mathrm{SO}_{4}$, the solvent was removed under reduced pressure and the residue purified by flash chromatography using $\mathrm{CH}_{2} \mathrm{Cl}_{2} / \mathrm{CH}_{3} \mathrm{OH} / \mathrm{NH}_{4} \mathrm{OH}$ 90:10:1 as eluent. The desired compound $31(0.950 \mathrm{~g}, 86 \%)$ was obtained as an oil. ${ }^{1} \mathrm{H}-\mathrm{NMR}\left(400 \mathrm{MHz}, \mathrm{CDCl}_{3}\right) \delta$ : $7.22(\mathrm{~s}, 2 \mathrm{H}, \mathrm{CH}) ; 4.24\left(\mathrm{t}, J=6.8 \mathrm{~Hz}, 2 \mathrm{H}, \mathrm{OCH}_{2}\right) ; 3.85\left(\mathrm{~s}, 6 \mathrm{H}, \mathrm{OCH}_{3}\right) ; 3.83\left(\mathrm{~s}, 3 \mathrm{H}, \mathrm{OCH}_{3}\right) ; 3.73(\mathrm{t}, J=5.2 \mathrm{~Hz}$, $\left.2 \mathrm{H}, \mathrm{CH}_{2} \mathrm{OH}\right) ; 3.45(\mathrm{bs}, 2 \mathrm{H}, \mathrm{NH}$ and $\mathrm{OH}) ; 2.82\left(\mathrm{t}, J=5.6 \mathrm{~Hz}, 2 \mathrm{H}, \mathrm{NCH}_{2}\right) ; 2.56\left(\mathrm{t}, J=7.2 \mathrm{~Hz}, 2 \mathrm{H}, \mathrm{NCH}_{2}\right)$; $1.72-1.63\left(\mathrm{~m}, 4 \mathrm{H}, \mathrm{CH}_{2}\right) ; 1.49-1.33\left(\mathrm{~m}, 6 \mathrm{H}, \mathrm{CH}_{2}\right) \mathrm{ppm}$. 
6-((3-Hydroxypropyl)amino)hexyl anthracene-9-carboxylate 32. Following the same procedure described for compound 31, starting from $1.44 \mathrm{~g}$ (3.34 mmol) of 6-iodohexyl anthracene-9-carboxylate [38], compound $32(0.766 \mathrm{~g}, 60 \%)$ was obtained as an oil. ${ }^{1} \mathrm{H}-\mathrm{NMR}\left(400 \mathrm{MHz}, \mathrm{CDCl}_{3}\right) \delta: 8.44(\mathrm{~s}, 1 \mathrm{H}, \mathrm{CH})$; 7.98-7.93 (m, 4H, CH); 7.50-7.40 (m, 4H, CH); $4.55\left(\mathrm{t}, J=6.8 \mathrm{~Hz}, 2 \mathrm{H}, \mathrm{OCH}_{2}\right) ; 3.67(\mathrm{t}, J=5.2 \mathrm{~Hz}, 2 \mathrm{H}$, $\left.\mathrm{CH}_{2} \mathrm{OH}\right) ; 2.70\left(\mathrm{t}, J=5.6 \mathrm{~Hz}, 2 \mathrm{H}, \mathrm{NCH}_{2}\right) ; 2.49\left(\mathrm{t}, J=6.8 \mathrm{~Hz}, 2 \mathrm{H}, \mathrm{NCH}_{2}\right) ; 1.83-1.77\left(\mathrm{~m}, 2 \mathrm{H}, \mathrm{CH}_{2}\right) ; 1.63-1.57$ $\left(\mathrm{m}, 2 \mathrm{H}, \mathrm{CH}_{2}\right) ; 1.42-1.31\left(\mathrm{~m}, 6 \mathrm{H}, \mathrm{CH}_{2}\right) \mathrm{ppm}$.

6-((3-Hydroxypropyl)(methyl)amino)hexyl 3,4,5-trimethoxybenzoate 33. Compound 31 ( $0.238 \mathrm{~g}, 0.65 \mathrm{mmol})$ was dissolved in $5 \mathrm{~mL}$ of anhydrous ethanol, then $\mathrm{HCOOH}(0.40 \mathrm{~mL})$ and $37 \% \mathrm{HCHO}$ solution $(0.09 \mathrm{~mL}, 3.23 \mathrm{mmol})$ were added. The mixture was heated at $80^{\circ} \mathrm{C}$ for $4-5 \mathrm{~h}$ and concentrated in vacuo. The residue was then dissolved in $\mathrm{CH}_{2} \mathrm{Cl}_{2}$ and the organic layer was washed with $10 \% \mathrm{NaOH}$ solution. After drying with $\mathrm{Na}_{2} \mathrm{SO}_{4}$, the solvent was removed under reduced pressure, and the residue purified by flash chromatography using $\mathrm{CH}_{2} \mathrm{Cl}_{2} / \mathrm{CH}_{3} \mathrm{OH} / \mathrm{NH}_{4} \mathrm{OH}$ 90:10:1 as eluent. The desired compound 33 $(0.169 \mathrm{~g}, 68 \%)$ was obtained as an oil. ${ }^{1} \mathrm{H}-\mathrm{NMR}\left(400 \mathrm{MHz}, \mathrm{CDCl}_{3}\right) \delta: 7.24(\mathrm{~s}, 2 \mathrm{H}, \mathrm{CH}) ; 4.25(\mathrm{t}, J=6.8 \mathrm{~Hz}$, $\left.2 \mathrm{H}, \mathrm{OCH}_{2}\right) ; 3.86\left(\mathrm{~s}, 6 \mathrm{H}, \mathrm{OCH}_{3}\right) ; 3.85\left(\mathrm{~s}, 3 \mathrm{H}, \mathrm{OCH}_{3}\right) ; 3.74\left(\mathrm{t}, J=5.2 \mathrm{~Hz}, 2 \mathrm{H}, \mathrm{CH}_{2} \mathrm{OH}\right) ; 2.55(\mathrm{t}, J=5.6 \mathrm{~Hz}$, $\left.2 \mathrm{H}, \mathrm{NCH}_{2}\right) ; 2.33\left(\mathrm{t}, J=7.2 \mathrm{~Hz}, 2 \mathrm{H}, \mathrm{NCH}_{2}\right) ; 2.20\left(\mathrm{~s}, 3 \mathrm{H}, \mathrm{NCH}_{3}\right) ; 1.74-1.63\left(\mathrm{~m}, 4 \mathrm{H}, \mathrm{CH}_{2}\right) ; 1.51-1.30(\mathrm{~m}, 6 \mathrm{H}$, $\left.\mathrm{CH}_{2}\right)$ ppm.

6-((3-Hydroxypropyl)(methyl)amino)hexyl anthracene-9-carboxylate 34. Following the same procedure described for compound 33, starting from $0.224(0.59 \mathrm{mmol})$ of 32, compound $34(0.226 \mathrm{~g}, 98 \%)$ was obtained as an oil. ${ }^{1} \mathrm{H}-\mathrm{NMR}\left(400 \mathrm{MHz}, \mathrm{CDCl}_{3}\right) \delta: 8.39(\mathrm{~s}, 1 \mathrm{H}, \mathrm{CH}) ; 8.01(\mathrm{~d}, J=8.8 \mathrm{~Hz}, 2 \mathrm{H}, \mathrm{CH}) ; 7.90$ $(\mathrm{d}, J=8.8 \mathrm{~Hz}, 2 \mathrm{H}, \mathrm{CH}) ; 7.50-7.38(\mathrm{~m}, 4 \mathrm{H}, \mathrm{CH}) ; 4.56\left(\mathrm{t}, J=6.8 \mathrm{~Hz}, 2 \mathrm{H}, \mathrm{OCH}_{2}\right) ; 3.71(\mathrm{t}, J=5.2 \mathrm{~Hz}, 2 \mathrm{H}$, $\left.\mathrm{CH}_{2} \mathrm{OH}\right) ; 2.43\left(\mathrm{t}, J=5.6 \mathrm{~Hz}, 2 \mathrm{H}, \mathrm{NCH}_{2}\right) ; 2.23\left(\mathrm{t}, J=7.2 \mathrm{~Hz}, 2 \mathrm{H}, \mathrm{NCH}_{2}\right) ; 2.12\left(\mathrm{~s}, 3 \mathrm{H}, \mathrm{NCH}_{3}\right) ; 1.85-1.78$ $\left(\mathrm{m}, 2 \mathrm{H}, \mathrm{CH}_{2}\right) ; 1.61-1.50\left(\mathrm{~m}, 2 \mathrm{H}, \mathrm{CH}_{2}\right) ; 1.49-1.28\left(\mathrm{~m}, 6 \mathrm{H}, \mathrm{CH}_{2}\right) \mathrm{ppm}$.

Ethyl 2-((2-oxo-2H-chromen-7-yl)oxy)acetate 47. To a solution of 7-hydroxy-2H-chromen-2-one (240 mg, $0.97 \mathrm{mmol})$ in $8 \mathrm{~mL}$ of acetone, $\mathrm{K}_{2} \mathrm{CO}_{3}(228 \mathrm{mg}, 1.63 \mathrm{mmol})$ was added. The mixture was stirred at room temperature for $15 \mathrm{~min}$, and then ethyl bromoacetate $(0.18 \mathrm{~mL}, 1.63 \mathrm{mmol})$ dissolved in $6 \mathrm{~mL}$ acetone was added dropwise. The reaction mixture was heated at $58^{\circ} \mathrm{C}$ for $6 \mathrm{~h}$ and, after cooling, water $(10 \mathrm{~mL})$ was added. The suspension was filtered under vacuum and the solid obtained was dried under vacuum. The title compound was obtained as a white solid. Yield: $89 \%, \mathrm{mp} 107-110{ }^{\circ} \mathrm{C}$. ${ }^{1} \mathrm{H}-\mathrm{NMR}\left(400 \mathrm{MHz}, \mathrm{CDCl}_{3}\right) \delta: 7.64(\mathrm{~d}, J=9.6 \mathrm{~Hz}, 1 \mathrm{H}, \mathrm{CH}) ; 7.40(\mathrm{~d}, J=8.4 \mathrm{~Hz}, 1 \mathrm{H}, \mathrm{CH}) ; 6.89(\mathrm{dd}, J=8.4$, $2.2 \mathrm{~Hz}, 1 \mathrm{H}, \mathrm{CH}) ; 6.78(\mathrm{~d}, J=2.2 \mathrm{~Hz}, 1 \mathrm{H}, \mathrm{CH}) ; 6.28(\mathrm{~d}, J=9.6 \mathrm{~Hz}, 1 \mathrm{H}, \mathrm{CH}) ; 4.68\left(\mathrm{~s}, 2 \mathrm{H}, \mathrm{OCH}_{2}\right) ; 4.30$ $\left(\mathrm{q}, J=7.2 \mathrm{~Hz}, 2 \mathrm{H}, \mathrm{OCH}_{2}\right) ; 1.32\left(\mathrm{t}, J=7.2 \mathrm{~Hz}, 3 \mathrm{H}, \mathrm{CH}_{3}\right) \mathrm{ppm}$.

2-((2-Oxo-2H-chromen-7-yl)oxy)acetic acid 48. Ten milliliters of $10 \% \mathrm{NaOH}$ solution were added to $225 \mathrm{mg}(0.95 \mathrm{mmol})$ of 47 . The mixture was heated at $100{ }^{\circ} \mathrm{C}$ for $3 \mathrm{~h}$. After cooling, the solution was acidified with $\mathrm{HCl} 2 \mathrm{~N}$ and the solid was filtered under vacuum and then dried. The title compound was obtained as a white solid. Yield: $100 \%, \mathrm{mp} 220-223{ }^{\circ} \mathrm{C} .{ }^{1} \mathrm{H}-\mathrm{NMR}\left(400 \mathrm{MHz}, \mathrm{DMSO}-\mathrm{d}_{6}\right) \delta: 7.98$ $(\mathrm{d}, J=9.6, \mathrm{~Hz} 1 \mathrm{H}, \mathrm{CH}) ; 7.62(\mathrm{~d}, J=8.4 \mathrm{~Hz}, 1 \mathrm{H}, \mathrm{CH}) ; 6.94(\mathrm{~s}, 1 \mathrm{H}, \mathrm{CH}) ; 6.93(\mathrm{~d}, J=8.4 \mathrm{~Hz}, 1 \mathrm{H}, \mathrm{CH}) ; 6.28$ $(\mathrm{d}, J=9.6 \mathrm{~Hz}, 1 \mathrm{H}, \mathrm{CH}) ; 4.81\left(\mathrm{~s}, 2 \mathrm{H}, \mathrm{OCH}_{2}\right) \mathrm{ppm}$.

\subsubsection{General Procedure for the Synthesis of Diester Compounds 1-14}

To a solution of $48(0.26 \mathrm{mmol})$ in $25 \mathrm{~mL}$ of anhydrous $\mathrm{CH}_{3} \mathrm{CN}, 0.33 \mathrm{mmol}$ of EDC hydrochloride and $0.33 \mathrm{mmol}$ of HOBt were added. The mixture was stirred at room temperature for $1 \mathrm{~h}$, and then the suitable (hydroxyalkyl) methylaminoester $33-46(0.22 \mathrm{mmol})$ dissolved in $5 \mathrm{~mL}$ of anhydrous $\mathrm{CH}_{3} \mathrm{CN}$ was added. The reaction mixture was stirred for $4 \mathrm{~h}$ at room temperature and the solvent was removed under reduce pressure. Then $\mathrm{CH}_{2} \mathrm{Cl}_{2}$ was added and the organic layer was washed twice with a saturated solution of $\mathrm{NaHCO}_{3}$. After drying with $\mathrm{Na}_{2} \mathrm{SO}_{4}$, the solvent was removed under reduced pressure. The crude product was then purified by flash chromatography, using the proper eluting system, yielding the desired compound as an oil. 
(E)-3-(methyl(3-(2-((2-oxo-2H-chromen-7-yl)oxy)acetoxy)propyl)amino)propyl 3-(3,4,5-trimethoxyphenyl)acrylate 1. From (hydroxyalkyl)methylaminoester 35 [35]. Oil. Chromatographic eluent: $\mathrm{CH}_{2} \mathrm{Cl}_{2} / \mathrm{CH}_{3} \mathrm{OH}$ 95:5. Yield: 37\%. ${ }^{1} \mathrm{H}-\mathrm{NMR}\left(400 \mathrm{MHz} \mathrm{CDCl}_{3}\right) \delta: 7.63(\mathrm{~d}, \mathrm{~J}=9.4 \mathrm{~Hz}, 1 \mathrm{H}, \mathrm{CH}) ; 7.58(\mathrm{~d}, \mathrm{~J}=16.0 \mathrm{~Hz}, 1 \mathrm{H}, \mathrm{CH}=\mathrm{CH}) ; 7.38$ $(\mathrm{d}, J=8.4 \mathrm{~Hz}, 1 \mathrm{H}, \mathrm{CH}) ; 6.87(\mathrm{dd}, J=8.4,2.2 \mathrm{~Hz}, 1 \mathrm{H}, \mathrm{CH}) ; 6.77(\mathrm{~d}, J=2.2 \mathrm{~Hz}, 1 \mathrm{H}, \mathrm{CH}) ; 6.74(\mathrm{~s}, 2 \mathrm{H}, \mathrm{CH})$; $6.33(\mathrm{~d}, J=16.0 \mathrm{~Hz}, 1 \mathrm{H}, \mathrm{CH}=\mathrm{CH}) ; 6.26(\mathrm{~d}, J=9.4 \mathrm{~Hz}, 1 \mathrm{H}, \mathrm{CH}) ; 4.68\left(\mathrm{~s}, 2 \mathrm{H}, \mathrm{OCH}_{2}\right) ; 4.30-4.22(\mathrm{~m}, 4 \mathrm{H}$, $\left.\mathrm{OCH}_{2}\right) ; 3.88\left(\mathrm{~s}, 6 \mathrm{H}, \mathrm{OCH}_{3}\right) ; 3.87\left(\mathrm{~s}, 3 \mathrm{H}, \mathrm{OCH}_{3}\right) ; 2.47-2.35\left(\mathrm{~m}, 4 \mathrm{H}, \mathrm{NCH}_{2}\right) ; 2.22\left(\mathrm{~s}, 3 \mathrm{H}, \mathrm{NCH}_{3}\right) ; 1.87-1.81$ $\left(\mathrm{m}, 4 \mathrm{H}, \mathrm{CH}_{2}\right)$ ppm. ${ }^{13} \mathrm{C}-\mathrm{NMR}\left(100 \mathrm{MHz}, \mathrm{CDCl}_{3}\right) \delta: 167.97(\mathrm{C}) ; 166.95(\mathrm{C}) ; 160.84(\mathrm{C}) ; 155.62(\mathrm{C}) ; 153.44$ (C); $144.73(\mathrm{CH}) ; 143.16(\mathrm{CH}) ; 129.88(\mathrm{C}) ; 128.97(\mathrm{CH}) ; 117.31(\mathrm{CH}) ; 113.78(\mathrm{CH}) ; 133.33(\mathrm{C}) ; 112.80$ $(\mathrm{CH}) ; 105.27(\mathrm{CH}) ; 101.70(\mathrm{CH}) ; 65.34\left(\mathrm{CH}_{2}\right) ; 64.02\left(\mathrm{CH}_{2}\right) ; 62.85\left(\mathrm{CH}_{2}\right) ; 60.95\left(\mathrm{OCH}_{3}\right) ; 56.17\left(\mathrm{OCH}_{3}\right)$; $54.20\left(\mathrm{CH}_{2}\right) ; 53.85\left(\mathrm{CH}_{2}\right) ; 41.95\left(\mathrm{NCH}_{3}\right) ; 26.67\left(\mathrm{CH}_{2}\right) ; 26.47\left(\mathrm{CH}_{2}\right)$ ppm. ESI-HRMS $(m / z)$ calculated for $[\mathrm{M}+\mathrm{H}]^{+}$ion species $\mathrm{C}_{30} \mathrm{H}_{36} \mathrm{NO}_{10}=570.2334$, found 570.2340.

(E)-3-(methyl(5-(2-((2-oxo-2H-chromen-7-yl)oxy)acetoxy)pentyl)amino)propyl 3-(3,4,5-trimethoxyphenyl)acrylate 2. From 36 [37]. Oil. Chromatographic eluent: $\mathrm{CH}_{2} \mathrm{Cl}_{2} / \mathrm{CH}_{3} \mathrm{OH}$ 93:7. Yield: $29 \%$. ${ }^{1} \mathrm{H}-\mathrm{NMR}(400 \mathrm{MHz}$, $\left.\mathrm{CDCl}_{3}\right) \delta: 7.60(\mathrm{~d}, J=9.6 \mathrm{~Hz}, 1 \mathrm{H}, \mathrm{CH}) ; 7.56(\mathrm{~d}, J=16.0 \mathrm{~Hz}, 1 \mathrm{H}, \mathrm{CH}=\mathrm{CH}) ; 7.36(\mathrm{~d}, J=8.4 \mathrm{~Hz}, 1 \mathrm{H}, \mathrm{CH})$; $6.85(\mathrm{dd}, J=8.4,2.2 \mathrm{~Hz}, 1 \mathrm{H}, \mathrm{CH}) ; 6.74(\mathrm{~d}, J=2.2 \mathrm{~Hz}, 1 \mathrm{H}, \mathrm{CH}) ; 6.72(\mathrm{~s}, 2 \mathrm{H}, \mathrm{CH}) ; 6.31(\mathrm{~d}, J=16.0 \mathrm{~Hz}$, $1 \mathrm{H}, \mathrm{CH}=\mathrm{CH}) ; 6.23(\mathrm{~d}, J=9.6 \mathrm{~Hz}, 1 \mathrm{H}, \mathrm{CH}) ; 4.66\left(\mathrm{~s}, 2 \mathrm{H}, \mathrm{OCH}_{2}\right) ; 4.23-4.16\left(\mathrm{~m}, 4 \mathrm{H}, \mathrm{OCH}_{2}\right) ; 3.85(\mathrm{~s}, 6 \mathrm{H}$, $\left.\mathrm{OCH}_{3}\right) ; 3.84\left(\mathrm{~s}, 3 \mathrm{H}, \mathrm{OCH}_{3}\right) ; 2.42\left(\mathrm{t}, J=6.8 \mathrm{~Hz}, 2 \mathrm{H}, \mathrm{NCH}_{2}\right) ; 2.30\left(\mathrm{t}, J=6.8 \mathrm{~Hz}, 2 \mathrm{H}, \mathrm{NCH}_{2}\right) ; 2.19(\mathrm{~s}, 3 \mathrm{H}$, $\left.\mathrm{NCH}_{3}\right) ; 1.88-1.83\left(\mathrm{~m}, 2 \mathrm{H}, \mathrm{CH}_{2}\right) ; 1.71-1.60\left(\mathrm{~m}, 2 \mathrm{H}, \mathrm{CH}_{2}\right) ; 1.50-1.40\left(\mathrm{~m}, 2 \mathrm{H}, \mathrm{CH}_{2}\right) ; 1.38-1.28(\mathrm{~m}, 2 \mathrm{H}$,

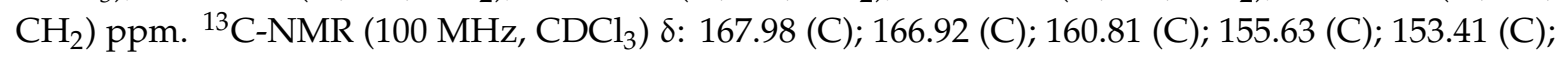
$144.65(\mathrm{CH}) ; 143.18(\mathrm{CH}) ; 129.87(\mathrm{C}) ; 128.95(\mathrm{CH}) ; 117.33(\mathrm{CH}) ; 113.70(\mathrm{CH}) ; 113.29(\mathrm{C}) ; 112.79(\mathrm{CH})$; $105.26(\mathrm{CH}) ; 101.71(\mathrm{CH}) ; 65.63\left(\mathrm{CH}_{2}\right) ; 65.32\left(\mathrm{CH}_{2}\right) ; 62.98\left(\mathrm{CH}_{2}\right) ; 60.92\left(\mathrm{OCH}_{3}\right) ; 57.45\left(\mathrm{CH}_{2}\right) ; 56.15$ $\left(\mathrm{OCH}_{3}\right) ; 54.19\left(\mathrm{CH}_{2}\right) ; 42.08\left(\mathrm{NCH}_{3}\right) ; 28.42\left(\mathrm{CH}_{2}\right) ; 26.87\left(\mathrm{CH}_{2}\right) ; 26.67\left(\mathrm{CH}_{2}\right) ; 23.67\left(\mathrm{CH}_{2}\right)$ ppm. ESI-HRMS $(\mathrm{m} / z)$ calculated for $[\mathrm{M}+\mathrm{H}]^{+}$ion species $\mathrm{C}_{32} \mathrm{H}_{40} \mathrm{NO}_{10}=598.2647$, found 598.2651.

(E)-5-(methyl(3-(2-((2-oxo-2H-chromen-7-yl)oxy)acetoxy)propyl)amino)pentyl 3-(3,4,5-trimethoxyphenyl)acrylate 3. From 37 [37]. Oil. Chromatographic eluent: $\mathrm{CH}_{2} \mathrm{Cl}_{2} / \mathrm{CH}_{3} \mathrm{OH}$ 95:5. Yield: 33\%. ${ }^{1} \mathrm{H}-\mathrm{NMR}(400 \mathrm{MHz}$, $\left.\mathrm{CDCl}_{3}\right) \delta: 7.59(\mathrm{~d}, J=9.6 \mathrm{~Hz}, 1 \mathrm{H}, \mathrm{CH}) ; 7.53(\mathrm{~d}, J=15.6 \mathrm{~Hz}, 1 \mathrm{H}, \mathrm{CH}=\mathrm{CH}) ; 7.34(\mathrm{~d}, J=8.4 \mathrm{~Hz}, 1 \mathrm{H}, \mathrm{CH})$; $6.82(\mathrm{dd}, J=8.4,2.2 \mathrm{~Hz}, 1 \mathrm{H}, \mathrm{CH}) ; 6.72(\mathrm{~d}, J=2.2 \mathrm{~Hz}, 1 \mathrm{H}, \mathrm{CH}) ; 6.70(\mathrm{~s}, 2 \mathrm{H}, \mathrm{CH}) ; 6.30(\mathrm{~d}, J=15.6 \mathrm{~Hz}$, $1 \mathrm{H}, \mathrm{CH}=\mathrm{CH}) ; 6.21(\mathrm{~d}, J=9.6 \mathrm{~Hz}, 1 \mathrm{H}, \mathrm{CH}) ; 4.64\left(\mathrm{~s}, 2 \mathrm{H}, \mathrm{OCH}_{2}\right) ; 4.22\left(\mathrm{t}, J=6.4 \mathrm{~Hz}, 2 \mathrm{H}, \mathrm{OCH}_{2}\right) ; 4.15$ $\left(\mathrm{t}, J=6.4 \mathrm{~Hz}, 2 \mathrm{H}, \mathrm{OCH}_{2}\right) ; 3.83\left(\mathrm{~s}, 6 \mathrm{H}, \mathrm{OCH}_{3}\right) ; 3.82\left(\mathrm{~s}, 3 \mathrm{H}, \mathrm{OCH}_{3}\right) ; 2.34\left(\mathrm{t}, J=6.8 \mathrm{~Hz}, 2 \mathrm{H}, \mathrm{NCH}_{2}\right) ; 2.29$ $\left(\mathrm{t}, J=7.2 \mathrm{~Hz}, 2 \mathrm{H}, \mathrm{NCH}_{2}\right) ; 2.15\left(\mathrm{~s}, 3 \mathrm{H}, \mathrm{NCH}_{3}\right) ; 1.82-1.75\left(\mathrm{~m}, 2 \mathrm{H}, \mathrm{CH}_{2}\right) ; 1.69-1.64\left(\mathrm{~m}, 2 \mathrm{H}, \mathrm{CH}_{2}\right) ; 1.52-1.32$

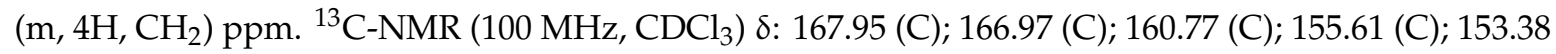
(C); $144.58(\mathrm{CH}) ; 143.20(\mathrm{CH}) ; 140.04(\mathrm{C}) ; 129.90(\mathrm{C}) ; 128.98(\mathrm{CH}) ; 117.41(\mathrm{CH}) ; 113.68(\mathrm{CH}) ; 113.29(\mathrm{C})$; $112.73(\mathrm{CH}) ; 105.21(\mathrm{CH}) ; 101.68(\mathrm{CH}) ; 65.29\left(\mathrm{CH}_{2}\right) ; 64.47\left(\mathrm{CH}_{2}\right) ; 64.06\left(\mathrm{CH}_{2}\right) ; 60.90\left(\mathrm{OCH}_{3}\right) ; 57.51\left(\mathrm{CH}_{2}\right)$; $56.12\left(\mathrm{OCH}_{3}\right) ; 53.88\left(\mathrm{CH}_{2}\right) ; 41.97\left(\mathrm{NCH}_{3}\right) ; 28.64\left(\mathrm{CH}_{2}\right) ; 26.81\left(\mathrm{CH}_{2}\right) ; 26.37\left(\mathrm{CH}_{2}\right) ; 23.81\left(\mathrm{CH}_{2}\right)$ ppm. ESI-HRMS $(m / z)$ calculated for $[\mathrm{M}+\mathrm{H}]^{+}$ion species $\mathrm{C}_{32} \mathrm{H}_{40} \mathrm{NO}_{10}=598.2647$, found 598.2642.

(E)-5-(methyl(5-(2-((2-oxo-2H-chromen-7-yl)oxy)acetoxy)pentyl)amino)pentyl 3-(3,4,5-trimethoxyphenyl)acrylate 4. From 38 [35]. Oil. Chromatographic eluent: $\mathrm{CH}_{2} \mathrm{Cl}_{2} / \mathrm{CH}_{3} \mathrm{OH}$ 95:5. Yield: 46\%. ${ }^{1} \mathrm{H}-\mathrm{NMR}(400 \mathrm{MHz}$, $\left.\mathrm{CDCl}_{3}\right) \delta: 7.62(\mathrm{~d}, J=9.6 \mathrm{~Hz}, 1 \mathrm{H}, \mathrm{CH}) ; 7.57(\mathrm{~d}, J=16.0 \mathrm{~Hz}, 1 \mathrm{H}, \mathrm{CH}=\mathrm{CH}) ; 7.38(\mathrm{~d}, J=8.8 \mathrm{~Hz}, 1 \mathrm{H}, \mathrm{CH})$; $6.87(\mathrm{dd}, J=8.8,2.2 \mathrm{~Hz}, 1 \mathrm{H}, \mathrm{CH}) ; 6.76(\mathrm{~d}, J=2.2 \mathrm{~Hz}, 1 \mathrm{H}, \mathrm{CH}) ; 6.74(\mathrm{~s}, 2 \mathrm{H}, \mathrm{CH}) ; 6.33(\mathrm{~d}, J=16.0 \mathrm{~Hz}$, $1 \mathrm{H}, \mathrm{CH}=\mathrm{CH}) ; 6.25(\mathrm{~d}, J=9.6 \mathrm{~Hz}, 1 \mathrm{H}, \mathrm{CH}) ; 4.67\left(\mathrm{~s}, 2 \mathrm{H}, \mathrm{OCH}_{2}\right) ; 4.22-4.15\left(\mathrm{~m}, 4 \mathrm{H}, \mathrm{OCH}_{2}\right) ; 3.87(\mathrm{~s}, 6 \mathrm{H}$, $\left.\mathrm{OCH}_{3}\right) ; 3.86\left(\mathrm{~s}, 3 \mathrm{H}, \mathrm{OCH}_{3}\right) ; 2.35-2.29\left(\mathrm{~m}, 4 \mathrm{H}, \mathrm{NCH}_{2}\right) ; 2.20\left(\mathrm{~s}, 3 \mathrm{H}, \mathrm{NCH}_{3}\right) ; 1.75-1.63\left(\mathrm{~m}, 4 \mathrm{H}, \mathrm{CH}_{2}\right)$; 1.55-1.30 (m, 8H, $\left.\mathrm{CH}_{2}\right)$ ppm. ${ }^{13} \mathrm{C}-\mathrm{NMR}\left(100 \mathrm{MHz}, \mathrm{CDCl}_{3}\right) \delta: 167.99(\mathrm{C}) ; 167.01(\mathrm{C}) ; 160.86(\mathrm{C}) ; 160.82$ (C); $155.66(\mathrm{C}) ; 153.43(\mathrm{C}) ; 144.61(\mathrm{CH}) ; 143.20(\mathrm{CH}) ; 140.21(\mathrm{C}) ; 129.93(\mathrm{C}) ; 128.97(\mathrm{CH}) ; 117.44(\mathrm{CH})$; $113.76(\mathrm{CH}) ; 113.32(\mathrm{C}) ; 112.85(\mathrm{CH}) ; 105.24(\mathrm{CH}) ; 101.70(\mathrm{CH}) ; 65.66\left(\mathrm{CH}_{2}\right) ; 65.34\left(\mathrm{CH}_{2}\right) ; 64.54\left(\mathrm{CH}_{2}\right)$; $60.95\left(\mathrm{OCH}_{3}\right) ; 57.64\left(\mathrm{CH}_{2}\right) ; 57.54\left(\mathrm{CH}_{2}\right) ; 56.16\left(\mathrm{OCH}_{3}\right) ; 42.15\left(\mathrm{NCH}_{3}\right) ; 28.70\left(\mathrm{CH}_{2}\right) ; 28.45\left(\mathrm{CH}_{2}\right) ; 26.88$ $\left(\mathrm{CH}_{2}\right) ; 26.80\left(\mathrm{CH}_{2}\right) ; 23.97\left(\mathrm{CH}_{2}\right) ; 23.77\left(\mathrm{CH}_{2}\right)$ ppm. ESI-HRMS $(\mathrm{m} / \mathrm{z})$ calculated for $[\mathrm{M}+\mathrm{H}]^{+}$ion species $\mathrm{C}_{34} \mathrm{H}_{44} \mathrm{NO}_{10}=626.2960$, found 626.2951. 
(E)-6-(methyl(3-(2-((2-oxo-2H-chromen-7-yl)oxy)acetoxy)propyl)amino)hexyl 3-(3,4,5-trimethoxyphenyl)acrylate 5. From 39 [38]. Oil. Chromatographic eluent: $\mathrm{CH}_{2} \mathrm{Cl}_{2} / \mathrm{CH}_{3} \mathrm{OH} 96: 4$. Yield: 80\%. ${ }^{1} \mathrm{H}-\mathrm{NMR}(400 \mathrm{MHz}$, $\left.\mathrm{CDCl}_{3}\right) \delta: 7.61(\mathrm{~d}, J=9.6 \mathrm{~Hz}, 1 \mathrm{H}, \mathrm{CH}) ; 7.56(\mathrm{~d}, J=16.0 \mathrm{~Hz}, 1 \mathrm{H}, \mathrm{CH}=\mathrm{CH}) ; 7.36(\mathrm{~d}, J=8.4 \mathrm{~Hz}, 1 \mathrm{H}, \mathrm{CH})$; $6.85(\mathrm{dd}, J=8.4,2.2 \mathrm{~Hz}, 1 \mathrm{H}, \mathrm{CH}) ; 6.74(\mathrm{~d}, J=2.2 \mathrm{~Hz}, 1 \mathrm{H}, \mathrm{CH}) ; 6.72(\mathrm{~s}, 2 \mathrm{H}, \mathrm{CH}) ; 6.32(\mathrm{~d}, J=16.0 \mathrm{~Hz}$, $1 \mathrm{H}, \mathrm{CH}=\mathrm{CH}) ; 6.24(\mathrm{~d}, J=9.6 \mathrm{~Hz}, 1 \mathrm{H}, \mathrm{CH}) ; 4.66\left(\mathrm{~s}, 2 \mathrm{H}, \mathrm{OCH}_{2}\right) ; 4.24\left(\mathrm{t}, J=6.4 \mathrm{~Hz}, 2 \mathrm{H}, \mathrm{OCH}_{2}\right) ; 4.16$ $\left(\mathrm{t}, J=6.4 \mathrm{~Hz}, 2 \mathrm{H}, \mathrm{OCH}_{2}\right) ; 3.85\left(\mathrm{~s}, 6 \mathrm{H}, \mathrm{OCH}_{3}\right) ; 3.84\left(\mathrm{~s}, 3 \mathrm{H}, \mathrm{OCH}_{3}\right) ; 2.35\left(\mathrm{t}, J=7.2 \mathrm{~Hz}, 2 \mathrm{H}, \mathrm{NCH}_{2}\right)$; $2.28\left(\mathrm{t}, J=7.6 \mathrm{~Hz}, 2 \mathrm{H}, \mathrm{NCH}_{2}\right) ; 2.16\left(\mathrm{~s}, 3 \mathrm{H}, \mathrm{NCH}_{3}\right) ; 1.84-1.77\left(\mathrm{~m}, 2 \mathrm{H}, \mathrm{CH}_{2}\right) ; 1.70-1.64\left(\mathrm{~m}, 2 \mathrm{H}, \mathrm{CH}_{2}\right)$; 1.47-1.30 (m, 6H, CH 2$)$ ppm. ${ }^{13} \mathrm{C}-\mathrm{NMR}\left(100 \mathrm{MHz}, \mathrm{CDCl}_{3}\right) \delta: 167.96(\mathrm{C}) ; 167.01(\mathrm{C}) ; 160.84(\mathrm{C}) ; 160.79$ (C); $155.64(\mathrm{C}) ; 153.41(\mathrm{C}) ; 144.57(\mathrm{CH}) ; 143.20(\mathrm{CH}) ; 140.06(\mathrm{C}) ; 129.93(\mathrm{C}) ; 128.98(\mathrm{CH}) ; 117.45(\mathrm{CH})$; $113.73(\mathrm{CH}) ; 113.31(\mathrm{C}) ; 112.77(\mathrm{CH}) ; 105.21(\mathrm{CH}) ; 101.70(\mathrm{CH}) ; 65.31\left(\mathrm{CH}_{2}\right) ; 64.55\left(\mathrm{CH}_{2}\right) ; 64.15\left(\mathrm{CH}_{2}\right)$; $60.93\left(\mathrm{OCH}_{3}\right) ; 57.62\left(\mathrm{CH}_{2}\right) ; 56.14\left(\mathrm{OCH}_{3}\right) ; 53.91\left(\mathrm{CH}_{2}\right) ; 42.01\left(\mathrm{NCH}_{3}\right) ; 28.71\left(\mathrm{CH}_{2}\right) ; 27.09\left(\mathrm{CH}_{2}\right) ; 26.40$ $\left(\mathrm{CH}_{2}\right) ; 25.90\left(\mathrm{CH}_{2}\right)$ ppm. ESI-HRMS $(\mathrm{m} / \mathrm{z})$ calculated for $[\mathrm{M}+\mathrm{H}]^{+}$ion species $\mathrm{C}_{33} \mathrm{H}_{42} \mathrm{NO}_{10}=612.2803$, found 612.2794 .

(E)-6-(methyl(4-(2-((2-oxo-2H-chromen-7-yl)oxy)acetoxy)butyl)amino)hexyl 3-(3,4,5-trimethoxyphenyl)acrylate 6. From 40 [38]. Oil. Chromatographic eluent: $\mathrm{CH}_{2} \mathrm{Cl}_{2} / \mathrm{CH}_{3} \mathrm{OH} / \mathrm{NH}_{4} \mathrm{OH}$ 97:3:0.3. Yield: 100\%. ${ }^{1} \mathrm{H}-\mathrm{NMR}$ $\left(400 \mathrm{MHz}, \mathrm{CDCl}_{3}\right) \delta: 7.61(\mathrm{~d}, J=9.6 \mathrm{~Hz}, 1 \mathrm{H}, \mathrm{CH}) ; 7.55(\mathrm{~d}, J=16.0 \mathrm{~Hz}, 1 \mathrm{H}, \mathrm{CH}=\mathrm{CH}) ; 7.36(\mathrm{~d}, J=8.4 \mathrm{~Hz}$, $1 \mathrm{H}, \mathrm{CH}) ; 6.84(\mathrm{dd}, J=8.4,2.2 \mathrm{~Hz}, 1 \mathrm{H}, \mathrm{CH}) ; 6.73(\mathrm{~d}, \mathrm{~J}=2.2 \mathrm{~Hz}, 1 \mathrm{H}, \mathrm{CH}) ; 6.71(\mathrm{~s}, 2 \mathrm{H}, \mathrm{CH}) ; 6.31$ $(\mathrm{d}, J=16.0 \mathrm{~Hz}, 1 \mathrm{H}, \mathrm{CH}=\mathrm{CH}) ; 6.23(\mathrm{~d}, J=9.6 \mathrm{~Hz}, 1 \mathrm{H}, \mathrm{CH}) ; 4.65\left(\mathrm{~s}, 2 \mathrm{H}, \mathrm{OCH}_{2}\right) ; 4.21-4.14\left(\mathrm{~m}, 4 \mathrm{H}, \mathrm{OCH}_{2}\right)$; $3.85\left(\mathrm{~s}, 6 \mathrm{H}, \mathrm{OCH}_{3}\right) ; 3.84\left(\mathrm{~s}, 3 \mathrm{H}, \mathrm{OCH}_{3}\right) 2.32-2.27\left(\mathrm{~m}, 4 \mathrm{H}, \mathrm{NCH}_{2}\right) ; 2.16\left(\mathrm{~s}, 3 \mathrm{H}, \mathrm{NCH}_{3}\right) ; 1.69-1.62(\mathrm{~m}, 4 \mathrm{H}$, $\left.\mathrm{CH}_{2}\right) ; 1.51-1.29\left(\mathrm{~m}, 8 \mathrm{H}, \mathrm{CH}_{2}\right)$ ppm. ${ }^{13} \mathrm{C}-\mathrm{NMR}\left(100 \mathrm{MHz}, \mathrm{CDCl}_{3}\right) \delta: 167.98(\mathrm{C}) ; 166.98(\mathrm{C}) ; 160.85(\mathrm{C})$; 160.77 (C); 155.59 (C); $153.38(\mathrm{C}) ; 144.54(\mathrm{CH}) ; 143.26(\mathrm{CH}) ; 139.99(\mathrm{C}) ; 129.91(\mathrm{C}) ; 129.00(\mathrm{CH}) ; 117.44$ $(\mathrm{CH}) ; 113.66(\mathrm{CH}) ; 113.29(\mathrm{C}) ; 112.73(\mathrm{CH}) ; 105.16(\mathrm{CH}) ; 101.69(\mathrm{CH}) ; 65.50\left(\mathrm{CH}_{2}\right) ; 65.28\left(\mathrm{CH}_{2}\right) ; 64.53$ $\left(\mathrm{CH}_{2}\right) ; 60.92\left(\mathrm{OCH}_{3}\right) ; 57.57\left(\mathrm{CH}_{2}\right) ; 56.96\left(\mathrm{CH}_{2}\right) ; 56.12\left(\mathrm{OCH}_{3}\right) ; 41.88\left(\mathrm{NCH}_{3}\right) ; 28.68\left(\mathrm{CH}_{2}\right) ; 27.11\left(\mathrm{CH}_{2}\right)$; $26.44\left(\mathrm{CH}_{2}\right) ; 25.89\left(\mathrm{CH}_{2}\right)$ ppm. ESI-HRMS $(\mathrm{m} / \mathrm{z})$ calculated for $[\mathrm{M}+\mathrm{H}]^{+}$ion species $\mathrm{C}_{34} \mathrm{H}_{44} \mathrm{NO}_{10}=$ 626.2960 , found 626.2966 .

(E)-7-(methyl(2-(2-((2-oxo-2H-chromen-7-yl)oxy)acetoxy)ethyl)amino)heptyl 3-(3,4,5-trimethoxyphenyl)acrylate 7. From 44 [38]. Oil. Chromatographic eluent: $\mathrm{CH}_{2} \mathrm{Cl}_{2} / \mathrm{CH}_{3} \mathrm{OH}$ 95:5. Yield: $10 \% .{ }^{1} \mathrm{H}-\mathrm{NMR}(400 \mathrm{MHz}$, $\left.\mathrm{CDCl}_{3}\right) \delta: 7.63(\mathrm{~d}, J=9.6 \mathrm{~Hz}, 1 \mathrm{H}, \mathrm{CH}) ; 7.58(\mathrm{~d}, J=16.0 \mathrm{~Hz}, 1 \mathrm{H}, \mathrm{CH}=\mathrm{CH}) ; 7.38(\mathrm{~d}, J=8.8 \mathrm{~Hz}, 1 \mathrm{H}, \mathrm{CH})$; $6.88(\mathrm{dd}, J=8.8,2.2 \mathrm{~Hz}, 1 \mathrm{H}, \mathrm{CH}) ; 6.78(\mathrm{~d}, J=2.2 \mathrm{~Hz}, 1 \mathrm{H}, \mathrm{CH}) ; 6.74(\mathrm{~s}, 2 \mathrm{H}, \mathrm{CH}) ; 6.33(\mathrm{~d}, J=16.0 \mathrm{~Hz}$, $1 \mathrm{H}, \mathrm{CH}=\mathrm{CH}) ; 6.27(\mathrm{~d}, J=9.6 \mathrm{~Hz}, 1 \mathrm{H}, \mathrm{CH}) ; 4.70\left(\mathrm{~s}, 2 \mathrm{H}, \mathrm{OCH}_{2}\right) ; 4.31\left(\mathrm{t}, J=5.6 \mathrm{~Hz}, 2 \mathrm{H}, \mathrm{OCH}_{2}\right) ; 4.18$ $\left(\mathrm{t}, J=5.6 \mathrm{~Hz}, 2 \mathrm{H}, \mathrm{OCH}_{2}\right) ; 3.88\left(\mathrm{~s}, 6 \mathrm{H}, \mathrm{OCH}_{3}\right) ; 3.87\left(\mathrm{~s}, 3 \mathrm{H}, \mathrm{OCH}_{3}\right) ; 2.64\left(\mathrm{t}, J=5.6 \mathrm{~Hz} 2 \mathrm{H}, \mathrm{NCH}_{2}\right) ; 2.38$ $\left(\mathrm{t}, J=7.2 \mathrm{~Hz}, 2 \mathrm{H}, \mathrm{NCH}_{2}\right) ; 2.26\left(\mathrm{~s}, 3 \mathrm{H}, \mathrm{NCH}_{3}\right) ; 1.71-1.65\left(\mathrm{~m}, 4 \mathrm{H}, \mathrm{CH}_{2}\right) ; 1.47-1.30\left(\mathrm{~m}, 6 \mathrm{H}, \mathrm{CH}_{2}\right) \mathrm{ppm}$.

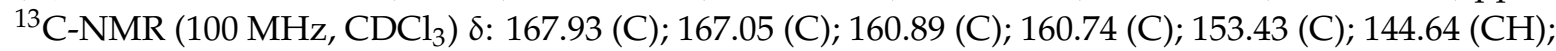
$143.21(\mathrm{CH}) ; 129.93(\mathrm{C}) ; 129.03(\mathrm{CH}) ; 117.43(\mathrm{CH}) ; 113.80(\mathrm{CH}) ; 113.38(\mathrm{C}) ; 112.79(\mathrm{CH}) ; 105.22(\mathrm{CH})$; $101.84(\mathrm{CH}) ; 65.35\left(\mathrm{CH}_{2}\right) ; 65.26\left(\mathrm{CH}_{2}\right) ; 64.52\left(\mathrm{CH}_{2}\right) ; 60.97\left(\mathrm{OCH}_{3}\right) ; 57.53\left(\mathrm{CH}_{2}\right) ; 56.17\left(\mathrm{OCH}_{3}\right) ; 54.99$ $\left(\mathrm{CH}_{2}\right) ; 52.50\left(\mathrm{NCH}_{3}\right) ; 29.02\left(\mathrm{CH}_{2}\right) ; 28.66\left(\mathrm{CH}_{2}\right) ; 27.07\left(\mathrm{CH}_{2}\right) ; 25.86\left(\mathrm{CH}_{2}\right)$ ppm. ESI-HRMS $(m / z)$ calculated for $[\mathrm{M}+\mathrm{H}]^{+}$ion species $\mathrm{C}_{33} \mathrm{H}_{42} \mathrm{NO}_{10}=612.2803$, found 612.2794.

(E)-7-(methyl(7-(2-((2-oxo-2H-chromen-7-yl)oxy)acetoxy)heptyl)amino)heptyl 3-(3,4,5-trimethoxyphenyl)acrylate 8. From 41 [35]. Oil. Chromatographic eluent: $\mathrm{CH}_{2} \mathrm{Cl}_{2} / \mathrm{CH}_{3} \mathrm{OH}$ 95:5. Yield: $31 \% .{ }^{1} \mathrm{H}-\mathrm{NMR}(400 \mathrm{MHz}$, $\left.\mathrm{CDCl}_{3}\right) \delta: 7.61(\mathrm{~d}, J=9.6 \mathrm{~Hz}, 1 \mathrm{H}, \mathrm{CH}) ; 7.56(\mathrm{~d}, \mathrm{~J}=16.0 \mathrm{~Hz}, 1 \mathrm{H}, \mathrm{CH}=\mathrm{CH}) ; 7.37(\mathrm{~d}, J=8.8 \mathrm{~Hz}, 1 \mathrm{H}, \mathrm{CH})$; $6.84(\mathrm{dd}, J=8.8,2.2 \mathrm{~Hz}, 1 \mathrm{H}, \mathrm{CH}) ; 6.75(\mathrm{~d}, J=2.2 \mathrm{~Hz}, 1 \mathrm{H}, \mathrm{CH}) ; 6.73(\mathrm{~s}, 2 \mathrm{H}, \mathrm{CH}) ; 6.33(\mathrm{~d}, J=16.0 \mathrm{~Hz}, 1 \mathrm{H}$, $\mathrm{CH}=\mathrm{CH}) ; 6.24(\mathrm{~d}, J=9.6 \mathrm{~Hz}, 1 \mathrm{H}, \mathrm{CH}) ; 4.66\left(\mathrm{~s}, 2 \mathrm{H}, \mathrm{OCH}_{2}\right) ; 4.20-4.15\left(\mathrm{~m}, 4 \mathrm{H}, \mathrm{OCH}_{2}\right) ; 3.86\left(\mathrm{~s}, 6 \mathrm{H}, \mathrm{OCH}_{3}\right)$; $3.85\left(\mathrm{~s}, 3 \mathrm{H}, \mathrm{OCH}_{3}\right) ; 2.34-2.28\left(\mathrm{~m}, 4 \mathrm{H}, \mathrm{NCH}_{2}\right) ; 2.20\left(\mathrm{~s}, 3 \mathrm{H}, \mathrm{NCH}_{3}\right) ; 1.70-1.62\left(\mathrm{~m}, 4 \mathrm{H}, \mathrm{CH}_{2}\right) ; 1.50-1.20$

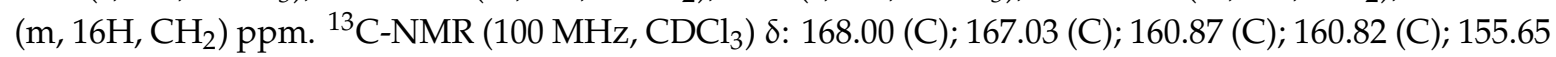
(C); $153.41(\mathrm{C}) ; 144.54(\mathrm{CH}) ; 143.22(\mathrm{CH}) ; 140.06(\mathrm{C}) ; 129.94(\mathrm{C}) ; 128.97(\mathrm{CH}) ; 117.48(\mathrm{CH}) ; 113.72(\mathrm{CH})$; $113.30(\mathrm{C}) ; 112.82(\mathrm{CH}) ; 105.21(\mathrm{CH}) ; 101.70(\mathrm{CH}) ; 65.73\left(\mathrm{CH}_{2}\right) ; 65.33\left(\mathrm{CH}_{2}\right) ; 64.63\left(\mathrm{CH}_{2}\right) ; 60.94\left(\mathrm{OCH}_{3}\right)$; $57.77\left(\mathrm{CH}_{2}\right) ; 57.74\left(\mathrm{CH}_{2}\right) ; 56.14\left(\mathrm{OCH}_{3}\right) ; 42.15\left(\mathrm{NCH}_{3}\right) ; 29.20\left(\mathrm{CH}_{2}\right) ; 29.08\left(\mathrm{CH}_{2}\right) ; 28.69\left(\mathrm{CH}_{2}\right) ; 28.43$ $\left(\mathrm{CH}_{2}\right) ; 27.44\left(\mathrm{CH}_{2}\right) ; 27.38\left(\mathrm{CH}_{2}\right) ; 27.04\left(\mathrm{CH}_{2}\right) ; 27.02\left(\mathrm{CH}_{2}\right) ; 25.92\left(\mathrm{CH}_{2}\right) ; 25.72\left(\mathrm{CH}_{2}\right)$ ppm. ESI-HRMS $(\mathrm{m} / z)$ calculated for $[\mathrm{M}+\mathrm{H}]^{+}$ion species $\mathrm{C}_{38} \mathrm{H}_{52} \mathrm{NO}_{10}=682.3586$, found 682.3573 . 
3-(methyl(5-(2-((2-oxo-2H-chromen-7-yl)oxy)acetoxy)pentyl)amino)propyl 3,4,5-trimethoxy benzoate 9 . From 42 [37]. Oil. Chromatographic eluent: $\mathrm{CH}_{2} \mathrm{Cl}_{2} / \mathrm{CH}_{3} \mathrm{OH} / \mathrm{NH}_{4} \mathrm{OH}$ 90:10:1. Yield: $86 \%$. ${ }^{1} \mathrm{H}-\mathrm{NMR}(400 \mathrm{MHz}$, $\left.\mathrm{CDCl}_{3}\right) \delta: 7.61(\mathrm{~d}, J=9.2 \mathrm{~Hz}, 1 \mathrm{H}, \mathrm{CH}) ; 7.36(\mathrm{~d}, J=8.4 \mathrm{~Hz}, 1 \mathrm{H}, \mathrm{CH}) ; 7.25(\mathrm{~s}, 2 \mathrm{H}, \mathrm{CH}) ; 6.85(\mathrm{dd}, J=8.4$, $2.2 \mathrm{~Hz}, 1 \mathrm{H}, \mathrm{CH}) ; 6.73(\mathrm{~d}, J=2.2 \mathrm{~Hz}, 1 \mathrm{H}, \mathrm{CH}) ; 6.23(\mathrm{~d}, J=9.2 \mathrm{~Hz}, 1 \mathrm{H}, \mathrm{CH}) ; 4.66\left(\mathrm{~s}, 2 \mathrm{H}, \mathrm{OCH}_{2}\right) ; 4.33$ $\left(\mathrm{t}, J=6.4 \mathrm{~Hz}, 2 \mathrm{H}, \mathrm{OCH}_{2}\right) ; 4.16\left(\mathrm{t}, J=6.4 \mathrm{~Hz}, 2 \mathrm{H}, \mathrm{OCH}_{2}\right) ; 3.86\left(\mathrm{~s}, 9 \mathrm{H}, \mathrm{OCH}_{3}\right) ; 2.56(\mathrm{t}, J=6.8 \mathrm{~Hz}, 2 \mathrm{H}$, $\left.\mathrm{NCH}_{2}\right) ; 2.41\left(\mathrm{t}, J=7.2 \mathrm{~Hz}, 2 \mathrm{H}, \mathrm{NCH}_{2}\right) ; 2.29\left(\mathrm{~s}, 3 \mathrm{H}, \mathrm{NCH}_{3}\right) ; 2.00-1.95\left(\mathrm{~m}, 2 \mathrm{H}, \mathrm{CH}_{2}\right) ; 1.67-1.60(\mathrm{~m}, 2 \mathrm{H}$, $\left.\mathrm{CH}_{2}\right) ; 1.52-1.46\left(\mathrm{~m}, 2 \mathrm{H}, \mathrm{CH}_{2}\right) ; 1.35-1.27\left(\mathrm{~m}, 2 \mathrm{H}, \mathrm{CH}_{2}\right)$ ppm. ${ }^{13} \mathrm{C}-\mathrm{NMR}\left(100 \mathrm{MHz}, \mathrm{CDCl}_{3}\right) \delta: 168.01(\mathrm{C})$; 166.15 (C); 160.88 (C); 160.80 (C); 155.61 (C); 152.91 (C); $143.27(\mathrm{CH}) ; 142.19$ (C); $129.00(\mathrm{CH}) ; 125.24(\mathrm{C})$; $113.69(\mathrm{CH}) ; 113.28(\mathrm{C}) ; 112.86(\mathrm{CH}) ; 106.78(\mathrm{CH}) ; 101.63(\mathrm{CH}) ; 65.50\left(\mathrm{CH}_{2}\right) ; 65.30\left(\mathrm{CH}_{2}\right) ; 63.30\left(\mathrm{CH}_{2}\right)$; $60.90\left(\mathrm{OCH}_{3}\right) ; 57.19\left(\mathrm{CH}_{2}\right) ; 56.24\left(\mathrm{OCH}_{3}\right) ; 53.96\left(\mathrm{CH}_{2}\right) ; 41.70\left(\mathrm{NCH}_{3}\right) ; 28.36\left(\mathrm{CH}_{2}\right) ; 26.37\left(\mathrm{CH}_{2}\right) ; 26.18$ $\left(\mathrm{CH}_{2}\right) ; 23.62\left(\mathrm{CH}_{2}\right)$ ppm. ESI-HRMS $(\mathrm{m} / \mathrm{z})$ calculated for $[\mathrm{M}+\mathrm{H}]^{+}$ion species $\mathrm{C}_{30} \mathrm{H}_{38} \mathrm{NO}_{10}=572.2490$, found 572.2479 .

6-(methyl(3-(2-((2-oxo-2H-chromen-7-yl)oxy)acetoxy)propyl)amino)hexyl 3,4,5-trimethoxy benzoate 10. From 33. Oil. Chromatographic eluent: $\mathrm{CH}_{2} \mathrm{Cl}_{2} / \mathrm{CH}_{3} \mathrm{OH} / \mathrm{NH}_{4} \mathrm{OH}$ 90:10:1. Yield: 83\%. ${ }^{1} \mathrm{H}-\mathrm{NMR}(400 \mathrm{MHz}$, $\left.\mathrm{CDCl}_{3}\right) \delta: 7.61(\mathrm{~d}, J=9.6 \mathrm{~Hz}, 1 \mathrm{H}, \mathrm{CH}) ; 7.37(\mathrm{~d}, J=8.4 \mathrm{~Hz}, 1 \mathrm{H}, \mathrm{CH}) ; 7.27(\mathrm{~s}, 2 \mathrm{H}, \mathrm{CH}) ; 6.85(\mathrm{~d}, J=8.4 \mathrm{~Hz}$, $1 \mathrm{H}, \mathrm{CH}) ; 6.75(\mathrm{~s}, 1 \mathrm{H}, \mathrm{CH}) ; 6.24(\mathrm{~d}, \mathrm{~J}=9.6 \mathrm{~Hz}, 1 \mathrm{H}, \mathrm{CH}) ; 4.67\left(\mathrm{~s}, 2 \mathrm{H}, \mathrm{OCH}_{2}\right) ; 4.29-4.23\left(\mathrm{~m}, 4 \mathrm{H}_{1} \mathrm{OCH}_{2}\right)$; $3.88\left(\mathrm{~s}, 9 \mathrm{H}, \mathrm{OCH}_{3}\right) ; 2.40\left(\mathrm{t}, J=7.2 \mathrm{~Hz}, 2 \mathrm{H}, \mathrm{NCH}_{2}\right) ; 2.33\left(\mathrm{t}, J=7.2 \mathrm{~Hz}, 2 \mathrm{H}, \mathrm{NCH}_{2}\right) ; 2.20\left(\mathrm{~s}, 3 \mathrm{H}, \mathrm{NCH}_{3}\right)$; 1.83-1.73 (m, 4H, CH $)$; 1.47-1.34 (m, 6H, CH 2$)$ ppm. ${ }^{13} \mathrm{C}-\mathrm{NMR}\left(100 \mathrm{MHz}, \mathrm{CDCl}_{3}\right) \delta: 167.92(\mathrm{C}) ; 166.18$ (C); $160.77(\mathrm{C}) ; 155.60(\mathrm{C}) ; 152.87(\mathrm{C}) ; 143.18(\mathrm{CH}) ; 142.14(\mathrm{C}) ; 128.97(\mathrm{CH}) ; 125.45(\mathrm{C}) ; 113.69(\mathrm{CH})$; $113.29(\mathrm{C}) ; 112.72(\mathrm{CH}) ; 106.80(\mathrm{CH}) ; 101.68(\mathrm{CH}) ; 65.29\left(\mathrm{CH}_{2}\right) ; 65.09\left(\mathrm{CH}_{2}\right) ; 63.99\left(\mathrm{CH}_{2}\right) ; 60.85\left(\mathrm{OCH}_{3}\right)$; $57.49\left(\mathrm{CH}_{2}\right) ; 56.22\left(\mathrm{OCH}_{3}\right) ; 53.85\left(\mathrm{CH}_{2}\right) ; 41.81\left(\mathrm{NCH}_{3}\right) ; 28.68\left(\mathrm{CH}_{2}\right) ; 27.02\left(\mathrm{CH}_{2}\right) ; 26.89\left(\mathrm{CH}_{2}\right) ; 26.22$ $\left(\mathrm{CH}_{2}\right) ; 25.89\left(\mathrm{CH}_{2}\right)$ ppm. ESI-HRMS $(\mathrm{m} / \mathrm{z})$ calculated for $[\mathrm{M}+\mathrm{H}]^{+}$ion species $\mathrm{C}_{31} \mathrm{H}_{40} \mathrm{NO}_{10}=586.2647$, found 586.2643 .

7-(methyl(2-(2-((2-oxo-2H-chromen-7-yl)oxy)acetoxy)ethyl)amino)heptyl 3,4,5-trimethoxy benzoate 11. From 45 [38]. Oil. Chromatographic eluent: $\mathrm{CH}_{2} \mathrm{Cl}_{2} / \mathrm{CH}_{3} \mathrm{OH} / \mathrm{NH}_{4} \mathrm{OH}$ 93:7:0.3. Yield: 89\%. ${ }^{1} \mathrm{H}-\mathrm{NMR}(400 \mathrm{MHz}$, $\left.\mathrm{CDCl}_{3}\right) \delta: 7.58(\mathrm{~d}, J=9.6 \mathrm{~Hz}, 1 \mathrm{H}, \mathrm{CH}) ; 7.33(\mathrm{~d}, J=8.4 \mathrm{~Hz}, 1 \mathrm{H}, \mathrm{CH}) ; 7.24(\mathrm{~s}, 2 \mathrm{H}, \mathrm{CH}) ; 6.83(\mathrm{~d}, J=8.4 \mathrm{~Hz}$, $1 \mathrm{H}, \mathrm{CH}) ; 6.73(\mathrm{~s}, 1 \mathrm{H}, \mathrm{CH}) ; 6.20(\mathrm{~d}, J=9.6 \mathrm{~Hz}, 1 \mathrm{H}, \mathrm{CH}) ; 4.66\left(\mathrm{~s}, 2 \mathrm{H}, \mathrm{OCH}_{2}\right) ; 4.29\left(\mathrm{t}, J=5.6 \mathrm{~Hz}, 2 \mathrm{H}, \mathrm{OCH}_{2}\right)$; $4.24\left(\mathrm{t}, J=6.4 \mathrm{~Hz}, 2 \mathrm{H}, \mathrm{OCH}_{2}\right) ; 3.85\left(\mathrm{~s}, 9 \mathrm{H}, \mathrm{OCH}_{3}\right) ; 2.67\left(\mathrm{t}, J=5.2 \mathrm{~Hz}, 2 \mathrm{H}, \mathrm{NCH}_{2}\right) ; 2.40(\mathrm{t}, J=7.6 \mathrm{~Hz}, 2 \mathrm{H}$, $\left.\mathrm{NCH}_{2}\right) ; 2.27\left(\mathrm{~s}, 3 \mathrm{H}, \mathrm{NCH}_{3}\right) ; 1.73-1.69\left(\mathrm{~m}, 2 \mathrm{H}, \mathrm{CH}_{2}\right) ; 1.45-1.26\left(\mathrm{~m}, 8 \mathrm{H}, \mathrm{CH}_{2}\right)$ ppm. ${ }^{13} \mathrm{C}-\mathrm{NMR}(100 \mathrm{MHz}$, $\left.\mathrm{CDCl}_{3}\right)$ \&: $167.86(\mathrm{C}) ; 166.08(\mathrm{C}) ; 160.70(\mathrm{C}) ; 155.52(\mathrm{C}) ; 152.82(\mathrm{C}) ; 143.21(\mathrm{CH}) ; 142.07(\mathrm{C}) ; 128.96(\mathrm{CH})$; $125.43(\mathrm{C}) ; 113.54(\mathrm{CH}) ; 113.23(\mathrm{C}) ; 112.60(\mathrm{CH}) ; 106.74(\mathrm{CH}) ; 101.72(\mathrm{CH}) ; 65.21\left(\mathrm{CH}_{2}\right) ; 65.06\left(\mathrm{CH}_{2}\right) ;$ $62.40\left(\mathrm{CH}_{2}\right) ; 60.76\left(\mathrm{OCH}_{3}\right) ; 57.53\left(\mathrm{CH}_{2}\right) ; 56.15\left(\mathrm{OCH}_{3}\right) ; 55.10\left(\mathrm{CH}_{2}\right) ; 42.00\left(\mathrm{NCH}_{3}\right) ; 29.01\left(\mathrm{CH}_{2}\right) ; 28.58$ $\left(\mathrm{CH}_{2}\right) ; 27.08\left(\mathrm{CH}_{2}\right) ; 26.46\left(\mathrm{CH}_{2}\right) ; 25.84\left(\mathrm{CH}_{2}\right)$ ppm. ESI-HRMS $(\mathrm{m} / \mathrm{z})$ calculated for $[\mathrm{M}+\mathrm{H}]^{+}$ion species $\mathrm{C}_{31} \mathrm{H}_{40} \mathrm{NO}_{10}=586.2647$, found 586.2638.

3-(methyl(5-(2-((2-oxo-2H-chromen-7-yl)oxy)acetoxy)pentyl)amino)propyl anthracene-9-carboxylate 12. From 43 [37]. Oil. Chromatographic eluent: $\mathrm{CH}_{2} \mathrm{Cl}_{2} / \mathrm{CH}_{3} \mathrm{OH}$ 95:5. Yield: $81 \%$. ${ }^{1} \mathrm{H}-\mathrm{NMR}\left(400 \mathrm{MHz}, \mathrm{CDCl}_{3}\right) \delta: 8.51$ (s, 1H, CH); 8.05-8.00 (m, 4H, CH); 7.56-7.46 (m, 5H, CH); $7.30(\mathrm{~d}, J=8.8 \mathrm{~Hz}, 1 \mathrm{H}, \mathrm{CH}) ; 6.82(\mathrm{dd}, J=8.8$, $2.2 \mathrm{~Hz}, 1 \mathrm{H}, \mathrm{CH}) ; 6.73(\mathrm{~d}, J=2.2 \mathrm{~Hz}, 1 \mathrm{H}, \mathrm{CH}) ; 6.23(\mathrm{~d}, J=9.2 \mathrm{~Hz}, 1 \mathrm{H}, \mathrm{CH}) ; 4.68\left(\mathrm{t}, J=6.4 \mathrm{~Hz}, 2 \mathrm{H}, \mathrm{OCH}_{2}\right)$; $4.64\left(\mathrm{~s}, 2 \mathrm{H}, \mathrm{OCH}_{2}\right) ; 4.19\left(\mathrm{t}, J=6.4 \mathrm{~Hz}, 2 \mathrm{H}, \mathrm{OCH}_{2}\right) ; 2.54\left(\mathrm{t}, J=7.2 \mathrm{~Hz}, 2 \mathrm{H}, \mathrm{NCH}_{2}\right) ; 2.35(\mathrm{t}, J=7.2 \mathrm{~Hz}$, $\left.2 \mathrm{H}, \mathrm{NCH}_{2}\right) ; 2.25\left(\mathrm{~s}, 3 \mathrm{H}, \mathrm{NCH}_{3}\right) ; 2.11-2.02\left(\mathrm{~m}, 2 \mathrm{H}, \mathrm{CH}_{2}\right) ; 1.68-1.61\left(\mathrm{~m}, 2 \mathrm{H}, \mathrm{CH}_{2}\right) ; 1.53-1.45(\mathrm{~m}, 2 \mathrm{H}$, $\left.\mathrm{CH}_{2}\right) ; 1.39-1.30\left(\mathrm{~m}, 2 \mathrm{H}, \mathrm{CH}_{2}\right)$ ppm. ${ }^{13} \mathrm{C}-\mathrm{NMR}\left(100 \mathrm{MHz}, \mathrm{CDCl}_{3}\right) \delta: 169.60(\mathrm{C}) ; 167.99(\mathrm{C}) ; 160.87(\mathrm{C})$; $160.77(\mathrm{C}) ; 155.59(\mathrm{C}) ; 143.19(\mathrm{CH}) ; 130.97(\mathrm{C}) ; 129.29(\mathrm{CH}) ; 128.93(\mathrm{CH}) ; 128.64(\mathrm{CH}) ; 128.38(\mathrm{C}) ; 127.98$ (C); $126.96(\mathrm{CH}) ; 125.48(\mathrm{CH}) ; 124.97(\mathrm{CH}) ; 113.66(\mathrm{CH}) ; 113.24(\mathrm{C}) ; 112.74(\mathrm{CH}) ; 101.68(\mathrm{CH}) ; 65.55$ $\left(\mathrm{CH}_{2}\right) ; 65.31\left(\mathrm{CH}_{2}\right) ; 64.04\left(\mathrm{CH}_{2}\right) ; 57.40\left(\mathrm{CH}_{2}\right) ; 54.13\left(\mathrm{CH}_{2}\right) ; 41.89\left(\mathrm{NCH}_{3}\right) ; 28.38\left(\mathrm{CH}_{2}\right) ; 26.59\left(\mathrm{CH}_{2}\right)$; $26.39\left(\mathrm{CH}_{2}\right) ; 23.67\left(\mathrm{CH}_{2}\right)$ ppm. ESI-HRMS $(\mathrm{m} / z)$ calculated for $[\mathrm{M}+\mathrm{H}]^{+}$ion species $\mathrm{C}_{35} \mathrm{H}_{36} \mathrm{NO}_{7}=$ 582.2486 , found 582.2489 .

6-(methyl(3-(2-((2-oxo-2H-chromen-7-yl)oxy)acetoxy)propyl)amino)hexyl anthracene-9-carboxylate 13. From 34. Oil. Chromatographic eluent: $\mathrm{CH}_{2} \mathrm{Cl}_{2} / \mathrm{CH}_{3} \mathrm{OH} / \mathrm{NH}_{4} \mathrm{OH}$ 90:10:1. Yield: $98 \%$. ${ }^{1} \mathrm{H}-\mathrm{NMR}\left(400 \mathrm{MHz}, \mathrm{CDCl}_{3}\right) \delta$ : 
$8.38(\mathrm{~s}, 1 \mathrm{H}, \mathrm{CH}) ; 7.96(\mathrm{~d}, J=8.4 \mathrm{~Hz}, 2 \mathrm{H}, \mathrm{CH}) ; 7.90(\mathrm{~d}, J=8.4 \mathrm{~Hz}, 2 \mathrm{H}, \mathrm{CH}) ; 7.47-7.37(\mathrm{~m}, 5 \mathrm{H}, \mathrm{CH}) ; 7.16$ $(\mathrm{d}, J=8.8 \mathrm{~Hz}, 1 \mathrm{H}, \mathrm{CH}) ; 6.70(\mathrm{dd}, J=8.8,2.2 \mathrm{~Hz}, 1 \mathrm{H}, \mathrm{CH}) ; 6.64(\mathrm{~d}, J=2.2 \mathrm{~Hz}, 1 \mathrm{H}, \mathrm{CH}) ; 6.10(\mathrm{~d}, J=9.6 \mathrm{~Hz}$, $1 \mathrm{H}, \mathrm{CH}) ; 4.57-4.52\left(\mathrm{~m}, 4 \mathrm{H}, \mathrm{OCH}_{2}\right) ; 4.17\left(\mathrm{t}, J=6.4 \mathrm{~Hz}, 2 \mathrm{H}, \mathrm{OCH}_{2}\right) ; 2.27\left(\mathrm{t}, J=6.8 \mathrm{~Hz}, 2 \mathrm{H}, \mathrm{NCH}_{2}\right) ; 2.21$ $\left(\mathrm{t}, J=6.8 \mathrm{~Hz}, 2 \mathrm{H}, \mathrm{NCH}_{2}\right) ; 2.09\left(\mathrm{~s}, 3 \mathrm{H}, \mathrm{NCH}_{3}\right) ; 1.85-1.69\left(\mathrm{~m}, 4 \mathrm{H}, \mathrm{CH}_{2}\right) ; 1.46-1.35\left(\mathrm{~m}, 4 \mathrm{H}, \mathrm{CH}_{2}\right) ; 1.33-1.26$ (m, 2H, $\mathrm{CH}_{2}$ ) ppm. ${ }^{13} \mathrm{C}-\mathrm{NMR}\left(100 \mathrm{MHz}, \mathrm{CDCl}_{3}\right) \delta: 169.71$ (C); 167.94 (C); 160.85 (C); 160.75 (C); 155.60 (C); $143.16(\mathrm{CH}) ; 142.69(\mathrm{C}) ; 141.90(\mathrm{C}) ; 130.98(\mathrm{C}) ; 129.22(\mathrm{CH}) ; 128.95(\mathrm{CH}) ; 128.63(\mathrm{CH}) ; 128.36(\mathrm{C})$; $128.16(\mathrm{C}) ; 126.93(\mathrm{CH}) ; 125.47(\mathrm{CH}) ; 124.99(\mathrm{CH}) ; 113.70(\mathrm{CH}) ; 113.28(\mathrm{C}) ; 112.69(\mathrm{CH}) ; 101.70(\mathrm{CH})$; $65.84\left(\mathrm{CH}_{2}\right) ; 65.30\left(\mathrm{CH}_{2}\right) ; 64.06\left(\mathrm{CH}_{2}\right) ; 57.52\left(\mathrm{CH}_{2}\right) ; 53.87\left(\mathrm{CH}_{2}\right) ; 41.91\left(\mathrm{NCH}_{3}\right) ; 28.75\left(\mathrm{CH}_{2}\right) ; 27.04$ $\left(\mathrm{CH}_{2}\right) ; 26.95\left(\mathrm{CH}_{2}\right) ; 26.30\left(\mathrm{CH}_{2}\right) ; 26.04\left(\mathrm{CH}_{2}\right)$ ppm. ESI-HRMS $(\mathrm{m} / z)$ calculated for $[\mathrm{M}+\mathrm{H}]^{+}$ion species $\mathrm{C}_{36} \mathrm{H}_{38} \mathrm{NO}_{7}=596.2643$, found 596.2652.

7-(methyl(2-(2-((2-oxo-2H-chromen-7-yl)oxy)acetoxy)ethyl)amino)heptyl anthracene-9-carboxylate 14. From 46 [38]. Oil. Chromatographic eluent: $\mathrm{CH}_{2} \mathrm{Cl}_{2} / \mathrm{CH}_{3} \mathrm{OH} / \mathrm{NH}_{4} \mathrm{OH}$ 96:4:0.4. Yield: $68 \%$. ${ }^{1} \mathrm{H}-\mathrm{NMR}(400 \mathrm{MHz}$, $\left.\mathrm{CDCl}_{3}\right)$ 8: $8.48(\mathrm{~s}, 1 \mathrm{H}, \mathrm{CH}) ; 8.03-7.98(\mathrm{~m}, 4 \mathrm{H}, \mathrm{CH}) ; 7.54-7.44(\mathrm{~m}, 5 \mathrm{H}, \mathrm{CH}) ; 7.28(\mathrm{~d}, J=8.4 \mathrm{~Hz}, 1 \mathrm{H}, \mathrm{CH})$; $6.80(\mathrm{dd}, J=8.4,2.2 \mathrm{~Hz}, 1 \mathrm{H}, \mathrm{CH}) ; 6.73(\mathrm{~d}, J=2.2 \mathrm{~Hz}, 1 \mathrm{H}, \mathrm{CH}) ; 6.20(\mathrm{~d}, J=9.6 \mathrm{~Hz}, 1 \mathrm{H}, \mathrm{CH}) ; 4.64(\mathrm{~s}, 2 \mathrm{H}$, $\left.\mathrm{OCH}_{2}\right) ; 4.60\left(\mathrm{t}, J=6.8 \mathrm{~Hz}, 2 \mathrm{H}, \mathrm{OCH}_{2}\right) ; 4.29\left(\mathrm{t}, J=5.6 \mathrm{~Hz}, 2 \mathrm{H}, \mathrm{OCH}_{2}\right) ; 2.62\left(\mathrm{t}, J=5.6 \mathrm{~Hz}, 2 \mathrm{H}, \mathrm{NCH}_{2}\right)$; $2.36\left(\mathrm{t}, J=7.2 \mathrm{~Hz}, 2 \mathrm{H}, \mathrm{NCH}_{2}\right) ; 2.24\left(\mathrm{~s}, 3 \mathrm{H}, \mathrm{NCH}_{3}\right) ; 1.90-1.83\left(\mathrm{~m}, 2 \mathrm{H}, \mathrm{CH}_{2}\right) ; 1.50-1.25\left(\mathrm{~m}, 8 \mathrm{H}, \mathrm{CH}_{2}\right)$ ppm. ${ }^{13} \mathrm{C}-\mathrm{NMR}\left(100 \mathrm{MHz}, \mathrm{CDCl}_{3}\right)$ 8: 169.71 (C); 167.94 (C); 160.85 (C); 160.73 (C); 155.59 (C); 143.15 (CH); $130.98(\mathrm{C}) ; 129.19(\mathrm{CH}) ; 128.91(\mathrm{CH}) ; 128.61(\mathrm{CH}) ; 128.35(\mathrm{C}) ; 126.90(\mathrm{CH}) ; 125.45(\mathrm{CH}) ; 124.99(\mathrm{CH})$; $113.68(\mathrm{CH}) ; 113.26(\mathrm{C}) ; 112.71(\mathrm{CH}) ; 101.75(\mathrm{CH}) ; 65.87\left(\mathrm{CH}_{2}\right) ; 65.29\left(\mathrm{CH}_{2}\right) ; 63.11\left(\mathrm{CH}_{2}\right) ; 57.91\left(\mathrm{CH}_{2}\right)$; $55.48\left(\mathrm{CH}_{2}\right) ; 42.49\left(\mathrm{NCH}_{3}\right) ; 29.14\left(\mathrm{CH}_{2}\right) ; 28.72\left(\mathrm{CH}_{2}\right) ; 27.24\left(\mathrm{CH}_{2}\right) ; 27.07\left(\mathrm{CH}_{2}\right) ; 26.07\left(\mathrm{CH}_{2}\right)$ ppm. ESI-HRMS $(m / z)$ calculated for $[\mathrm{M}+\mathrm{H}]^{+}$ion species $\mathrm{C}_{36} \mathrm{H}_{38} \mathrm{NO}_{7}=596.2643$, found 596.2631.

\subsubsection{General Procedure for the Synthesis of Diester Compounds 15-28}

A $1 \mathrm{mmol}$ portion of 4-sulfamoylbenzoic acid was transformed into the acyl chloride by reaction with $\mathrm{SOCl}_{2}(2 \mathrm{mmol})$ in $5 \mathrm{~mL}$ of $\mathrm{CHCl}_{3}$ (free of ethanol) at $60^{\circ} \mathrm{C}$ for $5 \mathrm{~h}$. The reaction mixture was cooled to room temperature, and the solvent was removed under reduced pressure; the mixture was then treated twice with cyclohexane and the solvent removed under reduced the pressure. The acyl chloride obtained was dissolved in $\mathrm{CHCl}_{3}$ (free of ethanol), and the suitable (hydroxyalkyl)methylaminoester 33-46 ( 1 eq) was added. The mixture was stirred for $17 \mathrm{~h}$ at room temperature and the solvent was removed under reduce pressure. Then $\mathrm{CH}_{2} \mathrm{Cl}_{2}$ was added and the organic layer was washed twice with a saturated solution of $\mathrm{NaHCO}_{3}$. After drying with $\mathrm{Na}_{2} \mathrm{SO}_{4}$, the solvent was removed under reduced pressure. The crude product was then purified by flash chromatography using the proper eluting system, yielding the desired compound as an oil.

All the compounds were transformed into the corresponding hydrochloride as a white solid. The salts were crystallized from abs. ethanol/petroleum ether.

(E)-3-(methyl(3-((3-(3,4,5-trimethoxyphenyl)acryloyl)oxy)propyl)amino)propyl 4-sulfamoyl benzoate 15. From (hydroxyalkyl) methylaminoester 35 [35]. Oil. Chromatographic eluent: $\mathrm{CH}_{2} \mathrm{Cl}_{2} / \mathrm{CH}_{3} \mathrm{OH} / \mathrm{NH}_{4} \mathrm{OH}$ 93:7:0.3. Yield: $63 \% .{ }^{1} \mathrm{H}-\mathrm{NMR}\left(400 \mathrm{MHz}, \mathrm{CDCl}_{3}\right) \delta: 8.02(\mathrm{~d}, J=8.4 \mathrm{~Hz}, 2 \mathrm{H}, \mathrm{CH}) ; 7.88(\mathrm{~d}, J=8.4 \mathrm{~Hz}$, $2 \mathrm{H}, \mathrm{CH}) ; 7.54(\mathrm{~d}, J=16.0 \mathrm{~Hz}, 1 \mathrm{H}, \mathrm{CH}=\mathrm{CH}) ; 6.69(\mathrm{~s}, 2 \mathrm{H}, \mathrm{CH}) ; 6.30(\mathrm{~d}, J=16.0 \mathrm{~Hz}, 1 \mathrm{H}, \mathrm{CH}=\mathrm{CH}) ; 4.35$ $\left(\mathrm{t}, J=6.4 \mathrm{~Hz}, 2 \mathrm{H}, \mathrm{OCH}_{2}\right) ; 4.22\left(\mathrm{t}, J=6.0 \mathrm{~Hz}, 2 \mathrm{H}, \mathrm{OCH}_{2}\right) ; 3.83\left(\mathrm{~s}, 6 \mathrm{H}, \mathrm{OCH}_{3}\right) ; 3.82\left(\mathrm{~s}, 3 \mathrm{H}, \mathrm{OCH}_{3}\right)$; $2.51-2.46\left(\mathrm{~m}, 4 \mathrm{H}, \mathrm{NCH}_{2}\right) ; 2.23\left(\mathrm{~s}, 3 \mathrm{H}, \mathrm{NCH}_{3}\right) ; 1.95-1.81\left(\mathrm{~m}, 4 \mathrm{H}, \mathrm{CH}_{2}\right)$ ppm. ${ }^{13} \mathrm{C}-\mathrm{NMR}\left(100 \mathrm{MHz}, \mathrm{CDCl}_{3}\right)$

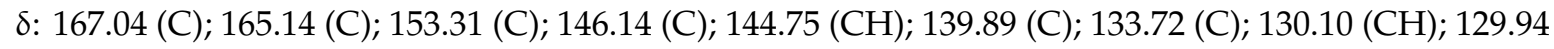
(C); $126.29(\mathrm{CH}) ; 117.29(\mathrm{CH}) ; 105.28(\mathrm{CH}) ; 64.04\left(\mathrm{CH}_{2}\right) ; 62.70\left(\mathrm{CH}_{2}\right) ; 60.95\left(\mathrm{OCH}_{3}\right) ; 56.16\left(\mathrm{OCH}_{3}\right)$; $54.00\left(\mathrm{CH}_{2}\right) ; 53.69\left(\mathrm{CH}_{2}\right) ; 41.99\left(\mathrm{NCH}_{3}\right) ; 26.47\left(\mathrm{CH}_{2}\right) ; 26.43\left(\mathrm{CH}_{2}\right)$ ppm. ESI-HRMS $(\mathrm{m} / z)$ calculated for $[\mathrm{M}+\mathrm{H}]^{+}$ion species $\mathrm{C}_{26} \mathrm{H}_{35} \mathrm{~N}_{2} \mathrm{O}_{9} \mathrm{~S}=551.2058$, found 551.2050. Hydrochloride: low melting solid.

(E)-5-(methyl(3-((3-(3,4,5-trimethoxyphenyl)acryloyl)oxy)propyl)amino)pentyl 4-sulfamoyl benzoate 16. From 36 [37]. Oil. Chromatographic eluent: $\mathrm{CH}_{2} \mathrm{Cl}_{2} / \mathrm{CH}_{3} \mathrm{OH} / \mathrm{NH}_{4} \mathrm{OH}$ 93:7:0.3. Yield: $21 \%$. ${ }^{1} \mathrm{H}-\mathrm{NMR}$ $\left(400 \mathrm{MHz}, \mathrm{CDCl}_{3}\right) \delta: 8.09(\mathrm{~d}, J=8.4 \mathrm{~Hz}, 2 \mathrm{H}, \mathrm{CH}) ; 7.95(\mathrm{~d}, J=8.4 \mathrm{~Hz}, 2 \mathrm{H}, \mathrm{CH}) ; 7.58(\mathrm{~d}, J=16.0 \mathrm{~Hz}$, $1 \mathrm{H}, \mathrm{CH}=\mathrm{CH}) ; 6.73(\mathrm{~s}, 2 \mathrm{H}, \mathrm{CH}) ; 6.33(\mathrm{~d}, J=16.0 \mathrm{~Hz}, 1 \mathrm{H}, \mathrm{CH}=\mathrm{CH}) ; 4.33\left(\mathrm{t}, J=6.8 \mathrm{~Hz}, 2 \mathrm{H}, \mathrm{OCH}_{2}\right) ; 4.22$ 
$\left(\mathrm{t}, J=6.4 \mathrm{~Hz}, 2 \mathrm{H}, \mathrm{OCH}_{2}\right) ; 3.86\left(\mathrm{~s}, 6 \mathrm{H}, \mathrm{OCH}_{3}\right) ; 3.85\left(\mathrm{~s}, 3 \mathrm{H}, \mathrm{OCH}_{3}\right) ; 2.48\left(\mathrm{t}, J=7.2 \mathrm{~Hz}, 2 \mathrm{H}, \mathrm{NCH}_{2}\right) ; 2.39$ $\left(\mathrm{t}, J=7.2 \mathrm{~Hz}, 2 \mathrm{H}, \mathrm{NCH}_{2}\right) ; 2.24\left(\mathrm{~s}, 3 \mathrm{H}, \mathrm{NCH}_{3}\right) ; 1.89-1.74\left(\mathrm{~m}, 4 \mathrm{H}, \mathrm{CH}_{2}\right) ; 1.59-1.41\left(\mathrm{~m}, 4 \mathrm{H}, \mathrm{CH}_{2}\right) \mathrm{ppm}$. ${ }^{13} \mathrm{C}-\mathrm{NMR}\left(100 \mathrm{MHz}, \mathrm{CDCl}_{3}\right)$ 8: 167.06 (C); 165.15 (C); 153.39 (C); 146.05 (C); $144.83(\mathrm{CH}) ; 140.09$ (C); $133.97(\mathrm{C}) ; 130.17(\mathrm{CH}) ; 129.90(\mathrm{C}) ; 126.37(\mathrm{CH}) ; 117.25(\mathrm{CH}) ; 105.35(\mathrm{CH}) ; 65.67\left(\mathrm{CH}_{2}\right) ; 62.88\left(\mathrm{CH}_{2}\right)$; $60.94\left(\mathrm{OCH}_{3}\right) ; 57.43\left(\mathrm{CH}_{2}\right) ; 56.18\left(\mathrm{OCH}_{3}\right) ; 53.93\left(\mathrm{CH}_{2}\right) ; 41.99\left(\mathrm{NCH}_{3}\right) ; 28.48\left(\mathrm{CH}_{2}\right) ; 26.76\left(\mathrm{CH}_{2}\right) ; 26.48$ $\left(\mathrm{CH}_{2}\right) ; 23.84\left(\mathrm{CH}_{2}\right)$ ppm. ESI-HRMS $(\mathrm{m} / z)$ calculated for $[\mathrm{M}+\mathrm{H}]^{+}$ion species $\mathrm{C}_{28} \mathrm{H}_{39} \mathrm{~N}_{2} \mathrm{O} 9 \mathrm{~S}=579.2371$, found 579.2380 . Hydrochloride: $\mathrm{mp} 98-100{ }^{\circ} \mathrm{C}$.

(E)-3-(methyl(5-((3-(3,4,5-trimethoxyphenyl)acryloyl)oxy)pentyl)amino)propyl 4-sulfamoyl benzoate 17. From 37 [37]. Oil. Chromatographic eluent: $\mathrm{CH}_{2} \mathrm{Cl}_{2} / \mathrm{CH}_{3} \mathrm{OH} / \mathrm{NH}_{4} \mathrm{OH}$ 93:7:0.3. Yield: $100 \% .{ }^{1} \mathrm{H}-\mathrm{NMR}$ $\left(400 \mathrm{MHz}, \mathrm{CDCl}_{3}\right) \delta: 8.10(\mathrm{~d}, J=8.4 \mathrm{~Hz}, 2 \mathrm{H}, \mathrm{CH}) ; 7.96(\mathrm{~d}, J=8.4 \mathrm{~Hz}, 2 \mathrm{H}, \mathrm{CH}) ; 7.58(\mathrm{~d}, J=16.0 \mathrm{~Hz}$, $1 \mathrm{H}, \mathrm{CH}=\mathrm{CH}) ; 6.73(\mathrm{~s}, 2 \mathrm{H}, \mathrm{CH}) ; 6.34(\mathrm{~d}, J=16.0 \mathrm{~Hz}, 1 \mathrm{H}, \mathrm{CH}=\mathrm{CH}) ; 4.40\left(\mathrm{t}, J=6.4 \mathrm{~Hz}, 2 \mathrm{H}, \mathrm{OCH}_{2}\right) ; 4.15$ $\left(\mathrm{t}, J=6.8 \mathrm{~Hz}, 2 \mathrm{H}, \mathrm{OCH}_{2}\right) ; 3.87\left(\mathrm{~s}, 6 \mathrm{H}, \mathrm{OCH}_{3}\right) ; 3.86\left(\mathrm{~s}, 3 \mathrm{H}, \mathrm{OCH}_{3}\right) ; 2.48\left(\mathrm{t}, J=6.8 \mathrm{~Hz}, 2 \mathrm{H}, \mathrm{NCH}_{2}\right)$; $2.35\left(\mathrm{t}, J=7.2 \mathrm{~Hz}, 2 \mathrm{H}, \mathrm{NCH}_{2}\right) ; 2.22\left(\mathrm{~s}, 3 \mathrm{H}, \mathrm{NCH}_{3}\right) ; 1.96-1.90\left(\mathrm{~m}, 2 \mathrm{H}, \mathrm{CH}_{2}\right) ; 1.71-1.64\left(\mathrm{~m}, 2 \mathrm{H}, \mathrm{CH}_{2}\right)$;

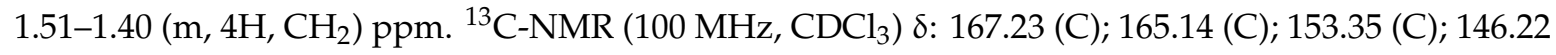
(C); $144.81(\mathrm{CH}) ; 139.97(\mathrm{C}) ; 133.79(\mathrm{C}) ; 130.14(\mathrm{CH}) ; 129.93(\mathrm{C}) ; 126.35(\mathrm{CH}) ; 117.33(\mathrm{CH}) ; 105.27(\mathrm{CH})$; $64.53\left(\mathrm{CH}_{2}\right) ; 64.06\left(\mathrm{CH}_{2}\right) ; 60.94\left(\mathrm{OCH}_{3}\right) ; 57.50\left(\mathrm{CH}_{2}\right) ; 56.15\left(\mathrm{OCH}_{3}\right) ; 53.75\left(\mathrm{CH}_{2}\right) ; 42.14\left(\mathrm{NCH}_{3}\right) ; 28.66$ $\left(\mathrm{CH}_{2}\right) ; 26.87\left(\mathrm{CH}_{2}\right) ; 26.39\left(\mathrm{CH}_{2}\right) ; 23.81\left(\mathrm{CH}_{2}\right) \mathrm{ppm}$. ESI-HRMS $(\mathrm{m} / \mathrm{z})$ calculated for $[\mathrm{M}+\mathrm{H}]^{+}$ion species $\mathrm{C}_{28} \mathrm{H}_{39} \mathrm{~N}_{2} \mathrm{O}_{9} \mathrm{~S}=579.2371$, found 579.2364 . Hydrochloride: $\mathrm{mp} 83-86^{\circ} \mathrm{C}$.

(E)-5-(methyl(5-((3-(3,4,5-trimethoxyphenyl)acryloyl)oxy)pentyl)amino)pentyl 4-sulfamoyl benzoate 18. From 38 [35]. Oil. Chromatographic eluent: $\mathrm{CH}_{2} \mathrm{Cl}_{2} / \mathrm{CH}_{3} \mathrm{OH} / \mathrm{NH}_{4} \mathrm{OH}$ 97:3:0.3. Yield: $19 \%$. ${ }^{1} \mathrm{H}-\mathrm{NMR}$ $\left(400 \mathrm{MHz}, \mathrm{CDCl}_{3}\right) \delta: 8.11(\mathrm{~d}, J=8.4 \mathrm{~Hz}, 2 \mathrm{H}, \mathrm{CH}) ; 7.96(\mathrm{~d}, J=8.4 \mathrm{~Hz}, 2 \mathrm{H}, \mathrm{CH}) ; 7.58(\mathrm{~d}, J=16.0 \mathrm{~Hz}$, $1 \mathrm{H}, \mathrm{CH}=\mathrm{CH}) ; 6.74(\mathrm{~s}, 2 \mathrm{H}, \mathrm{CH}) ; 6.33(\mathrm{~d}, J=16.0 \mathrm{~Hz}, 1 \mathrm{H}, \mathrm{CH}=\mathrm{CH}) ; 4.33\left(\mathrm{t}, J=6.4 \mathrm{~Hz}, 2 \mathrm{H}, \mathrm{OCH}_{2}\right) ; 4.17$ $\left(\mathrm{t}, J=6.8 \mathrm{~Hz}, 2 \mathrm{H}, \mathrm{OCH}_{2}\right) ; 3.87\left(\mathrm{~s}, 6 \mathrm{H}, \mathrm{OCH}_{3}\right) ; 3.85\left(\mathrm{~s}, 3 \mathrm{H}, \mathrm{OCH}_{3}\right) ; 2.40-2.32\left(\mathrm{~m}, 4 \mathrm{H}, \mathrm{NCH}_{2}\right) ; 2.22(\mathrm{~s}, 3 \mathrm{H}$, $\left.\mathrm{NCH}_{3}\right) ; 1.83-1.66\left(\mathrm{~m}, 4 \mathrm{H}, \mathrm{CH}_{2}\right) ; 1.58-1.37\left(\mathrm{~m}, 8 \mathrm{H}, \mathrm{CH}_{2}\right)$ ppm. ${ }^{13} \mathrm{C}-\mathrm{NMR}\left(100 \mathrm{MHz}, \mathrm{CDCl}_{3}\right) \delta: 167.15$ (C); 165.17 (C); 153.41 (C); 146.25 (C); 144.76 (CH); 140.14 (C); 133.94 (C); 130.17 (CH); 129.92 (C); 126.36 (CH); $117.36(\mathrm{CH}) ; 105.36(\mathrm{CH}) ; 65.79\left(\mathrm{CH}_{2}\right) ; 65.63\left(\mathrm{CH}_{2}\right) ; 64.53\left(\mathrm{CH}_{2}\right) ; 60.92\left(\mathrm{OCH}_{3}\right) ; 57.41\left(\mathrm{CH}_{2}\right)$; $57.38\left(\mathrm{CH}_{2}\right) ; 56.17\left(\mathrm{OCH}_{3}\right) ; 42.05\left(\mathrm{NCH}_{3}\right) ; 28.65\left(\mathrm{CH}_{2}\right) ; 28.53\left(\mathrm{CH}_{2}\right) ; 26.64\left(\mathrm{CH}_{2}\right) ; 23.96\left(\mathrm{CH}_{2}\right) ; 23.90$ $\left(\mathrm{CH}_{2}\right)$ ppm. ESI-HRMS $(\mathrm{m} / \mathrm{z})$ calculated for $[\mathrm{M}+\mathrm{H}]^{+}$ion species $\mathrm{C}_{30} \mathrm{H}_{43} \mathrm{~N}_{2} \mathrm{O}_{9} \mathrm{~S}=607.2684$, found 607.2672. Hydrochloride: $\mathrm{mp} 83-85{ }^{\circ} \mathrm{C}$.

(E)-3-(methyl(6-((3-(3,4,5-trimethoxyphenyl)acryloyl)oxy)hexyl)amino)propyl 4-sulfamoyl benzoate 19. From 39 [38]. Oil. Chromatographic eluent: $\mathrm{CH}_{2} \mathrm{Cl}_{2} / \mathrm{CH}_{3} \mathrm{OH} / \mathrm{NH}_{4} \mathrm{OH}$ 90:10:1. Yield: $40 \% .{ }^{1} \mathrm{H}-\mathrm{NMR}$ $\left(400 \mathrm{MHz}, \mathrm{CDCl}_{3}\right) \delta: 8.07(\mathrm{~d}, J=8.4 \mathrm{~Hz}, 2 \mathrm{H}, \mathrm{CH}) ; 7.94(\mathrm{~d}, J=8.4 \mathrm{~Hz}, 2 \mathrm{H}, \mathrm{CH}) ; 7.57(\mathrm{~d}, J=16.0 \mathrm{~Hz}, 1 \mathrm{H}$, $\mathrm{CH}=\mathrm{CH}) ; 6.73(\mathrm{~s}, 2 \mathrm{H}, \mathrm{CH}) ; 6.33(\mathrm{~d}, J=16.0 \mathrm{~Hz}, 1 \mathrm{H}, \mathrm{CH}=\mathrm{CH}) ; 4.99\left(\mathrm{bs}, 2 \mathrm{H}, \mathrm{NH}_{2}\right) ; 4.35(\mathrm{t}, J=6.4 \mathrm{~Hz}, 2 \mathrm{H}$, $\left.\mathrm{OCH}_{2}\right) ; 4.12\left(\mathrm{t}, J=6.8 \mathrm{~Hz}, 2 \mathrm{H}, \mathrm{OCH}_{2}\right) ; 3.85\left(\mathrm{~s}, 6 \mathrm{H}, \mathrm{OCH}_{3}\right) ; 3.83\left(\mathrm{~s}, 3 \mathrm{H}, \mathrm{OCH}_{3}\right) ; 2.49(\mathrm{t}, J=7.2 \mathrm{~Hz}, 2 \mathrm{H}$, $\left.\mathrm{NCH}_{2}\right) ; 2.35\left(\mathrm{t}, J=7.2 \mathrm{~Hz}, 2 \mathrm{H}, \mathrm{NCH}_{2}\right) ; 2.22\left(\mathrm{~s}, 3 \mathrm{H}, \mathrm{NCH}_{3}\right) ; 1.95-1.88\left(\mathrm{~m}, 2 \mathrm{H}, \mathrm{CH}_{2}\right) ; 1.69-1.60(\mathrm{~m}, 2 \mathrm{H}$, $\left.\mathrm{CH}_{2}\right) ; 1.49-1.32\left(\mathrm{~m}, 6 \mathrm{H}, \mathrm{CH}_{2}\right)$ ppm. ${ }^{13} \mathrm{C}-\mathrm{NMR}\left(100 \mathrm{MHz}, \mathrm{CDCl}_{3}\right) \delta: 167.28(\mathrm{C}) ; 165.16(\mathrm{C}) ; 153.35(\mathrm{C})$; 146.38 (C); 144. $83(\mathrm{CH}) ; 139.98(\mathrm{C}) ; 133.70(\mathrm{C}) ; 130.15(\mathrm{CH}) ; 129.91(\mathrm{C}) ; 126.34(\mathrm{CH}) ; 117.31(\mathrm{CH}) ; 105.26$ $(\mathrm{CH}) ; 64.63\left(\mathrm{CH}_{2}\right) ; 63.96\left(\mathrm{CH}_{2}\right) ; 60.93\left(\mathrm{OCH}_{3}\right) ; 57.51\left(\mathrm{CH}_{2}\right) ; 56.15\left(\mathrm{OCH}_{3}\right) ; 53.69\left(\mathrm{CH}_{2}\right) ; 42.00\left(\mathrm{NCH}_{3}\right)$; $28.63\left(\mathrm{CH}_{2}\right) ; 27.01\left(\mathrm{CH}_{2}\right) ; 26.93\left(\mathrm{CH}_{2}\right) ; 26.22\left(\mathrm{CH}_{2}\right) ; 25.87\left(\mathrm{CH}_{2}\right)$ ppm. ESI-HRMS $(m / z)$ calculated for $[\mathrm{M}+\mathrm{H}]^{+}$ion species $\mathrm{C}_{29} \mathrm{H}_{41} \mathrm{~N}_{2} \mathrm{O}_{9} \mathrm{~S}=593.2527$, found 593.2522. Hydrochloride: $\mathrm{mp} 73-76{ }^{\circ} \mathrm{C}$.

(E)-4-(methyl(6-((3-(3,4,5-trimethoxyphenyl)acryloyl)oxy)hexyl)amino)butyl 4-sulfamoyl benzoate 20. From 40 [38]. Oil. Chromatographic eluent: $\mathrm{CH}_{2} \mathrm{Cl}_{2} / \mathrm{CH}_{3} \mathrm{OH} / \mathrm{NH}_{4} \mathrm{OH}$ 93:7:0.3. Yield: $49 \%$. ${ }^{1} \mathrm{H}-\mathrm{NMR}$ $\left(400 \mathrm{MHz} \mathrm{CDCl}_{3}\right) \delta: 8.06(\mathrm{~d}, J=8.8 \mathrm{~Hz}, 2 \mathrm{H}, \mathrm{CH}) ; 7.92(\mathrm{~d}, J=8.8 \mathrm{~Hz}, 2 \mathrm{H}, \mathrm{CH}) ; 7.57(\mathrm{~d}, J=16.0 \mathrm{~Hz}, 1 \mathrm{H}$, $\mathrm{CH}=\mathrm{CH}) ; 6.73(\mathrm{~s}, 2 \mathrm{H}, \mathrm{CH}) ; 6.33(\mathrm{~d}, J=16.0 \mathrm{~Hz}, 1 \mathrm{H}, \mathrm{CH}=\mathrm{CH}) ; 5.50\left(\mathrm{bs}, 2 \mathrm{H}, \mathrm{NH}_{2}\right) ; 4.32(\mathrm{t}, J=6.4 \mathrm{~Hz}, 2 \mathrm{H}$, $\left.\mathrm{OCH}_{2}\right) ; 4.15\left(\mathrm{t}, J=6.8 \mathrm{~Hz}, 2 \mathrm{H}, \mathrm{OCH}_{2}\right) ; 3.85\left(\mathrm{~s}, 6 \mathrm{H}, \mathrm{OCH}_{3}\right) ; 3.84\left(\mathrm{~s}, 3 \mathrm{H}, \mathrm{OCH}_{3}\right) 2.40-2.31\left(\mathrm{~m}, 4 \mathrm{H}, \mathrm{NCH}_{2}\right)$; $2.20\left(\mathrm{~s}, 3 \mathrm{H}, \mathrm{NCH}_{3}\right) ; 1.79-1.72\left(\mathrm{~m}, 2 \mathrm{H}, \mathrm{CH}_{2}\right) ; 1.70-1.55\left(\mathrm{~m}, 4 \mathrm{H}, \mathrm{CH}_{2}\right) ; 1.50-1.30\left(\mathrm{~m}, 6 \mathrm{H}, \mathrm{CH}_{2}\right) \mathrm{ppm}$. ${ }^{13} \mathrm{C}-\mathrm{NMR}\left(100 \mathrm{MHz}, \mathrm{CDCl}_{3}\right.$ ) $\delta: 167.22$ (C); 165.21 (C); 153.35 (C); 146.39 (C); 144.75 (CH); 139.95 (C); $133.72(\mathrm{C}) ; 130.15(\mathrm{CH}) ; 129.92(\mathrm{C}) ; 126.31(\mathrm{CH}) ; 117.36(\mathrm{CH}) ; 105.21(\mathrm{CH}) ; 65.53\left(\mathrm{CH}_{2}\right) ; 64.61\left(\mathrm{CH}_{2}\right)$; 
$60.94\left(\mathrm{OCH}_{3}\right) ; 57.45\left(\mathrm{CH}_{2}\right) ; 57.03\left(\mathrm{CH}_{2}\right) ; 56.14\left(\mathrm{OCH}_{3}\right) ; 42.05\left(\mathrm{NCH}_{3}\right) ; 28.66\left(\mathrm{CH}_{2}\right) ; 27.14\left(\mathrm{CH}_{2}\right) ; 26.84$ $\left(\mathrm{CH}_{2}\right) ; 26.60\left(\mathrm{CH}_{2}\right) ; 25.86\left(\mathrm{CH}_{2}\right) ; 23.62\left(\mathrm{CH}_{2}\right) \mathrm{ppm}$. ESI-HRMS $(\mathrm{m} / \mathrm{z})$ calculated for $[\mathrm{M}+\mathrm{H}]^{+}$ion species $\mathrm{C}_{30} \mathrm{H}_{43} \mathrm{~N}_{2} \mathrm{O}_{9} \mathrm{~S}=607.2684$, found 607.2683. Hydrochloride: $\mathrm{mp} 89-91{ }^{\circ} \mathrm{C}$.

(E)-2-(methyl(7-((3-(3,4,5-trimethoxyphenyl)acryloyl)oxy)heptyl)amino)ethyl 4-sulfamoyl benzoate 21. From 44 [38]. Oil. Chromatographic eluent: $\mathrm{CH}_{2} \mathrm{Cl}_{2} / \mathrm{CH}_{3} \mathrm{OH} / \mathrm{NH}_{4} \mathrm{OH}$ 93:7:0.3. Yield: $45 \% .{ }^{1} \mathrm{H}-\mathrm{NMR}$ $\left(400 \mathrm{MHz}, \mathrm{CDCl}_{3}\right) \delta: 8.11(\mathrm{~d}, J=8.8 \mathrm{~Hz}, 2 \mathrm{H}, \mathrm{CH}) ; 7.95(\mathrm{~d}, \mathrm{~J}=8.8 \mathrm{~Hz}, 2 \mathrm{H}, \mathrm{CH}) ; 7.59(\mathrm{~d}, J=15.6 \mathrm{~Hz}$, $1 \mathrm{H}, \mathrm{CH}=\mathrm{CH}) ; 6.75(\mathrm{~s}, 2 \mathrm{H}, \mathrm{CH}) ; 6.34(\mathrm{~d}, J=15.6 \mathrm{~Hz}, 1 \mathrm{H}, \mathrm{CH}=\mathrm{CH}) ; 4.43\left(\mathrm{t}, J=5.6 \mathrm{~Hz}, 2 \mathrm{H}, \mathrm{OCH}_{2}\right) ; 4.14$ $\left(\mathrm{t}, J=6.4 \mathrm{~Hz}, 2 \mathrm{H}, \mathrm{OCH}_{2}\right) ; 3.87\left(\mathrm{~s}, 6 \mathrm{H}, \mathrm{OCH}_{3}\right) ; 3.86\left(\mathrm{~s}, 3 \mathrm{H}, \mathrm{OCH}_{3}\right) ; 2.76\left(\mathrm{t}, J=5.6 \mathrm{~Hz}, 2 \mathrm{H}, \mathrm{NCH}_{2}\right) ; 2.43$ $\left(\mathrm{t}, J=7.2 \mathrm{~Hz}, 2 \mathrm{H}, \mathrm{NCH}_{2}\right) ; 2.31\left(\mathrm{~s}, 3 \mathrm{H}, \mathrm{NCH}_{3}\right) ; 1.66-1.62\left(\mathrm{~m}, 2 \mathrm{H}, \mathrm{CH}_{2}\right) ; 1.49-1.45\left(\mathrm{~m}, 2 \mathrm{H}, \mathrm{CH}_{2}\right) ; 1.33-1.25$ (m, 6H, $\mathrm{CH}_{2}$ ) ppm. ${ }^{13} \mathrm{C}-\mathrm{NMR}\left(100 \mathrm{MHz}, \mathrm{CDCl}_{3}\right) \delta: 167.37$ (C); 165.14 (C); 153.40 (C); 146.19 (C); 144.92 $(\mathrm{CH}) ; 140.07(\mathrm{C}) ; 133.83(\mathrm{C}) ; 130.29(\mathrm{CH}) ; 129.90(\mathrm{C}) ; 126.36(\mathrm{CH}) ; 117.29(\mathrm{CH}) ; 105.29(\mathrm{CH}) ; 64.73\left(\mathrm{CH}_{2}\right)$; $63.46\left(\mathrm{CH}_{2}\right) ; 60.96\left(\mathrm{OCH}_{3}\right) ; 57.80\left(\mathrm{CH}_{2}\right) ; 56.17\left(\mathrm{OCH}_{3}\right) ; 55.47\left(\mathrm{CH}_{2}\right) ; 42.73\left(\mathrm{NCH}_{3}\right) ; 29.13\left(\mathrm{CH}_{2}\right) ; 28.66$ $\left(\mathrm{CH}_{2}\right) ; 27.20\left(\mathrm{CH}_{2}\right) ; 27.17\left(\mathrm{CH}_{2}\right) ; 25.92\left(\mathrm{CH}_{2}\right)$ ppm. ESI-HRMS $(\mathrm{m} / \mathrm{z})$ calculated for $[\mathrm{M}+\mathrm{H}]^{+}$ion species $\mathrm{C}_{29} \mathrm{H}_{41} \mathrm{~N}_{2} \mathrm{O}_{9} \mathrm{~S}=593.2527$, found 593.2524. Hydrochloride: $\mathrm{mp} 70-73{ }^{\circ} \mathrm{C}$.

(E)-7-(methyl(7-((3-(3,4,5-trimethoxyphenyl)acryloyl)oxy)heptyl)amino)heptyl 4-sulfamoyl benzoate 22. From 41 [35]. Oil. Chromatographic eluent: $\mathrm{CH}_{2} \mathrm{Cl}_{2} / \mathrm{CH}_{3} \mathrm{OH} / \mathrm{NH}_{4} \mathrm{OH}$ 93:7:0.3. Yield: $22 \% .{ }^{1} \mathrm{H}-\mathrm{NMR}$ $\left(400 \mathrm{MHz}, \mathrm{CDCl}_{3}\right)$ ): $8.15(\mathrm{~d}, J=8.4 \mathrm{~Hz}, 2 \mathrm{H}, \mathrm{CH}) ; 8.00(\mathrm{~d}, J=8.4 \mathrm{~Hz}, 2 \mathrm{H}, \mathrm{CH}) ; 7.61(\mathrm{~d}, J=15.6 \mathrm{~Hz}$, $1 \mathrm{H}, \mathrm{CH}=\mathrm{CH}) ; 6.77(\mathrm{~s}, 2 \mathrm{H}, \mathrm{CH}) ; 6.37(\mathrm{~d}, \mathrm{~J}=15.6 \mathrm{~Hz}, 1 \mathrm{H}, \mathrm{CH}=\mathrm{CH}) ; 4.36\left(\mathrm{t}, J=6.8 \mathrm{~Hz}, 2 \mathrm{H}, \mathrm{OCH}_{2}\right) ; 4.20$ $\left(\mathrm{t}, J=6.4 \mathrm{~Hz}, 2 \mathrm{H}, \mathrm{OCH}_{2}\right) ; 3.90\left(\mathrm{~s}, 6 \mathrm{H}, \mathrm{OCH}_{3}\right) ; 3.89\left(\mathrm{~s}, 3 \mathrm{H}, \mathrm{OCH}_{3}\right) ; 2.40-2.35\left(\mathrm{~m}, 4 \mathrm{H}, \mathrm{NCH}_{2}\right) ; 2.26(\mathrm{~s}, 3 \mathrm{H}$, $\left.\mathrm{NCH}_{3}\right) ; 1.82-1.65\left(\mathrm{~m}, 4 \mathrm{H}, \mathrm{CH}_{2}\right) ; 1.52-1.30\left(\mathrm{~m}, 16 \mathrm{H}, \mathrm{CH}_{2}\right)$ ppm. ${ }^{13} \mathrm{C}-\mathrm{NMR}\left(100 \mathrm{MHz}, \mathrm{CDCl}_{3}\right) \delta: 167.13$ (C); 165.18 (C); 153.42 (C); 146.07 (C); 144.64 (CH); 139.96 (C); 134.09 (C); 130.22 (CH); 129.96 (C); 126.42 (CH); $117.46(\mathrm{CH}) ; 105.29(\mathrm{CH}) ; 65.78\left(\mathrm{CH}_{2}\right) ; 64.66\left(\mathrm{CH}_{2}\right) ; 60.95\left(\mathrm{OCH}_{3}\right) ; 57.57\left(\mathrm{CH}_{2}\right) ; 56.17\left(\mathrm{OCH}_{3}\right)$; $42.02\left(\mathrm{NCH}_{3}\right) ; 29.14\left(\mathrm{CH}_{2}\right) ; 28.67\left(\mathrm{CH}_{2}\right) ; 28.53\left(\mathrm{CH}_{2}\right) ; 27.37\left(\mathrm{CH}_{2}\right) ; 27.36\left(\mathrm{CH}_{2}\right) ; 26.77\left(\mathrm{CH}_{2}\right) ; 25.95\left(\mathrm{CH}_{2}\right)$; $25.89\left(\mathrm{CH}_{2}\right)$ ppm. ESI-HRMS $(\mathrm{m} / \mathrm{z})$ calculated for $[\mathrm{M}+\mathrm{H}]^{+}$ion species $\mathrm{C}_{34} \mathrm{H}_{51} \mathrm{~N}_{2} \mathrm{O} 9 \mathrm{~S}=663.3310$, found 663.3298. Hydrochloride: $\mathrm{mp} 68-70{ }^{\circ} \mathrm{C}$.

3-(methyl(5-((4-sulfamoylbenzoyl)oxy)pentyl)amino)propyl 3,4,5-trimethoxybenzoate 23. From 42 [37]. Oil. Chromatographic eluent: $\mathrm{CH}_{2} \mathrm{Cl}_{2} / \mathrm{CH}_{3} \mathrm{OH} / \mathrm{NH}_{4} \mathrm{OH}$ 93:7:0.3. Yield: $22 \%$. ${ }^{1} \mathrm{H}-\mathrm{NMR}(400 \mathrm{MHz}$, $\left.\mathrm{CDCl}_{3}\right) \delta: 8.11(\mathrm{~d}, J=8.8 \mathrm{~Hz}, 2 \mathrm{H}, \mathrm{CH}) ; 7.97(\mathrm{~d}, J=8.8 \mathrm{~Hz}, 2 \mathrm{H}, \mathrm{CH}) ; 7.28(\mathrm{~s}, 2 \mathrm{H}, \mathrm{CH}) ; 4.37-4.32$ $\left(\mathrm{m}, 4 \mathrm{H}, \mathrm{CH}_{2}\right) ; 3.90\left(\mathrm{~s}, 9 \mathrm{H}, \mathrm{OCH}_{3}\right) ; 2.62\left(\mathrm{t}, J=6.8 \mathrm{~Hz}, 2 \mathrm{H}, \mathrm{NCH}_{2}\right) ; 2.51\left(\mathrm{t}, J=6.8 \mathrm{~Hz}, 2 \mathrm{H}, \mathrm{NCH}_{2}\right) ; 2.35$ $\left(\mathrm{s}, 3 \mathrm{H}, \mathrm{NCH}_{3}\right) ; 2.05-1.98\left(\mathrm{~m}, 2 \mathrm{H}, \mathrm{CH}_{2}\right) ; 1.83-1.76\left(\mathrm{~m}, 2 \mathrm{H}, \mathrm{CH}_{2}\right) ; 1.65-1.58\left(\mathrm{~m}, 2 \mathrm{H}, \mathrm{CH}_{2}\right) ; 1.51-1.43$ $\left(\mathrm{m}, 2 \mathrm{H}, \mathrm{CH}_{2}\right)$ ppm. ${ }^{13} \mathrm{C}-\mathrm{NMR}\left(100 \mathrm{MHz}, \mathrm{CDCl}_{3}\right)$ 8: $166.25(\mathrm{C}) ; 165.15(\mathrm{C}) ; 152.91(\mathrm{C}) ; 146.07$ (C); $133.93(\mathrm{C}) ; 130.21(\mathrm{CH}) ; 126.41(\mathrm{CH}) ; 125.20(\mathrm{C}) ; 106.87(\mathrm{CH}) ; 65.56\left(\mathrm{CH}_{2}\right) ; 63.28\left(\mathrm{CH}_{2}\right) ; 60.92\left(\mathrm{OCH}_{3}\right)$; $57.29\left(\mathrm{CH}_{2}\right) ; 56.28\left(\mathrm{OCH}_{3}\right) ; 54.00\left(\mathrm{CH}_{2}\right) ; 41.74\left(\mathrm{NCH}_{3}\right) ; 28.42\left(\mathrm{CH}_{2}\right) ; 26.33\left(\mathrm{CH}_{2}\right) ; 26.16\left(\mathrm{CH}_{2}\right) ; 23.82$ $\left(\mathrm{CH}_{2}\right)$ ppm. ESI-HRMS $(\mathrm{m} / \mathrm{z})$ calculated for $[\mathrm{M}+\mathrm{H}]^{+}$ion species $\mathrm{C}_{26} \mathrm{H}_{37} \mathrm{~N}_{2} \mathrm{O}_{9} \mathrm{~S}=553.2214$, found 553.2218. Hydrochloride: $\mathrm{mp} 52-55^{\circ} \mathrm{C}$.

6-(methyl(3-((4-sulfamoylbenzoyl)oxy)propyl)amino)hexyl 3,4,5-trimethoxybenzoate 24. From 33. Oil. Chromatographic eluent: $\mathrm{CH}_{2} \mathrm{Cl}_{2} / \mathrm{CH}_{3} \mathrm{OH} / \mathrm{NH}_{4} \mathrm{OH}$ 93:7:0.3. Yield: $55 \%$. ${ }^{1} \mathrm{H}-\mathrm{NMR}(400 \mathrm{MHz}$, $\left.\mathrm{CDCl}_{3}\right) \delta: 8.01(\mathrm{~d}, J=8.4 \mathrm{~Hz}, 2 \mathrm{H}, \mathrm{CH}) ; 7.88(\mathrm{~d}, J=8.4 \mathrm{~Hz}, 2 \mathrm{H}, \mathrm{CH}) ; 7.21(\mathrm{~s}, 2 \mathrm{H}, \mathrm{CH}) ; 5.56\left(\mathrm{bs}, 2 \mathrm{H}, \mathrm{NH}_{2}\right)$; $4.31\left(\mathrm{t}, J=6.0 \mathrm{~Hz}, 2 \mathrm{H}, \mathrm{OCH}_{2}\right) ; 4.19\left(\mathrm{t}, J=6.8 \mathrm{~Hz}, 2 \mathrm{H}, \mathrm{OCH}_{2}\right) ; 3.82\left(\mathrm{~s}, 6 \mathrm{H}, \mathrm{OCH}_{3}\right) ; 3.81\left(\mathrm{~s}, 3 \mathrm{H}, \mathrm{OCH}_{3}\right)$; $2.45\left(\mathrm{t}, J=7.2 \mathrm{~Hz}, 2 \mathrm{H}, \mathrm{NCH}_{2}\right) ; 2.31\left(\mathrm{t}, J=7.2 \mathrm{~Hz}, 2 \mathrm{H}, \mathrm{NCH}_{2}\right) ; 2.18\left(\mathrm{~s}, 3 \mathrm{H}, \mathrm{NCH}_{3}\right) ; 1.90-1.85(\mathrm{~m}, 2 \mathrm{H}$, $\left.\mathrm{CH}_{2}\right) ; 1.69-1.65\left(\mathrm{~m}, 2 \mathrm{H}, \mathrm{CH}_{2}\right) ; 1.42-1.28\left(\mathrm{~m}, 6 \mathrm{H}, \mathrm{CH}_{2}\right) \mathrm{ppm} .{ }^{13} \mathrm{C}-\mathrm{NMR}\left(100 \mathrm{MHz}, \mathrm{CDCl}_{3}\right) \delta: 166.39(\mathrm{C})$; 165.13 (C); 152.86 (C); 146.37 (C); 142.11 (C); 133.70 (C); $130.13(\mathrm{CH}) ; 126.33(\mathrm{CH}) ; 125.41$ (C); 106.85 $(\mathrm{CH}) ; 65.20\left(\mathrm{CH}_{2}\right) ; 63.98\left(\mathrm{CH}_{2}\right) ; 60.87\left(\mathrm{OCH}_{3}\right) ; 57.50\left(\mathrm{CH}_{2}\right) ; 56.25\left(\mathrm{OCH}_{3}\right) ; 53.77\left(\mathrm{CH}_{2}\right) ; 41.94\left(\mathrm{NCH}_{3}\right)$; $28.64\left(\mathrm{CH}_{2}\right) ; 27.03\left(\mathrm{CH}_{2}\right) ; 26.89\left(\mathrm{CH}_{2}\right) ; 26.23\left(\mathrm{CH}_{2}\right) ; 25.90\left(\mathrm{CH}_{2}\right)$ ppm. ESI-HRMS $(\mathrm{m} / z)$ calculated for $[\mathrm{M}+\mathrm{H}]^{+}$ion species $\mathrm{C}_{27} \mathrm{H}_{39} \mathrm{~N}_{2} \mathrm{O}_{9} \mathrm{~S}=567.2371$, found 567.2380 . Hydrochloride: $\mathrm{mp} 53-56{ }^{\circ} \mathrm{C}$.

7-(methyl(2-((4-sulfamoylbenzoyl)oxy)ethyl)amino)heptyl 3,4,5-trimethoxybenzoate 25. From 45 [38]. Oil. Chromatographic eluent: $\mathrm{CH}_{2} \mathrm{Cl}_{2} / \mathrm{CH}_{3} \mathrm{OH} / \mathrm{NH}_{4} \mathrm{OH}$ 93:7:0.3. Yield: $40 \%$. ${ }^{1} \mathrm{H}-\mathrm{NMR}(400 \mathrm{MHz}$, $\left.\mathrm{CDCl}_{3}\right) \delta: 8.08(\mathrm{~d}, J=8.4 \mathrm{~Hz}, 2 \mathrm{H}, \mathrm{CH}) ; 7.93(\mathrm{~d}, J=8.4 \mathrm{~Hz}, 2 \mathrm{H}, \mathrm{CH}) ; 7.27(\mathrm{~s}, 2 \mathrm{H}, \mathrm{CH}) ; 4.43(\mathrm{t}, J=5.6 \mathrm{~Hz}$, 
$\left.2 \mathrm{H}, \mathrm{OCH}_{2}\right) ; 4.26\left(\mathrm{t}, J=6.8 \mathrm{~Hz}, 2 \mathrm{H}, \mathrm{OCH}_{2}\right) ; 3.89\left(\mathrm{~s}, 6 \mathrm{H}, \mathrm{OCH}_{3}\right) ; 3.87\left(\mathrm{~s}, 3 \mathrm{H}, \mathrm{OCH}_{3}\right) ; 2.78(\mathrm{t}, J=5.6 \mathrm{~Hz}, 2 \mathrm{H}$, $\left.\mathrm{NCH}_{2}\right) ; 2.44\left(\mathrm{t}, J=7.2 \mathrm{~Hz}, 2 \mathrm{H}, \mathrm{NCH}_{2}\right) ; 2.32\left(\mathrm{~s}, 3 \mathrm{H}, \mathrm{NCH}_{3}\right) ; 1.74-1.71\left(\mathrm{~m}, 2 \mathrm{H}, \mathrm{CH}_{2}\right) ; 1.50-1.46(\mathrm{~m}, 2 \mathrm{H}$, $\left.\mathrm{CH}_{2}\right) ; 1.40-1.30\left(\mathrm{~m}, 6 \mathrm{H}, \mathrm{CH}_{2}\right)$ ppm. ${ }^{13} \mathrm{C}-\mathrm{NMR}\left(100 \mathrm{MHz}, \mathrm{CDCl}_{3}\right) \delta: 166.48(\mathrm{C}) ; 165.14(\mathrm{C}) ; 152.88$ (C); 146.32 (C); 142.14 (C); $133.65(\mathrm{C}) ; 130.24(\mathrm{CH}) ; 126.31(\mathrm{CH}) ; 125.40(\mathrm{C}) ; 106.86(\mathrm{CH}) ; 65.29\left(\mathrm{CH}_{2}\right)$; $63.35\left(\mathrm{CH}_{2}\right) ; 60.88\left(\mathrm{OCH}_{3}\right) ; 57.81\left(\mathrm{CH}_{2}\right) ; 56.26\left(\mathrm{OCH}_{3}\right) ; 55.40\left(\mathrm{CH}_{2}\right) ; 42.63\left(\mathrm{NCH}_{3}\right) ; 29.12\left(\mathrm{CH}_{2}\right) ; 28.63$ $\left(\mathrm{CH}_{2}\right) ; 27.19\left(\mathrm{CH}_{2}\right) ; 27.02\left(\mathrm{CH}_{2}\right) ; 25.93\left(\mathrm{CH}_{2}\right)$ ppm. ESI-HRMS $(\mathrm{m} / \mathrm{z})$ calculated for $[\mathrm{M}+\mathrm{H}]^{+}$ion species $\mathrm{C}_{27} \mathrm{H}_{39} \mathrm{~N}_{2} \mathrm{O}_{9} \mathrm{~S}=567.2371$, found 567.2368. Hydrochloride: $\mathrm{mp} 60-63{ }^{\circ} \mathrm{C}$.

3-(methyl(5-((4-sulfamoylbenzoyl)oxy)pentyl)amino)propyl anthracene-9-carboxylate 26. From 43 [37]. Oil. Chromatographic eluent: $\mathrm{CH}_{2} \mathrm{Cl}_{2} / \mathrm{CH}_{3} \mathrm{OH} / \mathrm{NH}_{4} \mathrm{OH}$ 93:7:0.3. Yield: $41 \%$. ${ }^{1} \mathrm{H}-\mathrm{NMR}(400 \mathrm{MHz}$, $\left.\mathrm{CDCl}_{3}\right) \delta: 8.52(\mathrm{~s}, 1 \mathrm{H}, \mathrm{CH}) ; 8.10(\mathrm{~d}, J=8.4 \mathrm{~Hz}, 2 \mathrm{H}, \mathrm{CH}) ; 8.02(\mathrm{~d}, J=8.4 \mathrm{~Hz}, 4 \mathrm{H}, \mathrm{CH}) ; 7.93(\mathrm{~d}, J=8.4 \mathrm{~Hz}$, $2 \mathrm{H}, \mathrm{CH}) ; 7.55-7.47(\mathrm{~m}, 4 \mathrm{H}, \mathrm{CH}) ; 4.66\left(\mathrm{t}, J=6.4 \mathrm{~Hz}, 2 \mathrm{H}, \mathrm{OCH}_{2}\right) ; 4.32\left(\mathrm{t}, J=6.4 \mathrm{~Hz}, 2 \mathrm{H}, \mathrm{OCH}_{2}\right) ; 2.60$ $\left(\mathrm{t}, J=7.2 \mathrm{~Hz}, 2 \mathrm{H}, \mathrm{NCH}_{2}\right) ; 2.44\left(\mathrm{t}, J=7.2 \mathrm{~Hz}, 2 \mathrm{H}, \mathrm{NCH}_{2}\right) ; 2.29\left(\mathrm{~s}, 3 \mathrm{H}, \mathrm{NCH}_{3}\right) ; 2.12-2.05\left(\mathrm{~m}, 2 \mathrm{H}, \mathrm{CH}_{2}\right)$; 1.79-1.72 (m, 2H, CH $) ; 1.60-1.40\left(\mathrm{~m}, 4 \mathrm{H}, \mathrm{CH}_{2}\right)$ ppm. ${ }^{13} \mathrm{C}-\mathrm{NMR}\left(100 \mathrm{MHz}, \mathrm{CDCl}_{3}\right) \delta: 169.68$ (C); 165.17 (C); $146.00(\mathrm{C}) ; 133.88$ (C); $130.94(\mathrm{C}) ; 130.20(\mathrm{CH}) ; 129.39(\mathrm{CH}) ; 128.67(\mathrm{CH}) ; 128.35(\mathrm{C}) ; 127.79$ (C); 127.05 (CH); $126.37(\mathrm{CH}) ; 125.52(\mathrm{CH}) ; 124.89(\mathrm{CH}) ; 65.56\left(\mathrm{CH}_{2}\right) ; 63.95\left(\mathrm{CH}_{2}\right) ; 57.32\left(\mathrm{CH}_{2}\right) ; 53.98\left(\mathrm{CH}_{2}\right)$; $41.73\left(\mathrm{NCH}_{3}\right) ; 28.42\left(\mathrm{CH}_{2}\right) ; 26.06\left(\mathrm{CH}_{2}\right) ; 23.82\left(\mathrm{CH}_{2}\right)$ ppm. ESI-HRMS $(\mathrm{m} / \mathrm{z})$ calculated for $[\mathrm{M}+\mathrm{H}]^{+}$ion species $\mathrm{C}_{31} \mathrm{H}_{35} \mathrm{~N}_{2} \mathrm{O}_{6} \mathrm{~S}=563.2210$, found 563.2211. Hydrochloride: $\mathrm{mp} 82-84{ }^{\circ} \mathrm{C}$.

6-(methyl(3-((4-sulfamoylbenzoyl)oxy)propyl)amino)hexyl anthracene-9-carboxylate 27. From 34. Oil. Chromatographic eluent: $\mathrm{CH}_{2} \mathrm{Cl}_{2} / \mathrm{CH}_{3} \mathrm{OH} / \mathrm{NH}_{4} \mathrm{OH}$ 93:7:0.3. Yield: $29 \%$. ${ }^{1} \mathrm{H}-\mathrm{NMR}(400 \mathrm{MHz}$, $\left.\mathrm{CDCl}_{3}\right) \delta: 8.51(\mathrm{~s}, 1 \mathrm{H}, \mathrm{CH}) ; 8.08(\mathrm{~d}, J=8.4 \mathrm{~Hz}, 2 \mathrm{H}, \mathrm{CH}) ; 8.01(\mathrm{~d}, J=8.4 \mathrm{~Hz}, 4 \mathrm{H}, \mathrm{CH}) ; 7.93(\mathrm{~d}, J=8.4 \mathrm{~Hz}$, $2 \mathrm{H}, \mathrm{CH}) ; 7.55-7.46(\mathrm{~m}, 4 \mathrm{H}, \mathrm{CH}) ; 5.08\left(\mathrm{bs}, 2 \mathrm{H}, \mathrm{NH}_{2}\right) ; 4.59\left(\mathrm{t}, J=6.8 \mathrm{~Hz}, 2 \mathrm{H}, \mathrm{OCH}_{2}\right) ; 4.37(\mathrm{t}, J=6.4 \mathrm{~Hz}$, $\left.2 \mathrm{H}, \mathrm{OCH}_{2}\right) ; 2.51\left(\mathrm{t}, J=7.2 \mathrm{~Hz}, 2 \mathrm{H}, \mathrm{NCH}_{2}\right) ; 2.38\left(\mathrm{t}, J=7.2 \mathrm{~Hz}, 2 \mathrm{H}, \mathrm{NCH}_{2}\right) ; 2.24\left(\mathrm{~s}, 3 \mathrm{H}, \mathrm{NCH}_{3}\right) ; 1.97-1.82$ (m, 4H, CH $)$; 1.51-1.35 (m, 6H, $\left.\mathrm{CH}_{2}\right)$ ppm. ${ }^{13} \mathrm{C}-\mathrm{NMR}\left(100 \mathrm{MHz}, \mathrm{CDCl}_{3}\right)$ 8: $169.85(\mathrm{C}) ; 165.09$ (C); 146.22 (C); 142.61 (C); 141.80 (C); 133.63 (C); 130.96 (C); $130.18(\mathrm{CH}) ; 129.28(\mathrm{CH}) ; 128.64(\mathrm{CH}) ; 128.32$ (C); $128.01(\mathrm{C}) ; 127.00(\mathrm{CH}) ; 126.37(\mathrm{CH}) ; 125.50(\mathrm{CH}) ; 124.91(\mathrm{CH}) ; 65.85\left(\mathrm{CH}_{2}\right) ; 63.71\left(\mathrm{CH}_{2}\right) ; 57.23$ $\left(\mathrm{CH}_{2}\right) ; 53.71\left(\mathrm{CH}_{2}\right) ; 41.60\left(\mathrm{NCH}_{3}\right) ; 28.62\left(\mathrm{CH}_{2}\right) ; 26.86\left(\mathrm{CH}_{2}\right) ; 26.39\left(\mathrm{CH}_{2}\right) ; 25.92\left(\mathrm{CH}_{2}\right) ; 25.84\left(\mathrm{CH}_{2}\right)$ ppm. ESI-HRMS $(m / z)$ calculated for $[\mathrm{M}+\mathrm{H}]^{+}$ion species $\mathrm{C}_{32} \mathrm{H}_{37} \mathrm{~N}_{2} \mathrm{O}_{6} \mathrm{~S}=577.2367$, found 577.2361. Hydrochloride: $\mathrm{mp} 81-84^{\circ} \mathrm{C}$.

7-(methyl(2-((4-sulfamoylbenzoyl)oxy)ethyl)amino)heptyl anthracene-9-carboxylate 28. From 46 [38]. Oil. Chromatographic eluent: $\mathrm{CH}_{2} \mathrm{Cl}_{2} / \mathrm{CH}_{3} \mathrm{OH} / \mathrm{NH}_{4} \mathrm{OH}$ 93:7:0.3. Yield: $33 \%$. ${ }^{1} \mathrm{H}-\mathrm{NMR}(400 \mathrm{MHz}$, $\left.\mathrm{CDCl}_{3}\right) \delta: 8.52(\mathrm{~s}, 1 \mathrm{H}, \mathrm{CH}) ; 8.11(\mathrm{~d}, J=8.0 \mathrm{~Hz}, 2 \mathrm{H}, \mathrm{CH}) ; 8.01(\mathrm{~d}, J=8.0 \mathrm{~Hz}, 4 \mathrm{H}, \mathrm{CH}) ; 7.93(\mathrm{~d}, J=8.0 \mathrm{~Hz}$, $2 \mathrm{H}, \mathrm{CH}) ; 7.56-7.47(\mathrm{~m}, 4 \mathrm{H}, \mathrm{CH}) ; 5.31\left(\mathrm{bs}, 2 \mathrm{H}, \mathrm{NH}_{2}\right) ; 4.60\left(\mathrm{t}, J=6.8 \mathrm{~Hz}, 2 \mathrm{H}, \mathrm{OCH}_{2}\right) ; 4.46(\mathrm{t}, J=5.6 \mathrm{~Hz}$, $\left.2 \mathrm{H}, \mathrm{OCH}_{2}\right) ; 2.80\left(\mathrm{t}, J=5.6 \mathrm{~Hz}, 2 \mathrm{H}, \mathrm{NCH}_{2}\right) ; 2.47\left(\mathrm{t}, J=7.2 \mathrm{~Hz}, 2 \mathrm{H}, \mathrm{NCH}_{2}\right) ; 2.35\left(\mathrm{~s}, 3 \mathrm{H}, \mathrm{NCH}_{3}\right) ; 1.88-1.82$ (m, 2H, $\left.\mathrm{CH}_{2}\right) ; 1.54-1.30\left(\mathrm{~m}, 8 \mathrm{H}, \mathrm{CH}_{2}\right)$ ppm. ${ }^{13} \mathrm{C}-\mathrm{NMR}\left(100 \mathrm{MHz}, \mathrm{CDCl}_{3}\right)$ 8: 169.93 (C); 165.08 (C); 146.27 (C); $133.47(\mathrm{C}) ; 130.96(\mathrm{C}) ; 130.28(\mathrm{CH}) ; 129.28(\mathrm{CH}) ; 128.64(\mathrm{CH}) ; 128.32(\mathrm{C}) ; 128.01(\mathrm{C}) ; 127.00(\mathrm{CH})$; 126.31 (CH); $125.50(\mathrm{CH}) ; 124.92(\mathrm{CH}) ; 65.97\left(\mathrm{CH}_{2}\right) ; 62.86\left(\mathrm{CH}_{2}\right) ; 57.65\left(\mathrm{CH}_{2}\right) ; 55.18\left(\mathrm{CH}_{2}\right) ; 42.34\left(\mathrm{NCH}_{3}\right)$; $29.03\left(\mathrm{CH}_{2}\right) ; 28.64\left(\mathrm{CH}_{2}\right) ; 27.10\left(\mathrm{CH}_{2}\right) ; 26.53\left(\mathrm{CH}_{2}\right) ; 26.00\left(\mathrm{CH}_{2}\right)$ ppm. ESI-HRMS $(m / z)$ calculated for $[\mathrm{M}+\mathrm{H}]^{+}$ion species $\mathrm{C}_{32} \mathrm{H}_{37} \mathrm{~N}_{2} \mathrm{O}_{6} \mathrm{~S}=577.2367$, found 577.2374. Hydrochloride: mp $71-73^{\circ} \mathrm{C}$.

\subsection{Stability Tests}

\subsubsection{Chemicals}

Acetonitrile (Chromasolv), formic acid and ammonium formate (MS grade), $\mathrm{NaCl}, \mathrm{KCl}, \mathrm{Na}_{2} \mathrm{HPO}_{4}$ $2 \mathrm{H}_{2} \mathrm{O}, \mathrm{KH}_{2} \mathrm{PO}_{4}$ (Reagent grade) and verapamil hydrochloride (analytical standard, used as an internal standard) were purchased by Sigma-Aldrich (Milan, Italy). MilliQ water $18 \mathrm{M} \Omega \mathrm{cm}^{-1}$ was obtained from Millipore's Simplicity system (Milan-Italy).

Phosphate buffer solution (PBS) was prepared by adding $8.01 \mathrm{~g} \mathrm{~L}^{-1}$ of $\mathrm{NaCl}, 0.2 \mathrm{~g} \mathrm{~L}^{-1}$ of $\mathrm{KCl}, 1.78$ $\mathrm{g} \mathrm{L}^{-1}$ of $\mathrm{Na}_{2} \mathrm{HPO}_{4} 2 \mathrm{H}_{2} \mathrm{O}$ and $0.27 \mathrm{~g} \mathrm{~L}^{-1}$ of $\mathrm{KH}_{2} \mathrm{PO}_{4}$. 


\subsubsection{Preparation of Samples}

Each sample was prepared adding $10 \mu \mathrm{L}$ of working solution 1 to $100 \mu \mathrm{L}$ of the tested matrix (PBS) in micro centrifuge tubes. The obtained solutions correspond to $1 \mu \mathrm{M}$ of analyte.

Each set of samples was incubated in triplicate at four different times, 0, 30, 60 and $120 \mathrm{~min}$ at $37^{\circ} \mathrm{C}$. Therefore, the degradation profile of each analyte was represented by a batch of 12 samples (4 incubation times $\times 3$ replicates). After the incubation, the samples were added with $300 \mu \mathrm{L}$ of ISTD solution and centrifuged (room temperature for $5 \mathrm{~min}$ at 10,000 rpm). The supernatants were transferred in auto sampler vials and dried under a gentle stream of nitrogen.

The dried samples were dissolved in $1.0 \mathrm{~mL}$ of $10 \mathrm{mM}$ of formic acid in $\mathrm{mQ}$ water: acetonitrile 80:20 solution. The obtained sample solutions were analyzed by LC-MS/MS methods described in the Supplementary Material.

\subsection{Biology and Enzymology}

\subsubsection{Cell lines and Cultures}

The K562 cell line is a highly undifferentiated erythroleukemia originally derived from a patient with chronic myelogenous leukemia [41]. The K562 leukemia cells and the P-gp expressing K562/DOX cells were obtained from Prof. J. P. Marie (Hopital Hotel-Dieu, Paris, France). These cells were cultured in RPMI 1640 medium with GlutaMAX I (GIBCO) medium supplemented with 10\% fetal calf serum (FCS; GIBCO) at $37^{\circ} \mathrm{C}$ in a humidified incubator with $5 \% \mathrm{CO}_{2}$. To maintain the resistance, every month, resistant cells were cultured for three days with $400 \mathrm{nM}$ doxorubicin. K562/DOX cells overexpress almost exclusively the membrane glycoprotein P-gp [42].

Human colon adenocarcinoma cell line (LoVo) was isolated from a metastatic nodule, and its MDR variant, $\mathrm{LoV} / \mathrm{DOX}$, were obtained from LoVo (parental line) by exposure to increasing concentrations of doxorubicin and maintained in vitro in Ham's F12 medium supplemented with $10 \%$ fetal bovine serum and vitamins (Life Technology, Monza, Italy) at $37{ }^{\circ} \mathrm{C}$ in a $5 \% \mathrm{CO}_{2}$ atmosphere [47]. These two cell lines have been kindly offered by Professor D'Incalci of the Department of Oncology, IRCCS (Istituto di Ricerche Farmacologiche Mario Negri, Milan, Italy).

\subsubsection{Rhodamine-123 (Rhd 123) Uptake}

The inhibition of P-gp activity was evaluated by measuring the uptake of the P-gp substrate rhodamine-123 (Rhd 123) in K562/DOX and LoVo/DOX cells, in the absence or in the presence of compounds by a flow cytometric test. Briefly, K562/DOX cells were sedimented and diluted to obtain a cell suspension at $5 \times 10^{5}$ cells/mL in complete RPMI 1640 medium; LoVo/DOX cells suspension was obtained by incubating monolayer cell cultures with EDTA and trypsin, then cells were diluted to obtain a cell suspension at $5 \times 10^{5}$ cells $/ \mathrm{mL}$ in complete Ham's F12. Cells were loaded with Rhd $123,5.0 \mu \mathrm{M}$, for $30 \mathrm{~min}$ at $37^{\circ} \mathrm{C}$ in a humidified atmosphere with $5 \% \mathrm{CO}_{2}$ in the presence of the tested compounds at 3.0, 10 and $30 \mu \mathrm{M}$ concentrations, or of the reference compound verapamil at $3.0 \mu \mathrm{M}$ concentration. An aliquot of cells (control) was incubated with the fluorochrome in the absence of inhibitors. All compounds were added 15 min before Rhd 123.

At the end of the uptake, cells were sedimented, washed twice in ice-cold PBS, placed in PBS on ice, and kept in the dark until flow cytometric analysis. Samples were analyzed on a FACScantoflow cytometer (Becton Dickinson, San Jose CA, USA) equipped with two lasers at 488/633 nm and FACSDIVA software. The green fluorescence of Rhd 123 was collected by a 530-nm band pass filter and at least 10,000 events were acquired.

The histograms were generated by program GraphPad Prism 5 (GraphPad Prism software, Inc., San Diego, CA, USA); the data were obtained from the ratio between the average fluorescence intensity of the samples preincubated with the compounds under study and subsequently exposed to rhodamine, and the fluorescence of the sample exposed only to the rhodamine. 


\subsubsection{Intrinsic Cytotoxicity}

The intrinsic toxicity of the compounds under study was determined by an MTT assay [43] after exposing the parental cells (K562 and LoVo) and resistant cells (K562/DOX and LoVo/DOX) to three concentrations $(3,10$ and $30 \mu \mathrm{M})$ for $72 \mathrm{~h}$. The percentage of growth compared to the untreated control was transformed into histograms with the GraphPad Prism 5 program (Graph Pad software, Adalta, Arezzo, Italy).

\subsubsection{CA Inhibition Assay}

An SX.18MV-R Applied Photophysics (Oxford, UK) stopped-flow instrument was used to assay the catalytic/inhibition of various CA isozymes [44]. Phenol Red (at a concentration of $0.2 \mathrm{mM}$ ) was used as an indicator, working at the absorbance maximum of $557 \mathrm{~nm}$, with $10 \mathrm{mM}$ Hepes (pH 7.4) as a buffer and, $0.1 \mathrm{M} \mathrm{Na}_{2} \mathrm{SO}_{4}$ or $\mathrm{NaClO}_{4}$ (for maintaining constant the ionic strength; these anions are not inhibitory in the used concentration), following the $\mathrm{CA}$-catalyzed $\mathrm{CO}_{2}$ hydration reaction for a period of 5-10 s. Saturated $\mathrm{CO}_{2}$ solutions in water at $25^{\circ} \mathrm{C}$ were used as a substrate. Stock solutions of inhibitors were prepared at a concentration of $10 \mu \mathrm{M}$ (in DMSO-water 1:1, v/v) and dilutions up to $0.01 \mathrm{nM}$ done with the assay buffer mentioned above. At least 7 different inhibitor concentrations have been used for measuring the inhibition constant. Inhibitor and enzyme solutions were preincubated together for 10 min at room temperature prior to the assay, in order to allow for the formation of the E-I complex. Triplicate experiments were done for each inhibitor concentration, and the values reported throughout the paper were the mean of such results. The inhibition constants were obtained by non-linear least-squares methods using the Cheng-Prusoff equation, as reported earlier [29], and represent the mean from at least three different determinations. All CA isozymes used here were recombinant proteins obtained as reported earlier by our group $[48,49]$.

\subsubsection{Reverse Transcription RT-PCR}

The expression levels of MDR1 and CAXII were analyzed by quantitative PCR (qRT-PCR) using a RotorGene 3000 (Qiagen, Hilden, Germany) instrument. Primers were purchased from IDT (Germany). Of the total RNA 500 ng was retro-transcribed using iScript (Bio-Rad, Hercules, CA, USA) and amplified with specific primers: for MDR1, Fw CAGCTATTCGAAGAGTGGGCACAAAC and Rv GCCTCTGCATCAGCTGGACTGTTG. For CAXII, Fw CAAAGGCCAGGAAGCATTCGTCCC and Rv ATGTGTGTGCAGTACAGGGCTGTCTC. PCR amplification was carried out by SsoAdvancedTM Universal SYBR ${ }^{\circledR}$ Green Supermix (Bio-Rad, USA) according to the manual's instruction. In the present analysis 18s rRNA was confirmed to be stable and was used as the normalizer Fw CGGCTACCACATCCAAGGAA and Rv GTTATTTTTCGTCACTACCTCCCCGGG. The RT-qPCR was performed using the following procedure: $98^{\circ} \mathrm{C}$ for $2 \mathrm{~min}, 40$ cycles of $98^{\circ} \mathrm{C}$ for $5 \mathrm{~s}$ and $60{ }^{\circ} \mathrm{C}$ for $10 \mathrm{~s}$. The program was set to reveal the melting curve of each amplicon from 60 to $95^{\circ} \mathrm{C}$ with a read every $0.5^{\circ} \mathrm{C}$.

\subsubsection{Flow cytometric P-Glycoprotein Expression}

Flow cytometric analysis was carried out on leukemic cells and on cell suspensions ( $10^{6}$ cells $\left./ \mathrm{mL}\right)$ of colon carcinoma cells obtained by incubating monolayer cell cultures with EDTA and trypsin. For the P-gp determination on the cell surface, the cells were incubated for 30 min at RT with MAb FITC conjugate CD243. After washing with ice-cold phosphate buffer saline (PBS, pH 7.2) with 1\% bovine serum albumin (BSA, Sigma), cells were immediately analyzed. Dead cells were excluded from the analysis by gate on cells size before the acquisitions. Ten thousand events were acquired and fluorescence was analyzed with a FACScanto flow cytometer (Becton Dickinson) equipped with a $15 \mathrm{~mW}, 488 \mathrm{~nm}$, air-cooled argon ion laser. The fluorescence emissions were collected through a $530 \mathrm{~nm}$ band-pass filter for fluorescein. 
For quantitative evaluation of P-gp expression, the mean fluorescence channel (MFC) was calculated by FCS5 express software (De Novo software). P-gp content in arbitrary units was expressed as the ratio of the MFC of labeled resistant cells on the MFC of parental ones.

\subsubsection{Doxorubicin $\mathrm{IC}_{50}$ and $\mathrm{IC}_{20}$ Evaluation on $\mathrm{K} 562 / \mathrm{DOX}$ and LoVo/DOX Cell Lines}

In regards to the leukemic line, $\mathrm{K} 562 / \mathrm{DOX}$, the values of doxorubicin $\mathrm{IC}_{50}$ and $\mathrm{IC}_{20}$ were extrapolated from the cytotoxicity curves previously performed [38].

For the LoVo/DOX cell line, the doxorubicin growth inhibition was determined by the MTT assay and the $\mathrm{IC}_{50}$ and $\mathrm{IC}_{20}$ values were determined. Approximately $10^{4}$ cells/well were plated onto 96-well plates and allowed to attach for $24 \mathrm{~h}$ before treatment with a range of drug concentrations from $3 \times 10^{-11}$ to $3 \times 10^{-5} \mathrm{M}$ for 3 days; each concentration was repeated four times. At the end of the incubation the cells were processed according to the MTT protocol [43] and the optical density of the chromogenic product was measured at $570 \mathrm{~nm}$. $\mathrm{IC}_{50}$ and $\mathrm{IC}_{20}$ values were determined graphically from relative survival curves obtained by GraphPad Prism 5 software (GraphPad, San Diego, CA, USA).

The resistance index to doxorubicin of the two resistant cell lines was obtained from the ratio between the doxorubicin $\mathrm{IC}_{50}(\mu \mathrm{M})$ values on the resistant and parental lines. The resistance index was 73 for K562/DOX cells [38] $\left(\mathrm{IC}_{50}=2.47 \pm 0.25 \mu \mathrm{M}\right.$ and $0.034 \pm 0.008 \mu \mathrm{M}$ on K562/DOX and K562 cells, respectively) and 13.5 for LoVo/DOX cells $\left(\mathrm{IC}_{50}=0.85 \pm 0.084 \mu \mathrm{M}\right.$ and $0.063 \pm 0.0066 \mu \mathrm{M}$ on LoVo/DOX and LoVo cells, respectively).

\subsubsection{Enhancement of Doxorubicin Toxicity in the Presence of Compounds 2, 5, 7, 8, 21, 25 and 26.}

Doxorubicin was used at the concentration corresponding to the $\mathrm{IC}_{20}$ of the resistant lines, which were $0.5 \mu \mathrm{M}$ and $0.3 \mu \mathrm{M}$ for K562/DOX and LoVo/DOX cell lines, respectively. Compounds 2, 5, 7, 8, 21, 25 and 26 were studied at two concentrations, 3 and $10 \mu \mathrm{M}$.

To evaluate the enhancement of doxorubicin toxicity in the presence of the tested compounds, the cells, in exponential growth phase, were seeded at $10^{4}$ cells/well and solutions of either compounds or doxorubicin, or a solution of doxorubicin in combination with the compounds, were added to the wells repeated in quadruplicate. Then the plates were incubated at $37{ }^{\circ} \mathrm{C}$ for $72 \mathrm{~h}$ in a humidified atmosphere with $5 \% \mathrm{CO}_{2} / 95 \%$ air. The MTT working solution was then added and plates were further incubated for $3 \mathrm{~h}$. Following incubation cells and formazan crystals were inspected microscopically. The supernatant was then carefully removed by slow aspiration and the formazan crystals were dissolved in $150 \mathrm{~mL}$ of acidified isopropanol solution. The absorbance of the solution was then read on an automated plate reader at a wavelength of $570 \mathrm{~nm}$. The increase in the toxicity of doxorubicin was quantified by the ratio between the growth of the cell sample treated with $\mathrm{IC}_{20}$ of doxorubicin and that of the cell sample treated with $\mathrm{IC}_{20}$ of doxorubicin in combination with the various concentrations of the tested compounds.

\section{Conclusions}

In this work a new series of P-glycoprotein and CA XII inhibitor hybrids was synthesized and studied for their ability to reverse the P-gp mediated MDR in cancer cells, which overexpressed both the transmembrane P-gp and CA XII proteins. A dual P-gp and CA XII inhibitory activity could be useful for a synergistic antitumor mechanism with consequent selective inhibition of P-glycoprotein overexpressed in resistant cancer cells.

The synthesized compounds are characterized by the presence of both P-gp and CA XII binding moieties, such as a $N, N$-bis(alkanol)amine diester scaffold combined with a coumarin or benzene sulfonamide moieties endowed with a dual P-gp and CA XII inhibitory activity.

Many compounds showed multitarget activity against the two transmembrane proteins P-gp and CA XII. Derivatives bearing a coumarin residue, displayed high and selective hCA XII inhibitory activity and a moderate P-gp inhibitory activity on K562/DOX cells, which overexpressed only P-gp. Interestingly, some coumarin compounds showed a synergistic MDR reversal effect; indeed, they were 
more active in the P-gp inhibition on LoVo/DOX cells, which overexpressed both P-gp and CA XII, than on K562/DOX cells, which overexpressed only P-gp, in both rhodamine-123 uptake and doxorubicin cytotoxicity enhancement tests.

In particular, the coumarin derivatives 7 and 8 , which incorporate a (E)-3-(3,4,5-trimethoxyphenyl)vinyl moiety linked to a 7-methylenes spacer $(n=7, \mathrm{Ar}=\mathbf{a}$, see Table 1$)$ showed the best inhibitory profile, being more potent on LoVo/DOX than on K562/DOX cells both in the Rhd 123 uptake test and in the doxorubicin cytotoxicity enhancement assay. Moreover, when tested at $10 \mu \mathrm{M}$ concentrations, these two compounds showed higher activity than verapamil in both tests on LoVo/DOX line. In fact, they were able to increase the Rhd 123 intracellular fluorescence intensity with $F R=12.60$ and 9.90, respectively, vs. FR $=6.40$ of verapamil, and to reduce the cell growth rate from $80 \%$ to $34.9 \%$ and $32.2 \%$, respectively, vs. $51.0 \%$ of verapamil. These two compounds were very potent and selective for hCA XII with respect to the physiological relevant cytosolic isoenzymes hCA I and hCA II (hCA XII, Ki = 9.1 and $7.1 \mathrm{nM}$ for $\mathbf{7}$ and $\mathbf{8}$, respectively, and hCA I and hCA II, $\mathrm{Ki}=>10,000 \mathrm{nM}$ ).

Taking all these results into account, we discovered a new class of hybrid derivatives with an innovative synergistic inhibitory activity mechanism on P-glycoprotein and carbonic anhydrases. More work is needed to optimize the interaction of these molecules with both targets and to study their pharmacokinetic properties. Notably, compounds 7 and 8 can be considered valuable candidates as chemosensitizers able to overcome P-gp mediated MDR in cancer cells with a synergistic mechanism that make them potentially selective inhibitors of P-glycoprotein overexpressed in resistant cancer cells.

Supplementary Materials: The following are available online. Figure S1: mRNA expression level of MDR1 and CA XII genes, Figure S2: Fluorescence curves obtained with a FACScanto flow cytometer, Table S1: Elution gradient of mobile phase used for LC-MS/MS analyses, Table S2: MRM parameters, Table S3: Linear regression data, linearity coefficients, precision and LOD values for each analyte.

Author Contributions: Conceptualization, E.T., M.N.R., S.D. and C.T.S., Funding acquisition, E.T., M.N.R. and S.D., Investigation, L.B., S.B., A.L., G.B., D.M. and M.C., Methodology, L.B., Project administration, E.T., L.B. and S.D.; Supervision, E.T., S.D. and C.T.S., Validation, L.B., S.B., A.L. and G.B., Writing-original draft, E.T., L.B., G.B, S.D. and M.C., Writing-review and editing, E.T., D.M., M.N.R., S.D. and C.T.S. All authors have read and agreed to the published version of the manuscript.

Funding: This project was supported grants from the University of Florence (Fondo Ricerca Ateneo RICATEN17 and RICATEN18).

Conflicts of Interest: The authors declare no conflict of interest.

\section{References}

1. Holohan, C.; Van Schaeybroeck, S.; Longley, D.B.; Johnston, P.G. Cancer drug resistance: An evolving paradigm. Nat. Rev. Cancer 2013, 13, 714-726. [CrossRef] [PubMed]

2. Longley, D.B.; Johnston, P.G. Molecular mechanisms of drug resistance. J. Pathol. 2005, 205, $275-292$. [CrossRef] [PubMed]

3. Gillet, J.P.; Gottesman, M.M. Mechanisms of multidrug resistance in cancer. Methods Mol. Biol. 2010, 596, 47-76. [PubMed]

4. Gottesman, M.M.; Fojo, T.; Bates, S.E. Multidrug resistance in cancer: Role of ATP-dependent transporters. Nat. Rev. Cancer 2002, 2, 48-58. [CrossRef]

5. Szakacs, G.; Paterson, J.K.; Ludwig, J.A.; Booth-Genthe, C.; Gottesman, M.M. Targeting multidrug resistance in cancer. Nat. Rev. Drug Discov. 2006, 5, 219-234. [CrossRef]

6. Alvarez, M.; Paull, K.; Monks, A.; Hose, C.; Lee, J.S.; Weinstein, J.; Grever, M.; Bates, S.; Fojo, T. Generation of a drug resistance profile by quantitation of mdr-1/P-glycoprotein in the cell lines of the National Cancer Institute Anticancer Drug Screen. J. Clin. Investig. 1995, 95, 2205-2214. [CrossRef]

7. Szakacs, G.; Annereau, J.P.; Lababidi, S.; Shankavaram, U.; Arciello, A.; Bussey, K.J.; Reinhold, W.; Guo, Y.; Kruh, G.D.; Reimers, M.; et al. Predicting drug sensitivity and resistance: Profiling ABC transporter genes in cancer cells. Cancer Cell 2004, 6, 129-137. [CrossRef]

8. Gottesman, M.M.; Ling, V. The molecular basis of multidrug resistance in cancer: The early years of P-glycoprotein research. FEBS Lett. 2006, 580, 998-1009. [CrossRef] 
9. Darby, R.A.J.; Callaghan, R.; McMahon, R.M. P-glycoprotein inhibition: The past, the present and the future. Curr. Drug Metab. 2011, 12, 722-731. [CrossRef]

10. Coley, H.M. Overcoming multidrug resistance in cancer: Clinical studies of P-glycoprotein inhibitors. Methods Mol. Biol. 2010, 596, 341-358.

11. Sarkadi, B.; Homolya, L.; Szakács, G.; Váradi, A. Human multidrug resistance ABCB and ABCG transporters: Participation in a chemoimmunity defense system. Physiol Rev. 2006, 86, 1179-1236. [CrossRef]

12. Ueda, K. ABC proteins protect the human body and maintain optimal health. Biosci. Biotechnol. Biochem. 2011, 75, 401-409. [CrossRef]

13. Modok, S.; Mellor, H.R.; Callaghan, R. Modulation of multidrug resistance efflux pump activity to overcome chemoresistance in cancer. Curr. Opin. Pharm. 2006, 6, 350-354. [CrossRef] [PubMed]

14. Supuran, C.T.; De Simone, G. Carbonic Anhydrases: An Overview. In Carbonic Anhydrases as Biocatalysts-From Theory to Medical and Industrial Applications; Supuran, C.T., De Simone, G., Eds.; Elsevier: Amsterdam, The Netherlands, 2015.

15. Leppilampi, M.; Saarnio, J.; Karttunen, T.J.; Kivelä, J.; Pastoreková, S.; Pastorek, J.; Waheed, A.; Sly, W.S.; Parkkila, S. Carbonic anhydrase isozymes IX and XII in gastric tumours. World. J. Gastroenterol. 2003, 9, 1398-1403. [CrossRef] [PubMed]

16. Semenza, G.L. Hypoxia-inducible factor 1: Oxygen homeostasis and disease pathophysiology. Trends Mol. Med. 2001, 7, 345-350. [CrossRef]

17. Pouysségur, J.; Dayan, F.; Mazure, N.M. Hypoxia signalling in cancer and approaches to enforce tumour regression. Nature 2006, 441, 437-443. [CrossRef] [PubMed]

18. Hockel, M.; Vaupel, P. Tumour hypoxia: Definitions and current clinical, biologic, and molecular aspects. J. Natl. Cancer Inst. 2001, 93, 266-276. [CrossRef] [PubMed]

19. Boron, W.F. Regulation of intracellular pH. Adv. Physiol. Educ. 2004, 28, 160-179. [CrossRef] [PubMed]

20. Gatenby, R.A.; Gillies, R.J. A microenvironmental model of carcinogenesis. Nat. Rev. Cancer 2008, 8, 56-61. [CrossRef]

21. Gatenby, R.A.; Gillies, R.J. Why do cancers have high aerobic glycolysis? Nat. Rev. Cancer 2004, 4, 891-899. [CrossRef]

22. Fiaschi, T.; Giannoni, E.; Taddei, M.L.; Cirri, P.; Marini, A.; Pintus, G.; Nativi, C.; Richichi, B.; Scozzafava, A.; Carta, F.; et al. Carbonic anhydrase IX from cancer-associated fibroblasts drives epithelial-mesenchymal transition in prostate carcinoma cells. Cell Cycle 2013, 12, 1791-1801. [CrossRef] [PubMed]

23. Supuran, C.T. Carbonic anhydrase inhibitors as emerging agents for the treatment and imaging of hypoxic tumors. Expert Opin. Investig. Drugs 2018, 27, 963-970. [CrossRef] [PubMed]

24. Chiche, J.; Ilc, K.; Laferrière, J.; Trottier, E.; Dayan, F.; Mazure, N.M.; Brahimi-Horn, M.C.; Pouysségur, J. Hypoxia-inducible carbonic anhydrase IX and xii promote tumor cell growth by counteracting acidosis through the regulation of the intracellular pH. Cancer Res. 2009, 69, 358-368. [CrossRef] [PubMed]

25. Kappler, M.; Pabst, U.; Weinholdt, C.; Taubert, H.; Rot, S.; Kaune, T.; Kotrba, J.; Porsch, M.; Güttler, A.; Bache, M.; et al. Causes and consequences of a glutamine induced normoxic HIF1 activity for the tumor metabolism. Int. J. Mol. Sci. 2019, 20, 4742. [CrossRef]

26. Kopecka, J.; Campia, I.; Jacobs, A.; Frei, A.P.; Ghigo, D.; Wollscheid, B.; Riganti, C. Carbonic anhydrase $\mathrm{XII}$ is a new therapeutic target to overcome chemoresistance in cancer cells. Oncotarget 2015, 6, 6776-6793. [CrossRef]

27. Kopecka, J.; Rankin, G.M.; Salaroglio, I.C.; Poulsen, S.A.; Riganti, C. P-glycoprotein-mediated chemoresistance is reversed by carbonic anhydrase XII inhibitors. Oncotarget 2016, 7, 85861-85875. [CrossRef]

28. Supuran, C.T. Structure and function of carbonic anhydrases. Biochem. J. 2016, 473, 2023-2032. [CrossRef]

29. Maresca, A.; Temperini, C.; Vu, H.; Pham, N.B.; Poulsen, S.A.; Scozzafava, A.; Quinn, R.J.; Supuran, C.T. Non-zinc mediated inhibition of carbonic anhydrases: Coumarins are a new class of suicide inhibitors. J. Am. Chem. Soc. 2009, 131, 3057-3062. [CrossRef]

30. Supuran, C.T. Carbonic anhydrase inhibitors and their potential in a range of therapeutic areas. Expert Opin. Pat. 2018, 28, 709-712. [CrossRef]

31. Alterio, V.; Di Fiore, A.; D’Ambrosio, K.; Supuran, C.T.; De Simone, G. Multiple binding modes of inhibitors to carbonic anhydrases: How to design specific drugs targeting 15 different isoforms? Chem. Rev. 2012, 112, 4421-4468. [CrossRef] 
32. Nocentini, A.; Carta, F.; Ceruso, M.; Bartolucci, G.; Supuran, C.T. Click-tailed coumarins with potent and selective inhibitory action against the tumour-associated carbonic anhydrases IX and XII. Bioorg. Med. Chem. 2015, 23, 6955-6966. [CrossRef] [PubMed]

33. Martelli, C.; Dei, S.; Lambert, C.; Manetti, D.; Orlandi, F.; Romanelli, M.N.; Scapecchi, S.; Salerno, M.; Teodori, E. Inhibition of P-glycoprotein-mediated Multidrug Resistance (MDR) by N,N-bis(cyclohexanol)amine aryl esters: Further restriction of molecular flexibility maintains high potency and efficacy. Bioorg. Med. Chem. Lett. 2011, 21, 106-109. [CrossRef] [PubMed]

34. Orlandi, F.; Coronnello, M.; Bellucci, C.; Dei, S.; Guandalini, L.; Manetti, D.; Martelli, C.; Romanelli, M.N.; Scapecchi, S.; Salerno, M.; et al. New structure-activity relationship studies in a series of $\mathrm{N}, \mathrm{N}$-bis(cyclohexanol)amine aryl esters as potent reversers of P-glycoprotein-mediated multidrug resistance (MDR). Bioorg. Med. Chem. 2013, 21, 456-465. [CrossRef] [PubMed]

35. Teodori, E.; Dei, S.; Garnier-Suillerot, A.; Gualtieri, F.; Manetti, D.; Martelli, C.; Romanelli, M.N.; Scapecchi, S.; Sudwan, P.; Salerno, M. Exploratory chemistry toward the identification of a new class of multidrug resistance reverters inspired by pervilleine and verapamil models. J. Med. Chem. 2005, 48, 7426-7436. [CrossRef] [PubMed]

36. Martelli, C.; Coronnello, M.; Dei, S.; Manetti, D.; Orlandi, F.; Scapecchi, S.; Romanelli, M.N.; Salerno, M.; Mini, E.; Teodori, E. Structure-activity relationships studies in a series of $N, N$-bis(alkanol)amine aryl esters as P-glycoprotein (Pgp) dependent multidrug resistance (MDR) inhibitors. J. Med. Chem. 2010, 53, 1755-1762. [CrossRef] [PubMed]

37. Dei, S.; Coronnello, M.; Floriddia, E.; Bartolucci, G.; Bellucci, C.; Guandalini, L.; Manetti, D.; Romanelli, M.N.; Salerno, M.; Bello, I.; et al. Multidrug resistance (MDR) reversers: High activity and efficacy in a series of asymmetrical $N, N$-bis(alkanol)amine aryl esters. Eur. J. Med. Chem. 2014, 87, 398-412. [CrossRef]

38. Dei, S.; Braconi, L.; Trezza, A.; Menicatti, M.; Contino, M.; Coronnello, M.; Chiaramonte, N.; Manetti, D.; Perrone, M.G.; Romanelli, M.N.; et al. Modulation of the spacer in N,N-bis(alkanol)amine aryl ester heterodimers led to the discovery of a series of highly potent P-glycoprotein-based multidrug resistance (MDR) modulators. Eur. J. Med. Chem. 2019, 172, 71-94. [CrossRef]

39. Teodori, E.; Contino, M.; Riganti, C.; Bartolucci, G.; Braconi, L.; Manetti, D.; Romanelli, M.N.; Trezza, A.; Athanasios, A.; Spiga, O.; et al. Design, synthesis and biological evaluation of stereo- and regioisomers of amino aryl esters as multidrug resistance (MDR) reversers. Eur. J. Med. Chem. 2019, 182, 111655. [CrossRef]

40. Seelig, A.; Landwojtowicz, E. Structure-activity relationship of P-glycoprotein substrates and modifiers. Eur. J. Pharm. Sci. 2000, 12, 31-40. [CrossRef]

41. Lozzio, C.B.; Lozzio, B.B. Human chronic myelogenous leukemia cell line positive philadelphia chromosome. Blood 1975, 45, 321-334. [CrossRef]

42. Yalçintepe, L.; Halis, E.; Ulku, S. Effect of CD38 on the multidrug resistance of human chronic myelogenous leukemia K562 cells to doxorubicin. Oncol. Lett. 2016, 11, 2290-2296. [CrossRef] [PubMed]

43. Alley, M.C.; Scudiero, D.A.; Monks, A.; Hursey, M.L.; Czerwinski, M.J.; Fine, D.L.; Abbott, B.J.; Mayo, J.G.; Shoemaker, R.H.; Boyd, M.R. Feasibility of drug screening with panels of human tumour cell lines using a microculture tetrazolium assay. Cancer Res. 1988, 48, 589-601. [PubMed]

44. Khalifah, R.G. The carbon dioxide hydration activity of carbonic anhydrase. J. Biol. Chem. 1971, 246, 2561-2573. [PubMed]

45. Mini, E.; Lapucci, A.; Perrone, G.; D’Aurizio, R.; Napoli, C.; Brugia, M.; Landini, I.; Tassi, R.; Picariello, L.; Simi, L.; et al. RNA sequencing reveals PNN and KCNQ1OT1 as predictive biomarkers of clinical outcome in stage III colorectal cancer patients treated with adjuvant chemotherapy. Int. J. Cancer 2019, 145, 2580-2593. [CrossRef]

46. Marshall, A.G.; Hendrickson, C.L. High-resolution mass spectrometers. Annu. Rev. Anal. Chem. 2008, 1, 579-599. [CrossRef]

47. Grandi, M.; Geroni, C.; Giuliani, F.C. Isolation and characterization of a human colon adenocarcinoma cell line resistant to doxorubicin. Br. J. Cancer 1986, 54, 515-518. [CrossRef] 
48. Köhler, K.; Hillebrecht, A.; Schulze Wischeler, J.; Innocenti, A.; Heine, A.; Supuran, C.T.; Klebe, G. Saccharin inhibits carbonic anhydrases: Possible explanation for its unpleasant metallic aftertaste. Angew. Chem. Int. Ed. Engl. 2007, 46, 7697-7699. [CrossRef]

49. Tars, K.; Vullo, D.; Kazaks, A.; Leitans, J.; Lends, A.; Grandane, A.; Zalubovskis, R.; Scozzafava, A.; Supuran, C.T. Sulfocoumarins (1,2-benzoxathiine-2,2-dioxides): A class of potent and isoform-selective inhibitors of tumor-associated carbonic anhydrases. J. Med. Chem. 2013, 56, 293-300. [CrossRef]

Sample Availability: Not available.

(C) 2020 by the authors. Licensee MDPI, Basel, Switzerland. This article is an open access article distributed under the terms and conditions of the Creative Commons Attribution (CC BY) license (http://creativecommons.org/licenses/by/4.0/). 